\title{
SIMULTANEOUS NITRIFICATION AND DENITRIFICATION OF WASTEWATER USING A SILICONE MEMBRANE AERATED BIOREACTOR
}

\author{
A Master's Thesis Presented to the Faculty of \\ California Polytechnic State University, \\ San Luis Obispo
}

\author{
In Partial Fulfillment \\ of the Requirements for the Degree \\ Master of Science in \\ Civil and Environmental Engineering
}

By

Kirk Hjelte Waltz

March 2009 


\section{COPYRIGHT PAGE}

I grant permission for the reproduction of this thesis in its entirety or any parts, without further authorization from me, provided the author and major advisor are properly referenced.

Signature

Date 


\section{COMMITTEE MEMBERSHIP PAGE}

SIMULTANEOUS NITRIFICATION AND DENITRIFICATION OF WASTEWATER USING A MEMBRANE AERATED BIOREACTOR

KIRK HJELTE WALTZ

SUBMITTED:

Committee Chair: Dr. Nirupam Pal, Ph. D

Date

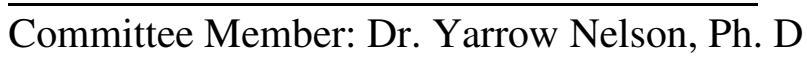

Date

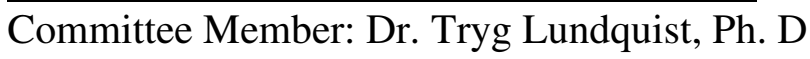

Date 


\begin{abstract}
Simultaneous Nitrification and Denitrification of Wastewater Using a Silicon Membrane Aerated Bioreactor

Kirk Hjelte Waltz
\end{abstract}

The purpose of this thesis is to investigate the use of a single reactor to biologically treat wastewater by simultaneously oxidizing ammonia, and reducing nitrate and nitrite. The Environmental Protection Agency (EPA) places strict discharge restrictions on these compounds due to their inherent toxicity to humans, wildlife, and ecosystems. The use of a simultaneous system can assist the conventional wastewater treatment technology that requires separate systems, by creating a system that needs less time and smaller size to reach effluent requirements. To conduct this research, a bench-scale membrane aerated biofilm reactor was built using silicone tubing for aeration. Batch and continuous-flow experiments were conducted to investigate the reactor's capability to oxidize ammonia using a defined growth media and monitor nitrate production and reduction. Also, wastewater from a local reclamation facility was used to determine the reactor's ability to nitrify ammonia and denitrify nitrate concentrations within wastewater. The wastewater was taken from different locations within the reclamation facility, and combinations of primary and nitrified effluent were used to monitor ammonia and nitrate concentration changes. The batch experiments showed the greatest changes, and one batch experiment showed a $79 \%$ decrease in ammonium concentrations, and followed a first-order kinetics rate constant of $-0.0284 \mathrm{hrs}^{-1}$. The continuous-flow experiments showed much greater fluctuations in results, but one of the experiments showed an ammonia oxidation efficiency of $86 \%$. The wastewater experiments had even greater fluctuations, and the effluent concentrations of ammonia, nitrate and nitrite showed no changes when compared to the influent. 


\section{ACKNOWLEDGMENTS}

I would like to thank everyone who helped me complete this thesis. I greatly appreciate all my thesis advisors for their support, assistance, and guidance throughout this project, and all the CE/ENVE graduate students that kept me company in lab and who helped me. I would like to thank Dr. Nirupam Pal for providing me with this great learning experience, and for giving me the opportunity to work on this project. I especially want to thank Ramzi Chaabane for sharing the long hours of analysis and planning needed for the project to be completed, and for doing a very good job on everything he did.

Most importantly, I want to thank my family for providing me with everything I could have every dreamed of throughout my life and giving me every opportunity to succeed. Their love and support have gotten me through the toughest of times, and their unbiased and thoughtful judgments have always kept me determined and confident to stay focused and never give up. 


\section{TABLE OF CONTENTS}

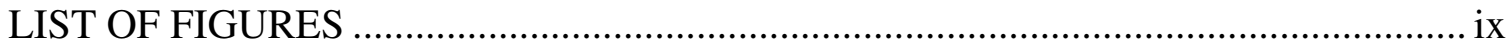

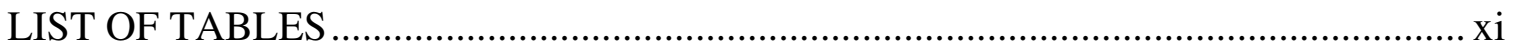

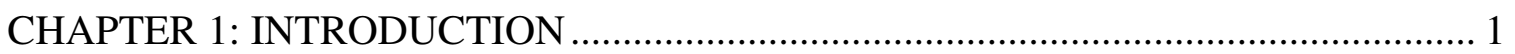

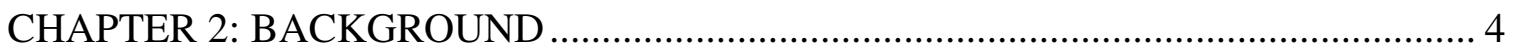

2.1 COMMON METHODS FOR REMOVAL OF AMMONIA, NITRATES AND NITRITES IN

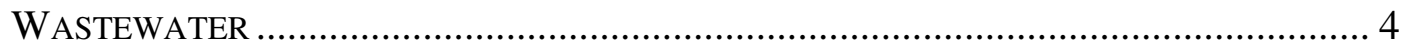

2.2 SimUltaNEOUS BIOLOGICAL NitRIFICATION/DENITRIFICATION ............................... 8

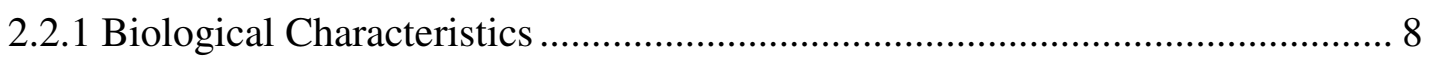

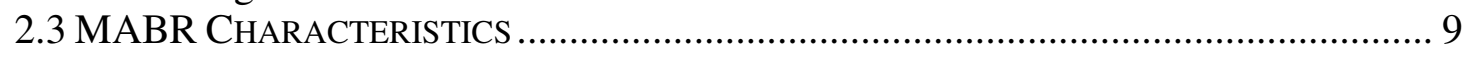

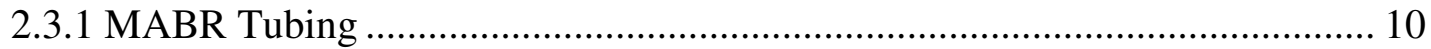

2.3.2 Biofilm and MABR Investigations .......................................................... 12

2.2.4 Previous Research with Current MABR ...................................................... 16

CHAPTER 3: MATERIALS AND METHODS ………....................................... 18

3.1 MEMBRANE AERATED BIOFILM REACTOR SETUP ……….................................. 18

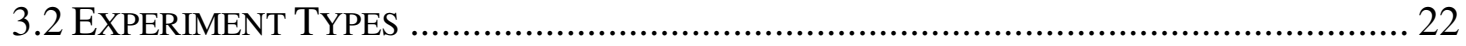

3.2.1 Batch Experiments ................................................................................. 22

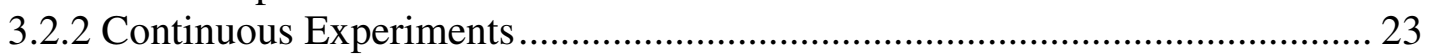

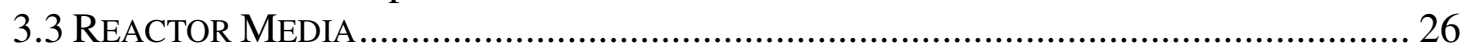

3.3.1 Initial $50 \mathrm{mg} / \mathrm{L} \mathrm{NH}_{4}{ }^{+}$as $\mathrm{NH}_{4}{ }^{+}$minimal growth media ................................... 27

$3.3 .210 \mathrm{mg} / \mathrm{L} \mathrm{NH}_{4}{ }^{+}$minimal growth media........................................................ 27

$3.3 .325 \mathrm{mg} / \mathrm{L} \mathrm{NH}_{4}{ }^{+}$minimal growth media......................................................... 29

$3.3 .45 \mathrm{mg} / \mathrm{L} \mathrm{NH}_{4}{ }^{+}$minimal growth media.......................................................... 30

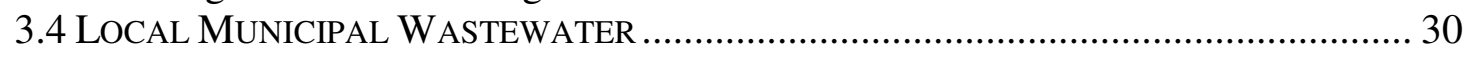

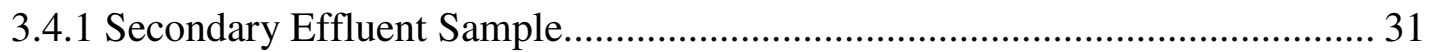

3.4.2 Nitrified Effluent Sample....................................................................... 32

3.4.3 Nitrified and Primary Effluent Mixtures........................................................ 33

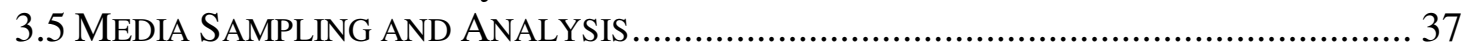

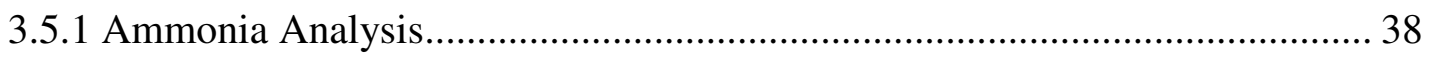

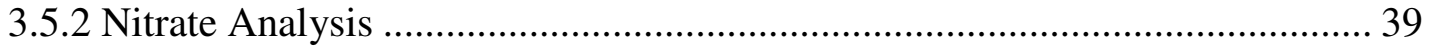

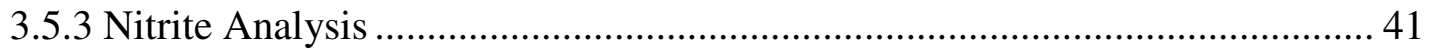

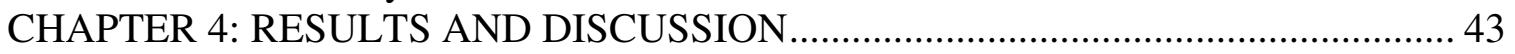

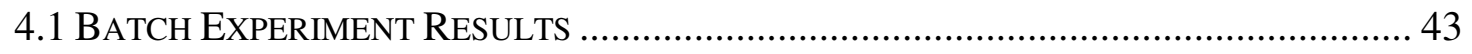

4.1.1 Batch Experiment B1 Results ..................................................................... 43

4.1.2 Batch Experiment B2 Results .................................................................. 46

4.1.3 Batch Experiment B3 Results ..................................................................... 49

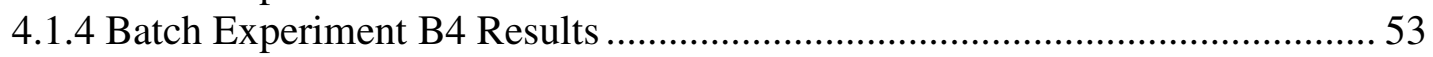

4.2 ConTINUOUS - Flow EXPERIMENT RESULTS ………………………………....... 57

4.2.1 Continuous - Flow Experiment C1 Results................................................... 58

4.2.2 Continuous - Flow Experiment C2 Results........................................................... 60

4.2.3 Continuous - Flow Experiment C3 Results...................................................... 63

4.2.4 Continuous - Flow Experiment C4 Results........................................................6 65

4.2.5 Continuous - Flow Experiment C5 Results..................................................... 68

4.2.6 Continuous - Flow Experiment C6 Results................................................... 70

4.3 LOCAL MuNICIPAL WASTEWATER RESULTS ………............................................ 73 
4.3.1 Secondary Effluent Experiment CW1 Results

4.3.2 100\% Nitrified Effluent Experiment CW2 Results ......................................... 75

4.3.3 5\% Primary, 95\% Nitrified Effluent Experiment CW3 Results ....................... 77

4.3.4 25\% Primary, 75\% Nitrified Effluent Experiment CW4 Results ..................... 79

4.3.5 15\% Primary, 85 \% Nitrified Effluent Experiment CW5 Results ................... 82

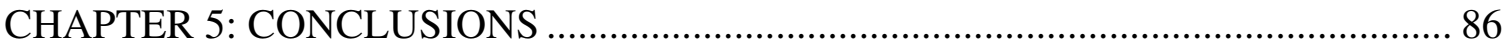

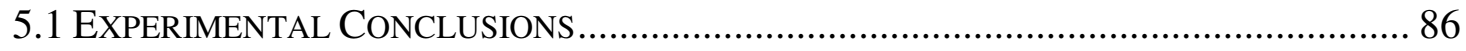

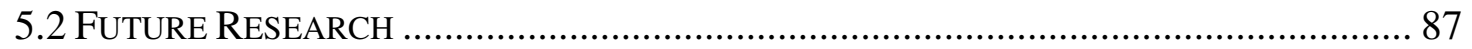

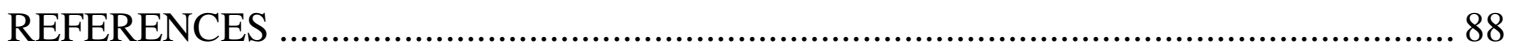

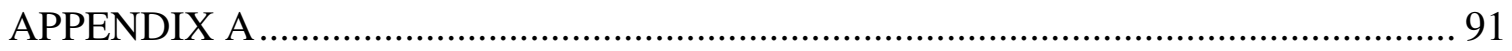

AMMONIA, NitRATE AND NitRITE CALIBRATION CURVES ........................................... 91 


\section{LIST OF FIGURES}

Figure 2.1: Typical Activated sludge process at San Luis Obispo Water Reclamation Facility

Figure 2.2: Ludzak-Ettinger Nitrogen Removal (Metcalf and Eddy, 2003)..................... 5

Figure 2.3: Modified Ludzak-Ettinger Nitrogen Removal (Metcalf and Eddy, 2003) ....... 6

Figure 2.4: Single-sludge Nitrogen Removal (Metcalf and Eddy, 2003) ......................... 7

Figure 2.5: Bardenpho Nitrogen Removal (Metcalf and Eddy, 2003) ............................ 7

Figure 2.6: Membrane Aerated Biofilm Reactor (Terada et al., 2002)............................ 10

Figure 2.7: Concentration profile schematic (Brindle et al., 1998) ................................ 12

Figure 3.1: Three Membrane Aerated Biofilm Reactor Set-ups ..................................... 18

Figure 3.2: MABR Top Schematic View .................................................................... 19

Figure 3.3: Biofilm Growing on Silicone Tubing during the Experiment....................... 19

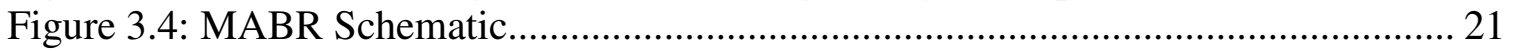

Figure 3.5: Reactor Set-up with Initial Feed Tank (Left) and Replacement Feed Tank

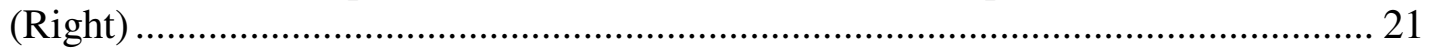

Figure 3.6: Secondary Clarifier Effluent San Luis Obispo Water Reclamation Facility.. 31

Figure 3.7: Nitrified Effluent from Final Clarifier San Luis Obispo Water Reclamation

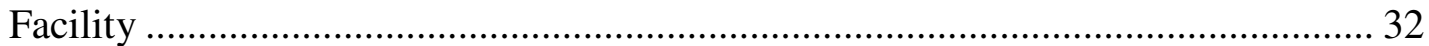

Figure 3.8: Primary Effluent from Primary Clarifier of San Luis Obispo Water

Reclamation Facility .................................................................................... 34

Figure 4.1: $\mathrm{pH}$ and Temperature Profile for Experiment B1 ...................................... 44

Figure 4.2: Ammonia, Nitrate and Nitrite Concentrations during Experiment B1 .......... 45

Figure 4.3: pH and Temperature Profile for Experiment B2 ........................................ 47

Figure 4.4: Ammonia, Nitrate and Nitrite Curves for Experiment B2 .......................... 48

Figure 4.5: First-Order Nitrification Kinetics for Experiment B2 ............................... 49

Figure 4.6: $\mathrm{pH}$ and Temperature Profile for Experiment B3 ..................................... 50

Figure 4.7: Ammonia, Nitrate and Nitrite Concentrations for Experiment B3 MABR

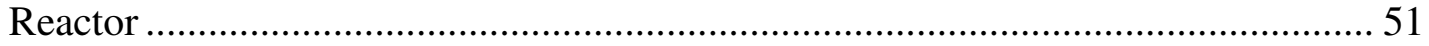

Figure 4.8: Ammonia, Nitrate and Nitrite Concentrations for Experiment B3 Anoxic

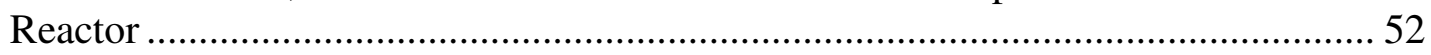

Figure 4.9: Nitrate and Nitrite IC Curves for Experiment B3 .................................... 53

Figure 4.10: $\mathrm{pH}$ and Temperature Profile for Experiment B4 ..................................... 54

Figure 4.11: Ammonia, Nitrate and Nitrite Concentrations for Experiment B4 MABR

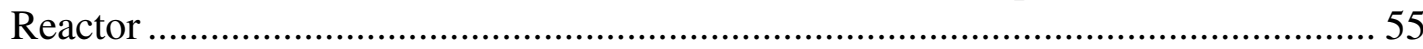

Figure 4.12: Ammonia, Nitrate and Nitrite Concentrations for Experiment B4 Anoxic

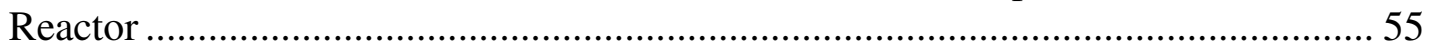

Figure 4.13: Nitrate and Nitrite IC Curves for Experiment B4 .................................. 56

Figure 4.14: $\mathrm{pH}$ and Temperature Profile for Experiment $\mathrm{C} 1$......................................58

Figure 4.15: Ammonia, Nitrate and Nitrite Curves for Experiment C1 ........................ 59

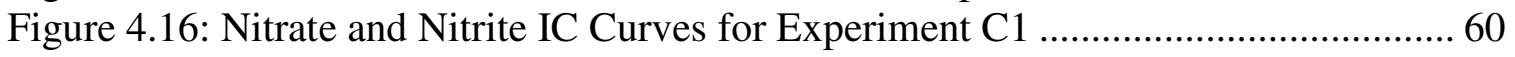

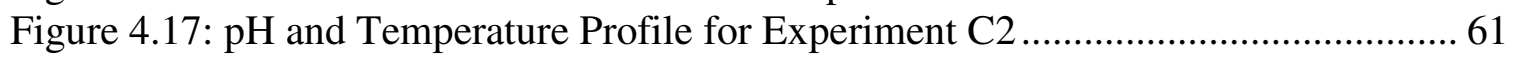

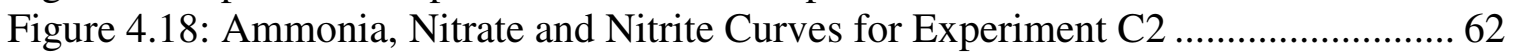

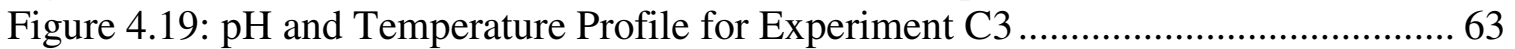

Figure 4.20: Ammonia, Nitrate and Nitrite Curves for Experiment C3 .......................... 64

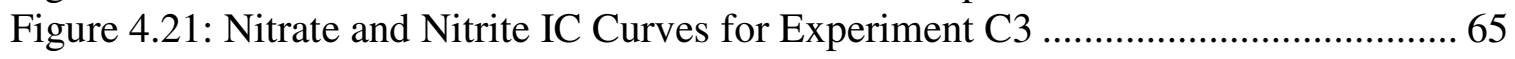




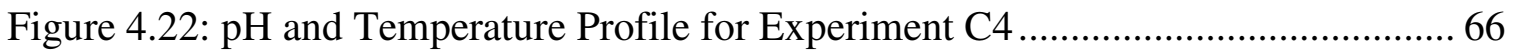

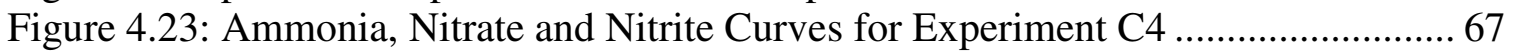

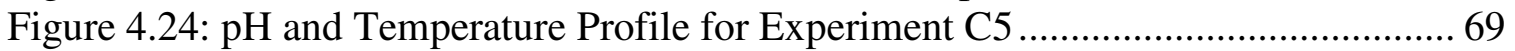

Figure 4.25: Ammonia, Nitrate and Nitrite Curves for Experiment C5 ........................ 70

Figure 4.26: $\mathrm{pH}$ and Temperature Profile for Experiment C6 ..................................... 71

Figure 4.27: Ammonia, Nitrate and Nitrite Curves for Experiment C6 ........................ 72

Figure 4.28: $\mathrm{pH}$ and Temperature Profile for Experiment $\mathrm{CW} 1$.................................. 74

Figure 4.29: Ammonia, Nitrate and Nitrite Curves for Experiment CW1 ...................... 75

Figure 4.30: $\mathrm{pH}$ and Temperature Profile for Experiment CW2 .................................. 76

Figure 4.31: Ammonia, Nitrate and Nitrite Curves for Experiment CW2 ..................... 77

Figure 4.32: $\mathrm{pH}$ and Temperature Profile for Experiment CW3 ................................. 78

Figure 4.33: Ammonia, Nitrate and Nitrite Curves for Experiment CW3 ...................... 79

Figure 4.34: $\mathrm{pH}$ and Temperature Profile for Experiment CW4 .................................. 80

Figure 4.35: Ammonia, Nitrate and Nitrite Curves for Experiment CW4 ...................... 81

Figure 4.36: Nitrate and Nitrite IC Curves for Experiment CW4 ............................... 82

Figure 4.37: $\mathrm{pH}$ and Temperature Profile for Experiment CW5 ................................. 83

Figure 4.38: Ammonia, Nitrate and Nitrite Curves for Experiment CW5 ..................... 84

Figure 4.39: Nitrate and Nitrite IC Curves for Experiment CW5 ................................ 85 


\section{LIST OF TABLES}

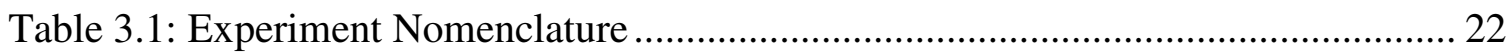

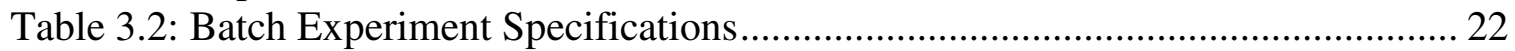

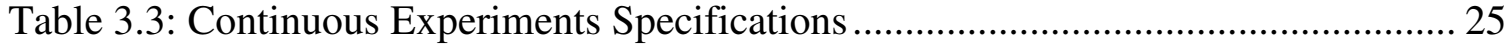

Table 3.4: Initial $50 \mathrm{mg} / \mathrm{L} \mathrm{NH}_{4}{ }^{+}$minimal growth media ............................................... 27

Table 3.5: $10 \mathrm{mg} / \mathrm{L} \mathrm{NH}_{4}{ }^{+}$minimal growth media........................................................ 28

Table 3.6: $10 \mathrm{mg} / \mathrm{L} \mathrm{NH}_{4}{ }^{+}$minimal growth media using limited nutrients...................... 28

Table 3.7: $25 \mathrm{mg} / \mathrm{L} \mathrm{NH}_{4}{ }^{+}$minimal growth media.................................................... 29

Table 3.8: $25 \mathrm{mg} / \mathrm{L} \mathrm{NH}_{4}{ }^{+}$minimal growth media using limited nutrients....................... 29

Table 3.9: $5 \mathrm{mg} / \mathrm{L} \mathrm{NH}_{4}{ }^{+}$minimal growth media using limited nutrients........................ 30

Table 3.10: Secondary Effluent Constituent Concentrations (Experiment CW1) ............ 31

Table 3.11: Nitrified Effluent Constituent Concentrations (Experiment CW2) ............... 32

Table 3.12: Primary Effluent Constituent Concentrations............................................. 35

Table 3.13: 5\% Primary, 95\% Nitrified Effluent Mixture Constituents Concentrations

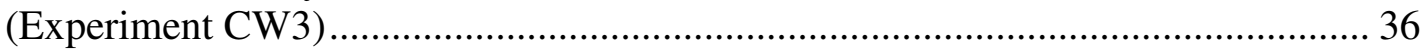

Table 3.14: 25\% Primary, 75\% Nitrified Effluent Mixture Constituents Concentrations

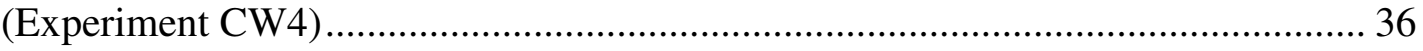

Table 3.15: 15\% Primary, 85\% Nitrified Effluent Mixture Constituents Concentrations

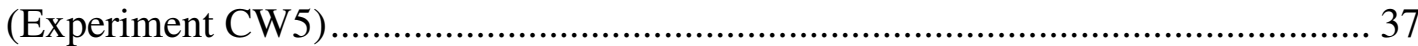

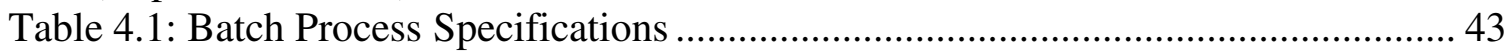

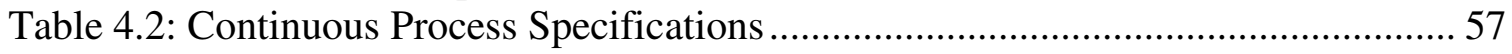

Table 4.3: Continuous Wastewater Process Specifications ............................................ 73 


\section{CHAPTER 1: INTRODUCTION}

Nitrogen compounds are an essential building block for the growth of microorganisms, plants, and animals. Known as nutrients or biostimulants, they can also have extremely negative effects when in contact with bodies of water. There are several oxidation states of nitrogen based compounds, but the most common and important compounds to water environments are ammonia $\left(\mathrm{NH}_{3}\right)$, ammonium $\left(\mathrm{NH}_{4}^{+}\right)$, nitrogen gas $\left(\mathrm{N}_{2}\right)$, nitrite ions $\left(\mathrm{NO}_{2}{ }^{-}\right.$ ), and nitrate ions $\left(\mathrm{NO}_{3}^{-}\right)$(Metcalf and Eddy, 2003). These compounds can be detrimental to water environments through the promotion of cell growth and the creation of toxic conditions. The ammonia compound is toxic to fish and other aquatic life, and the microbial growth increases the biological oxygen demand and decreases dissolved oxygen concentrations within the aquatic habitat. This creates "dead zones" caused by a lack of dissolved oxygen in the water, and is very detrimental to all aquatic life.

Short-term and long-term exposures to nitrate and nitrite can cause major health problems to humans when contaminated drinking water is consumed. Short-term exposure to infants through drinking water contamination can cause methemoglobinemia (LaPara and Ghosh, 2006), also known as blue baby syndrome. The highly soluble nitrates and nitrites attach to the hemoglobin in the blood and cause displacement of oxygen in the blood causing oxygen deprivation, which can be fatal within only a few days. Long-term exposures to nitrates and nitrites can cause diuresis, which is an increased starchy buildup and hemorrhaging of the spleen (Environmental Protection Agency, 2006). For this reason, the Environmental Protection Agency (EPA) implemented a primary drinking water standard of $10 \mathrm{mg} / \mathrm{L}$ as $\mathrm{NO}_{3}^{-}$and $1 \mathrm{mg} / \mathrm{L}$ as $\mathrm{NO}_{2}^{-}$in surface water and groundwater. 
The main sources of nitrate, nitrite and ammonia contamination in surface and groundwater come from anthropogenic sources. Fertilizers, fish canning waste, refineries, tanneries, agricultural run-off, and domestic wastewater are a few examples, and all can reach water environments and be detrimental to aquatic habitats, people and animals (Sabumon, 2007). An example of the compounds' negative effects is at the mouth of the Mississippi River in the Northern Gulf of Mexico. Since the 1950's and 60 's nutrient pollution that reached the Gulf of Mexico created an aquatic dead zone. With an area of $8000 \mathrm{~km}^{2}$, the low dissolved oxygen concentrations caused a hypoxic zone formation unable to sustain major aquatic life (LaPara and Ghosh, 2006). Drinking water supplies are commonly contaminated with nitrogen compounds as well, and with growing populations the contamination will only continue.

Many treatment technologies exist to treat biostimulants that are found in wastewater, especially ammonia, nitrite, and nitrite. My study follows up an investigation of using a membrane aerated biofilm reactor (MABR) to degrade nitrate and nitrite in a wastewater media and convert it to nitrogen gas (Copeland, 2007).

Our study focused on the treatment of ammonia, nitrites and nitrates in a wastewater media and nitrified wastewater with the same MABR as previously used, to investigate the effectiveness of ammonia, nitrite, and nitrate removal. A minimal media was used to establish bacterial growth on the silicone membranes in order for the biofilm to nitrify ammonia used as the nitrogen source within the media. Initial concentrations ranged from 5 to $50 \mathrm{mg} / \mathrm{L} \mathrm{NH}_{4}^{+}$as $\mathrm{NH}_{4}^{+}$to study the effectiveness of the inlet ammonia oxidation within the reactor. After one complete ammonia oxidation, it was established that the 
biofilm was capable of experiments with a local wastewater used to determine the reactor's ability to simultaneously degrade the ammonia, nitrite and nitrate compounds within it. A mixture of nitrified effluent and primary effluent wastewater were used in different percentage mixtures based on volume to determine the greatest ammonia, nitrate, and nitrite degradation efficiency. The mixtures included a 5\% primary effluent and $95 \%$ nitrified effluent mixture, a $15 \%$ primary effluent and $85 \%$ nitrified effluent mixture, and a $25 \%$ primary effluent and $75 \%$ nitrified effluent mixture all percentages were based on the total reactor volume. The purpose of adding the primary effluent was to investigate the use of primary effluent as the carbon source for denitrification. 


\section{CHAPTER 2: BACKGROUND}

\subsection{Common Methods for Removal of Ammonia, Nitrates and Nitrites in Wastewater}

Due to the maximum contamination level of nitrogen concentrations in water environments set by the EPA, wastewater treatment facilities are required to decrease ammonia, nitrite, and nitrate concentrations in their effluent prior to discharge. Physical and chemical methods of treatment include air stripping of ammonia, chemical oxidation by breakpoint chlorination, ion exchange, and steam stripping of ammonia (Metcalf and Eddy, 2003). The more prevalent treatment processes are biological, and they are an integral part of modern treatment plant design. Common biological nitrogen removal treatment technologies include an aerobic stage for nitrification and an anoxic stage for denitrification. Nitrification is the process of oxidizing ammonia into nitrite and nitrate in an aerated reactor. This is typically done in activated sludge processes, which promote microbiological growth to breakdown organic compounds and nutrients by steady mixing and high aeration (Figure 2.1).

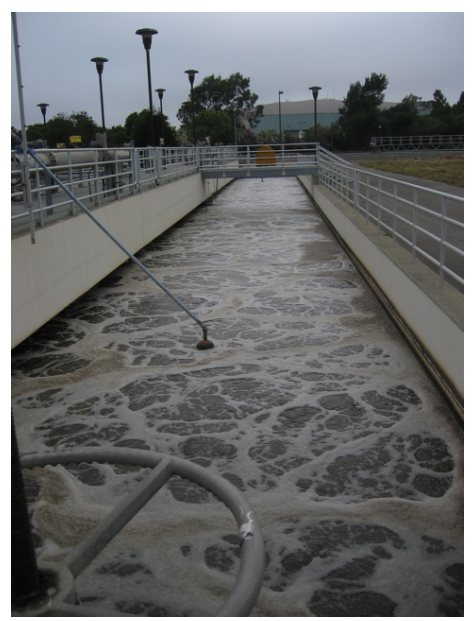

Figure 2.1: Typical Activated sludge process at San Luis Obispo Water Reclamation Facility 
In the aerated nitrification process, nitrifying bacteria have slow growth rates relative to the growth rates of heterotrophic bacteria. The nitrifying bacteria are out-competed for available oxygen, and as a result nitrification occurs at lower organic carbon concentrations, and requires large hydraulic retention times (Satoh et al., 2004). The anoxic zone following aeration than reduces nitrite and nitrate ions to the form of nitrogen gas (Metcalf and Eddy, 2003). Using the Ludzak-Ettinger, Preanoxic nitrogen removal process, the anoxic denitrification precedes the nitrification stage and the bacteria present reduce the developed nitrate and nitrite ions into nitrogen gas (Figure 2.2). This sequence process was developed by Ludzak and Ettinger in 1962 (Metcalf and Eddy, 2003). The nitrates formed in the aerobic zone return to the anoxic zone through the returned activated sludge (RAS), entering the anoxic zone to be reduced. However, this process is very limited since the RAS flow is the only source of nitrates to the anoxic zone. This type of process is used most often with an increased RAS recycle rates to prevent increased sludge quantities in the secondary clarifier caused by denitrification in the aerobic zone (Metcalf and Eddy, 2003).

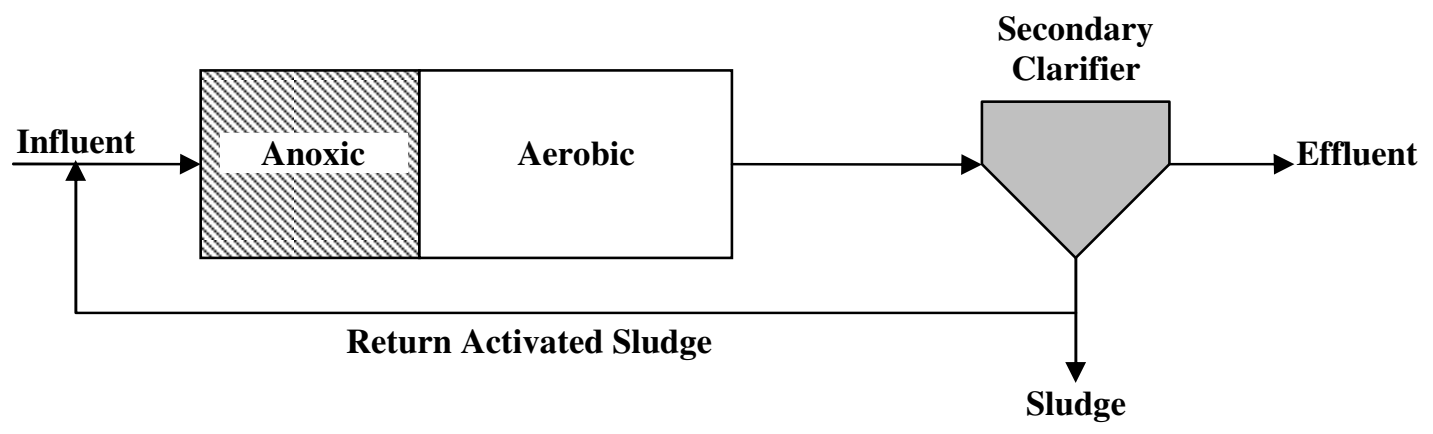

Figure 2.2: Ludzak-Ettinger Nitrogen Removal (Metcalf and Eddy, 2003) 
Another very common biological removal process is called the Modified Ludzak-Ettinger process (Figure 2.3). In 1973 the Ludzak-Ettinger process was modified by Barnard to improve the anoxic zone's ability to denitrify the wastewater in the anoxic zone (Metcalf and Eddy, 2003). The added internal recycle line provides higher nitrate concentrations to enter the anoxic zone, which than increases the denitrification rate and overall nitrogen removal. The process can have nitrate effluent concentrations ranging from 4 to $7 \mathrm{mg} / \mathrm{L}$ as $\mathrm{N}$, and can be very adaptable for existing activated sludge systems to meet EPA effluent standards (Metcalf and Eddy, 2003).

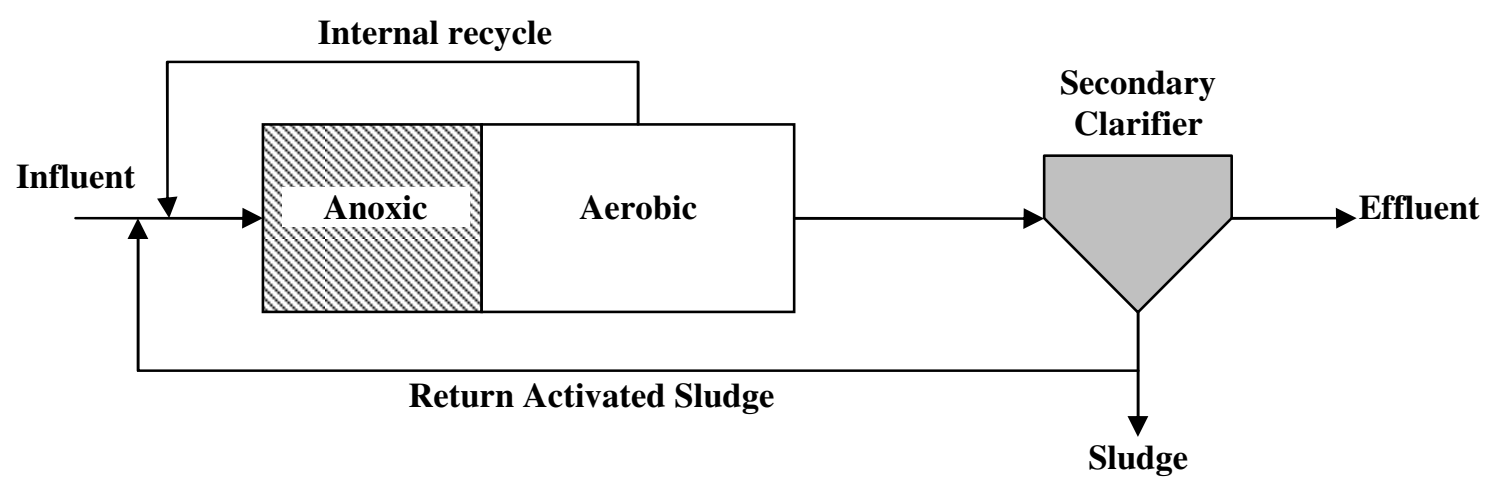

Figure 2.3: Modified Ludzak-Ettinger Nitrogen Removal (Metcalf and Eddy, 2003)

Opposite to the previous biological nitrogen removal process, another common system uses a Postanoxic design (Figure 2.4). The Single-sludge, Postanoxic process was developed by Wuhrmann in order to achieve nitrogen removal in an activated-sludge system by placing an anoxic zone for denitrification prior to the aerobic nitrification (Metcalf and Eddy, 2003). In order to maintain high denitrification rate efficiencies, the hydraulic and sludge retention times within the anoxic tank need to be long since the denitrification rate has a direct correlation with the endogenous respiration of the bacteria and their slow growth rate (Metcalf and Eddy, 2003). 


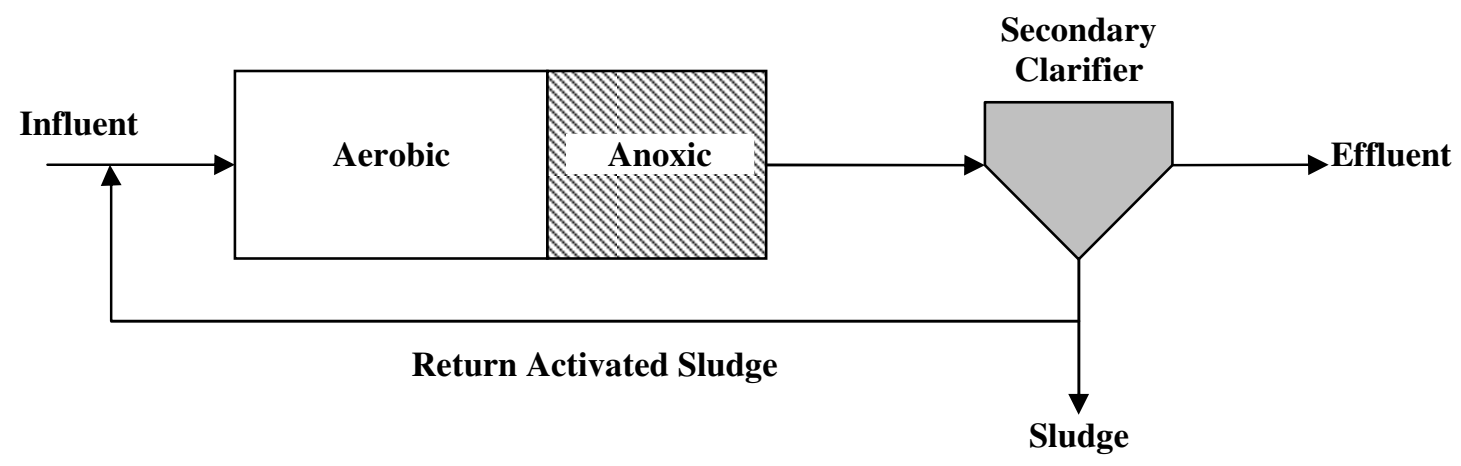

Figure 2.4: Single-sludge Nitrogen Removal (Metcalf and Eddy, 2003)

Another biological nitrogen removal system uses both the Preanoxic and Postanoxic treatment process. The Bardenpho process, invented by Barnard in 1974, (Figure 2.5) was first developed and used for municipal wastewater treatment in South Africa during the mid-1970s, before first being used in the United States in 1978 (Metcalf and Eddy, 2003). It consists of a four-stage process with two anoxic and two aerobic zones in succession. The long hydraulic retention time and sludge retention time stays constant through the Postanoxic and Preanoxic stages of the system, and the effluent nitrate concentrations typically range from 5 to $7 \mathrm{mg} / \mathrm{L}$ as $\mathrm{N}$, and can be as low as $3 \mathrm{mg} / \mathrm{L}$ nitrate as N (Metcalf and Eddy, 2003).

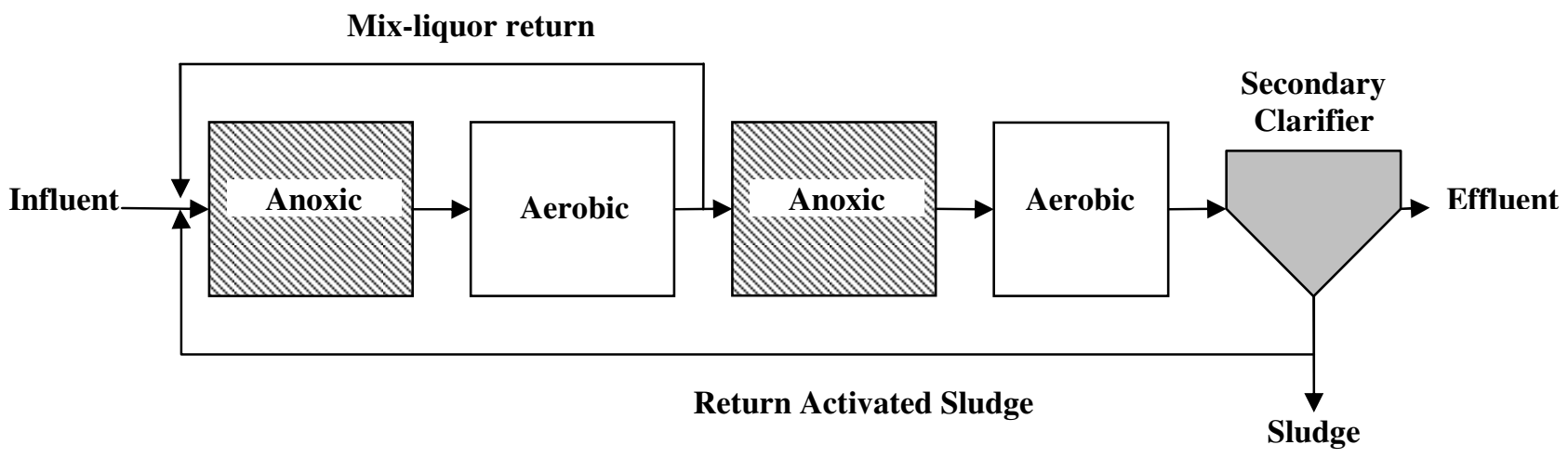

Figure 2.5: Bardenpho Nitrogen Removal (Metcalf and Eddy, 2003) 
These multistage processes require a large footprint for treatment facilities, and take large amounts of time to reach effluent compliance for nitrogen removal. The hydraulic retention time of activated sludge processes and multi-stage aerobic and anoxic systems range from a few hours to a couple days, and with the combination of nitrification and denitrification, the process requires the latter (Metcalf and Eddy, 2003).

\subsection{Simultaneous Biological Nitrification/Denitrification}

In order to decrease the time it takes for total nitrogen removal of wastewater, many investigations have been done to create simultaneous nitrification and denitrification in a single reactor (Casey, 1998). Many investigations studied the growth and maintenance of bacterial strains capable of oxidizing ammonia and reducing nitrates within a single-stage bioreactor. Based on the stoichiometry for the two run experiment, both of the processes require very separate conditions. Nitrification requires high levels of oxygen as seen below:

$$
3 \mathrm{NH}_{4}^{+}+6 \mathrm{O}_{2} \cdot 3 \mathrm{NO}_{3}^{-}+6 \mathrm{H}^{+}+3 \mathrm{H}_{2} \mathrm{O}
$$

Denitrification however requires anoxic or anaerobic conditions, where $[\mathrm{H}]$ equals reducing equivalents which would be supplied by an external carbon source:

$$
3 \mathrm{NO}_{3}^{-}+3 \mathrm{H}^{+}+15[\mathrm{H}] \cdot 1.5 \mathrm{~N}_{2}+9 \mathrm{H}_{2} \mathrm{O}
$$

In order to maintain both conditions, both need to be controlled and maintained (Schmidt et al., 2003). These different chemical environments are able to keep only specific bacteria capable of surviving in these conditions, and there are only a few known bacteria strains that can use the conditions to their benefit (Schmidt et al., 2003).

\subsubsection{Biological Characteristics}


Simultaneous nitrification and denitrification requires both nitrifying and denitrifying bacteria and the conditions to support them. The nitrifying bacteria are characterized as autotrophic bacteria that derive energy from the oxidation of ammonia or nitrite. However, there is a limited presence of bacterial genera capable of this. The most common include Nitrosomonas and Nitrobacter. The Nitrosomonas are the best known aerobic ammonia oxidizers, and the Nitrobacter genera oxidize nitrites to form nitrates (Grunditz et al., 2001). The oxidized nitrogen compounds produced, can then be used as alternative electron acceptors for the denitrifying bacteria capable of reducing the nitrates formed. The Nitrosomonas and Nitrobacter bacteria are characterized as being heterotrophic, and need a low carbonaceous oxygen demand for energy and carbon supply in anoxic or anaerobic conditions to have growth capable of degrading ammonia and nitrates (Sliekers et al., 2002; Schmidt et al., 2003). There are bacteria capable of doing both though, and research has also been done by Shrestha et al. (2002) who studied the bacteria strain Nitrosomonas europea and its effectiveness to both oxidize ammonia and reduce nitrates to form nitrogen gas. The bacteria were grown lithoautotrophically in a growth medium with the ammonium concentration of $360 \mathrm{mg} / \mathrm{L}$ as nitrogen. The incubation time for the study was 52 hours, and results concluded the bacteria had ammonia to nitrite conversion efficiencies of 47 and $37 \%$ respectively. The ammonia to nitrogen gas conversion efficiencies ranged between 2.34 and $6.74 \%$ respectively (Shrestha et al., 2002).

\subsection{MABR Characteristics}


The hopeful future of the treatment is the use of conducting both reactions in a single reactor. One type of reactor used for simultaneous nitrification/denitrification was a membrane aerated biofilm reactor (MABR), which allows for aerobic nitrification and anoxic denitrification zones to occur within the single reactor (Casey, 1999). Aeration for the MABR was provided through hollow fiber membrane tubing to the bulk liquid of the reactor, and the outside surface of the tubing also acted as a carrier to immobilize the bacteria (Figure 2.6).

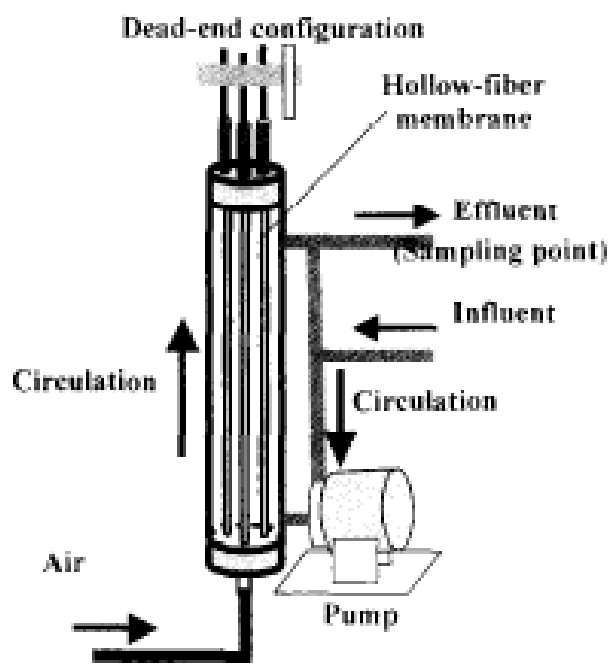

Figure 2.6: Membrane Aerated Biofilm Reactor (Terada et al., 2002)

The air than penetrates through the membrane tubing into the biofilm that forms on the outer surface of the membrane. The bacteria in the biofilm consume the oxygen to oxidize pollutants diffusing from the bulk solution (Terada et al., 2003; Casey, 1999). For our investigation, we used dense film membrane silicone tubing.

\subsubsection{MABR Tubing}


Air transfer through the membrane tubing depends on the membrane classification. This includes three types: microporous hydrophobic membranes such as polypropylene, dense film membranes such as dimethylsiloxane (silicone), or composite membranes where a porous membrane is coated with a thin film of dense material (Casey, 1999). The microporous hydrophobic membrane mass transfer occurs by diffusion within the gasfilled pores. A problem with this is the possibility of liquid penetrating into the pores, which causes a large drop in the mass transfer coefficient. Another drawback is the low bubble point of the membrane. This limits the maximum intramembrane pressure if bubble formation wants to be avoided (Casey, 1999). Dense film membrane transport mechanisms occur through solution diffusion, but the high permeability is due to the fact that some compounds, oxygen especially, have solubility four of five times more soluble in silicone than in water. Other benefits of using dense membranes include their ability to withstand pressures up to 43.5 pounds per square inch (psi), and their high resistance to chemicals and mechanical stress. Also, the high density membrane is also less likely to have pore clogging and liquidity entry as does the microporous membranes (Casey, 1999). The composite membrane uses a $1 \mu \mathrm{m}$ thick polymer coating on a microporous membrane with pore sizes ranging between 0.04 and $1.0 \mu \mathrm{m}$. The advantage of having microporous membranes and dense membranes allows for bubble-less aeration at pressures up to 100 psi. This style of membrane has been used for high-rate nitrification in both laboratory and pilot-scale studies (Casey, 1999). Other benefits of the membrane system include the protection of the microorganisms against microbial loss by flushing, shear stress, and inhibitory substances. The support matrix provided by the membrane tubing helped maintain the biofilm and promoted greater flow rates through the reactor systems (Franco-Rivera et al., 2007). 


\subsubsection{Biofilm and MABR Investigations}

For conventional MABRs, a conventional biofilm's active layer (oxic layer) ranges typically between 50 and $200 \mu \mathrm{m}$ thick. This thickness corresponds to the depth of oxygen penetration into the biofilm, and if the overall biofilm thickness is larger than the oxygen penetration from the membrane an anoxic zone develops within the boundary layer between the bulk liquid of the reactor and the biofilm (Casey, 1999). An example of this can be seen in Figure 2.7. The schematic illustrates the oxygen and ammonia concentration profile through the biofilm grown on the membrane tubing. The oxygen profile shows high oxygen concentrations within the pressurized tube (the lumen) and within the membrane itself. As the air transfers through the biofilm the oxygen is consumed. As the oxygen gradient decreases, the ammonia conversion conversely changes with the higher oxygen concentration causing higher ammonia oxidation with less being degraded as it gets closer to the bulk liquid in the reactor (Brindle et al., 1998).

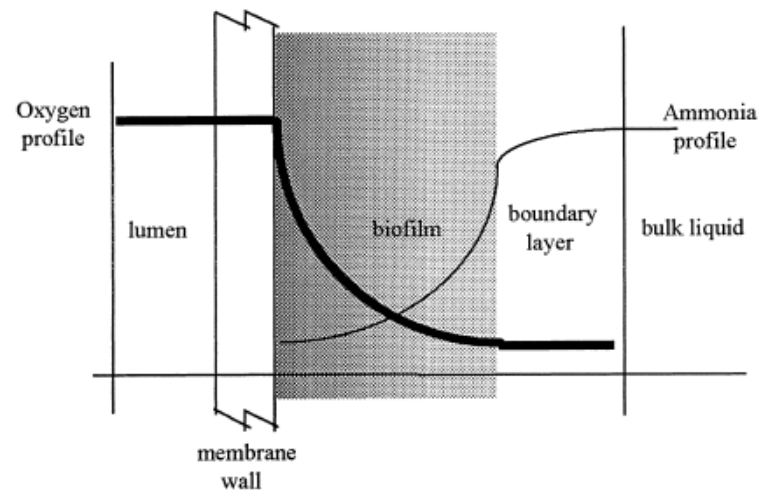

Figure 2.7: Concentration profile schematic (Brindle et al., 1998)

With this dichotomy within the same reactor, the simultaneous nitrification and denitrification can be a complimentary process. The nitrite and nitrate produced by the nitrification can become and electron acceptor for denitrification. Also, nitrification 
lowers $\mathrm{pH}$ that is than raised by denitrification, and the alkalinity generated by denitrification is required for nitrification to occur (Terada et al., 2003). The spatial distribution of both nitrifying and denitrifying organisms within a MABR biofilm allows the nitrifying bacteria to predominate at the oxygen rich membrane side of the biofilm, while the denitrifying organisms were located adjacent to the oxygen depleted biofilmliquid interface (Casey, 1999; Matsumoto et al., 2007). To maximize air transfer to the active biofilm layer the ends of the membranes furthest from the air source are sealed to ensure $100 \%$ air transfer efficiency. This configuration is known as dead-end configuration (Brindle et al., 1998). In a MABR study using the dead-end configuration for the removal of nitrogen in wastewater, Terada et al. (2003) found the nitrogen removal efficiency through the research to be $83 \%$. The bubble-less transfer through the membrane walls directly to the biofilm suggested the aerobic zone in the biofilm was fairly limited, while the anoxic and anaerobic zones were relatively wide.

Other Important aspects to the membrane tubing include the tubing surface area. Removal rates for nitrification of ammonia are influenced by the membrane surface area and the supplied air pressure. Ammonia removal rates per attached biomass decreased with an increase in membrane surface area (Terada et al., 2006). Also, GonzalezBrambila et al. (2006), and Terada et al. (2006) studied the MABR system for simultaneous nitrification/denitrification, and concluded from their research that there was a direct correlation between oxygen flux within a biofilm and the supplying gas pressure to the membrane. This meant that the necessary air pressure must be provided to establish sufficient growth on the biofilm (Gonzalez-Brambila et al., 2006; Terada et al., 2006). 
Another investigation for the simultaneous nitrification/denitrification within an MABR system was conducted by Satoh et al. (2004). The MABR system contained polyurethane hollow fiber membranes in a parallel sheet. The investigation consisted of using different carbonaceous oxygen demand (COD) loading rates and adjusting the intra-membrane pressures to examine where nitrification occurred in the biofilm using $\mathrm{O}_{2}, \mathrm{NH}_{4}^{+}, \mathrm{NO}_{2}^{-}$, $\mathrm{NO}_{3}^{-}$, and $\mathrm{pH}$ microelectrodes. The investigation concluded that simultaneous COD removal, nitrification and denitrification were achieved, with removal efficiencies being 90\% and 95\% respectively. The greatest efficiency occurred with low COD loading rates around $1.0 \mathrm{~g}-\mathrm{COD} / \mathrm{m}^{2} / \mathrm{day}$, and within the reactor denitrification occurred just above the nitrification zones. Studies conducted on ammonia oxidizing bacteria by LaPara and Ghosh (2006) researched the relationship between Nitrosomonas and Nitrospira bacteria populations and the efficiency of nitrogenous pollutant removal in a full-scale municipal wastewater treatment facility. During their study period, significantly higher bacterial populations were detected when compared to the periods of lower reactor efficiency. The Nitrosomonas and Nitrospira bacteria population had a direct correlation to the reactor efficiency. Conditions within a reactor have a major affect on the growth of nitrifying and denitrifying bacteria. Previous studies based on the simultaneous nitrification and denitrification inhibitors have been conducted by Matsumoto et al. (2007), Grunditz et al. (2001), Brindle et al. (1998), and Vadivelu et al. (2007). The major inhibitory factors found from the studies included oxygen concentration, temperature, and $\mathrm{pH}$ within the reactor. 
Matsumoto et al. studied the effects of carbon/nitrogen ratio, biofilm thickness and surface loading of oxygen to a biofilm using a simulation model to determine what parameter has the largest effect on effluent quality for simultaneous nitrification/denitrification. They concluded that the necessary oxygen to nitrogen ratio by weight was $4.57 \mathrm{~g}-\mathrm{O}_{2} / \mathrm{g}-\mathrm{N}$ for complete nitrification, the oxygen concentration when not high enough can become the limiting factor for nitrification when not supplied at a necessary flow rate, and the maximum total-nitrogen removal through simultaneous nitrification/denitrification occurred with a carbon/nitrogen ratio of 3.75 .

Temperature and $\mathrm{pH}$ of the reactor media also plays an integral role in developing the most beneficial environment for nitrifying bacteria (Grunditz et al., 2001). Grunditz et al. (2001) conducted test tube experiments with isolated Nitrosomonas and Nitrobacter bacteria, and wastewater samples were inoculated with the pure cultures to study the effects of temperature and $\mathrm{pH}$ on the bacteria's ability to nitrify the media with ammonium concentrations of $50 \mathrm{mg} / \mathrm{L}$ as $\mathrm{N}$. Grunditz et al. (2001) concluded that the highest microbial activity for Nitrosomonas and Nitrobacter occurred at 35 and 38 degrees Centigrade. For $\mathrm{pH}$ the most activity occurred at $\mathrm{pH} 8.1$ for Nitrosomonas, and 7.9 for Nitrobacter. However, $\mathrm{pH}$ and temperature are not the only inhibitors for the nitrification and denitrification processes. The studies conducted by Brindle et al. (1998) concluded that nitrification can be inhibited by the presence of organic matter and suspended solids within a media, but their studies found simultaneous nitrification/denitrification effectively removed approximately $94 \%$ ammonia as $\mathrm{N}$. The research done by Vadivelu et al. (2006) concluded that Nitrobacter bacteria showed significant inhibitory effects in the presence of free ammonia. The inhibitory effects 
were clearly seen at concentrations below $1.0 \mathrm{mg} / \mathrm{L}$ of ammonia as $\mathrm{N}$, but inhibitory effects leveled off at concentrations ranging 4.0 to $9.0 \mathrm{mg} / \mathrm{L}$ of ammonia as $\mathrm{N}$. This is of significant concern when trying to simultaneously nitrify ammonia and denitrify the nitrate compounds present together in a single reactor.

\subsubsection{Previous Research with Current MABR}

The MABR used for this current research had previously been used to compare denitrification rates of nitrate when compared to an aerobic reactor and an anoxic reactor (Copeland, 2007). The aerobic reactor contained an air sparge system, and the anoxic reactor had no aeration. Aeration occurred within the MABR system by pressurizing silicone tubing and allowing air to permeate through the silicone tubes. Experiments conducted included three batch experiments and two continuous flow experiments. The batch experiments used three media with nitrate concentrations of $50 \mathrm{mg} / \mathrm{L}, 100 \mathrm{mg} / \mathrm{L}$ and $20 \mathrm{mg} / \mathrm{L}$ respectively. The continuous flow experiments included the use of two media with nitrate concentrations of $50 \mathrm{mg} / \mathrm{L}$ and $20 \mathrm{mg} / \mathrm{L}$ respectively.

The results concluded that the batch experiments conducted in the aerated reactor had little or no denitrification, while the anoxic and MABR showed steady denitrification. The MABR denitrification rate constants followed first-order kinetics, with rate constants ranging between 0.03 and $0.11 \mathrm{hr}^{-1}$. The denitrification rate within the anoxic reactor resembled zero-order kinetics, and the rate constants ranged between 0.06 and 0.64 mg/L-hr. The continuous flow results concluded that their short run times and retention times resulted in low removal rates, and nitrite production was depleted before exit from the MABR and the anoxic reactor. 


\section{CHAPTER 3: MATERIALS AND METHODS}

\subsection{Membrane Aerated Biofilm Reactor Setup}

The MABR systems were made from 41-inch tall, 6-inch diameter, schedule-40 polyvinyl-chloride (PVC) tubing, sealed at either end with 6-inch diameter, schedule-40 PVC caps. The three sampling ports were 0.5-inch diameter PVC ball valves, and the open ends of the ball valves were connected with silicone septum caps. The total volume of each MABR was 19-liters (Figure 3.1).

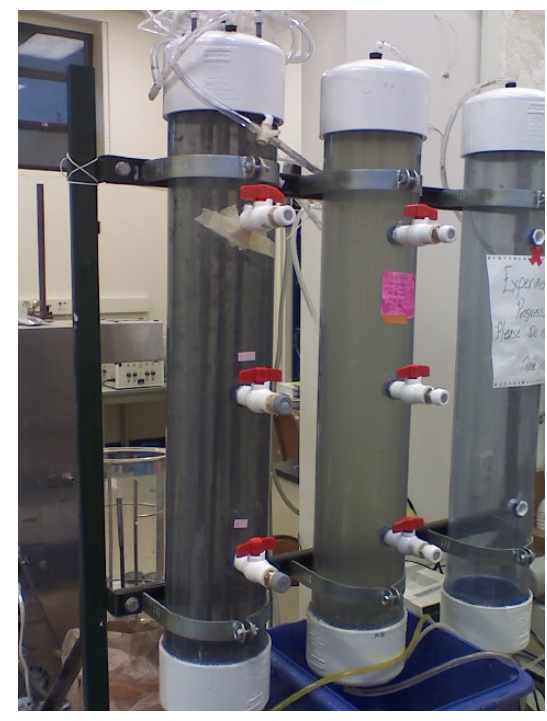

Figure 3.1: Three Membrane Aerated Biofilm Reactor Set-ups

The silicone tubing aerators were assembled from five Masterflex ${ }^{\circledR}, 0.25$-inch $(6.35-\mathrm{mm})$ diameter, 43-inch (1.1-m) long silicone tubes, with membrane wall thickness of 0.0625inches $(1.59-\mathrm{mm})$. The dead-end configuration was established by inserting 1-inch glass rods in the ends of the tubing to seal the bottom ends. Each silicone membrane had a surface area of 33.8 square inches, and each reactor had a total membrane surface area of 169 square inches. The membrane tubing was placed in a vertical configuration centrally distributed within the MABR (Figure 3.2). Air entered the tubing at the top of the reactor 
sourced from a wall-mounted compressed air distribution line. The supplied air allowed the aerobic bacteria to grow along the silicone tubing (Figure 3.3). The air pressure was controlled by a general-purpose compressed gas regulator.

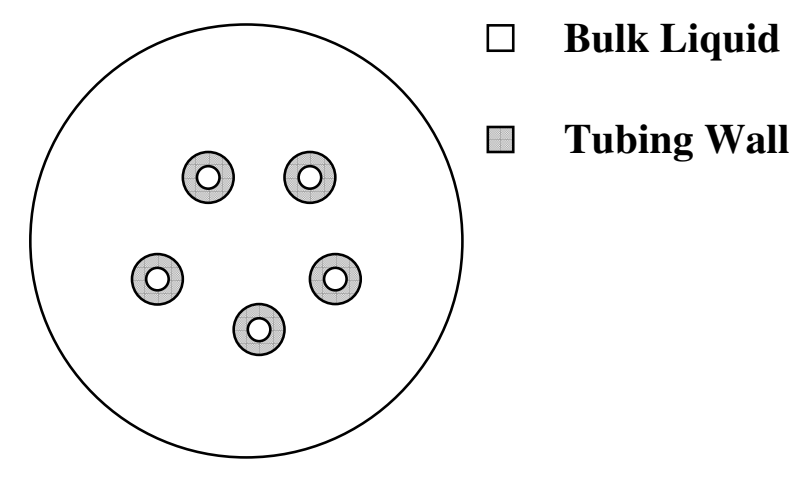

Figure 3.2: MABR Top Schematic View

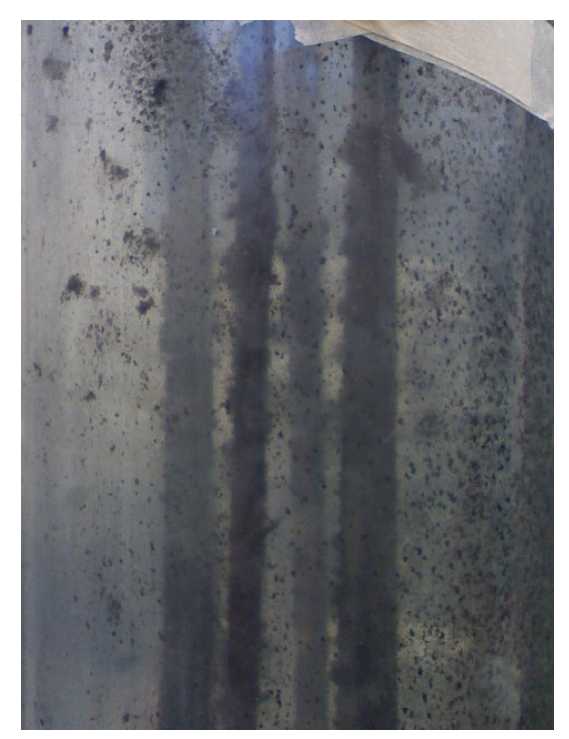

Figure 3.3: Biofilm Growing on Silicone Tubing during the Experiment

The single air line was than distributed to the five silicone tubing membranes at the top of the reactor. The liquid within the MABR was fed from a feed storage tank and pumped using a Masterflex ${ }^{\oplus}$ peristaltic pump, and the inlet flow was controlled by a Masterflex ${ }^{\oplus}$ 
Controller/Distributor flow meter. The reactor liquid was fed through the bottom of the MABR, and the effluent exited the reactor through three converging effluent tubes located at the top of the reactor. The effluent was then released to the sink adjacent to the MABR. All of the air and feed liquid distribution was connected with 0.375 -inch and 0.5 -inch PVC

and vinyl tubing,

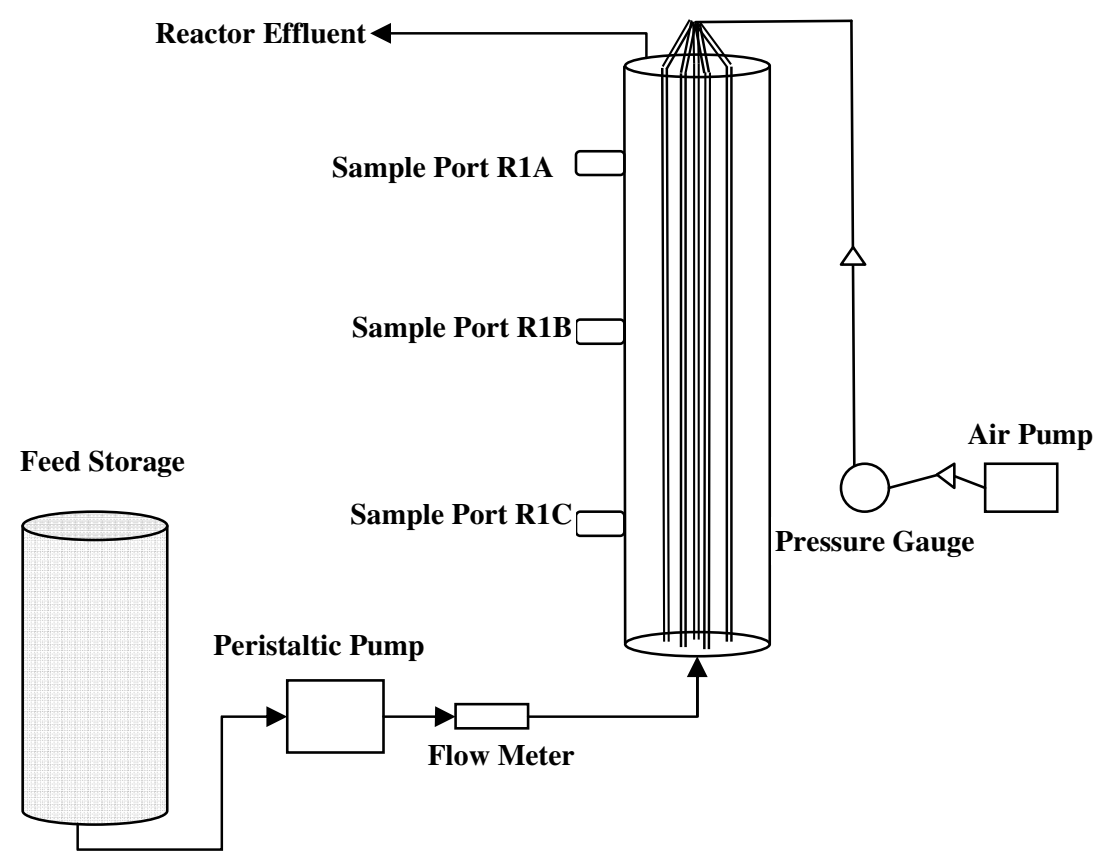

necessary PVC connectors (Figure 3.4). 


\section{Figure 3.4: MABR Schematic}

The initial liquid storage tank used was a 50-gallon PVC drum with a 1-inch diameter ball valve near the bottom to release the feed liquid, and sealed at the top with a $0.2-\mu \mathrm{m}$ air filter. The feed tank connected to the peristaltic pump and the MABR using 0.25-inch Cole-Parmer Tygon ${ }^{\circledR}$ vinyl tubing. The 50-gallon feed tank was used for the first three experiments, but microbial growth within the feed storage tank led to it being replaced with a different container. The replacement tank was a 5-gallon polycarbonate bottle, sealed with a large rubber stopper and a $0.2-\mu \mathrm{m}$ air filter. The feed line reached the bottom of the storage bottle using 0.25 -inch copper tubing and connected to the peristaltic pump using 0.25-inch PVC tubing (Figure 3.5). The pH within the replacement tanks was maintained at a neutral $\mathrm{pH}$ to avoid $\mathrm{Cu}$ leaching.
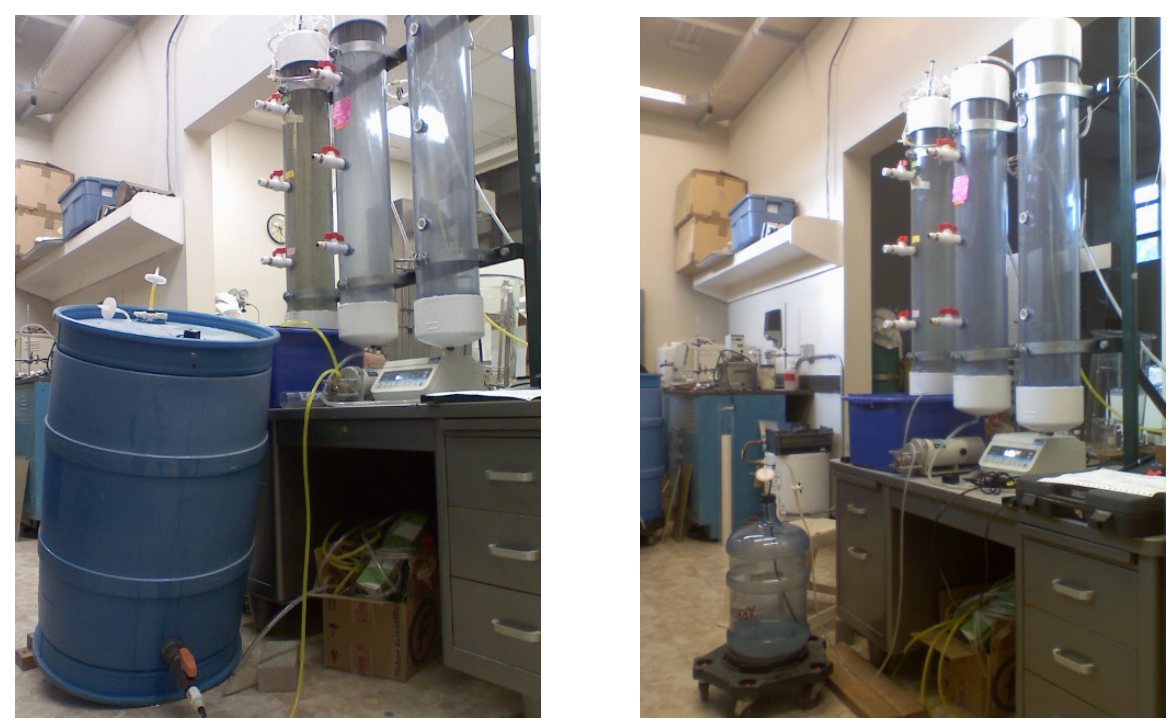

Figure 3.5: Reactor Set-up with Initial Feed Tank (Left) and Replacement Feed Tank (Right) 


\subsection{Experiment Types}

The MABR experiments were conducted in both batch and continuous modes, and the reaction times ranged from about 8 to 20 days for the batch modes and 5 to 17 days for the continuous modes respectively. The nomenclature for both experiments is as follows (Table 3.1Error! Reference source not found.).

Table 3.1: Experiment Nomenclature

\begin{tabular}{ccc}
\hline $\begin{array}{c}\text { Batch } \\
\text { Experiment }\end{array}$ & $\begin{array}{c}\text { Continuous } \\
\text { Minimal Media } \\
\text { Experiment }\end{array}$ & $\begin{array}{c}\text { Continuous } \\
\text { Wastewater } \\
\text { Experiment }\end{array}$ \\
\hline B1 & C1 & CW1 \\
B2 & C2 & CW2 \\
B3 & C3 & CW3 \\
B4 & C4 & CW4 \\
& C5 & CW5 \\
& C6 & \\
\hline
\end{tabular}

\subsubsection{Batch Experiments}

The batch run experiments were conducted during the months of February, March, and April 2008. The purpose of the batch run experiment was to develop microbial growth along the silicone tubing within the MABR, and also determine reaction times for the nitrification of ammonia within the minimal media. The minimal media concentrations for ammonia differed between $50 \mathrm{mg} / \mathrm{L}$ and $5 \mathrm{mg} / \mathrm{L}_{\text {as }} \mathrm{NH}_{4}^{+}$, and reaction times varied for each reaction (Table 3.2Error! Reference source not found.). For comparison of reaction times to the MABR batch reaction, an anoxic reactor with no aeration was used and analyzed to determine the effectiveness of the MABR system. The anoxic reactor was used for the $10 \mathrm{mg} / \mathrm{L}, 25 \mathrm{mg} / \mathrm{L}$ and $5 \mathrm{mg} / \mathrm{L}$ as $\mathrm{NH}_{4}{ }^{+}$concentrations run experiment.

Table 3.2: Batch Experiment Specifications

\begin{tabular}{ccc}
\hline Experiment & $\begin{array}{c}\text { Total Run } \\
\text { Hours }\end{array}$ & $\begin{array}{c}\text { Ammonia } \\
\text { Concentration } \\
\text { as NH }_{4}^{+}(\mathbf{m g} / \mathbf{L})\end{array}$ \\
\hline B1 & 192 & 50 \\
\hline
\end{tabular}




\begin{tabular}{ccc}
\hline B2 & 172 & 10 \\
B3 & 476 & 25 \\
B4 & 160.5 & 5 \\
\hline
\end{tabular}

For each batch reaction the minimal media was mixed based on the media specifications for each individual run. The media was measured to meet targeted ammonia concentrations based on the 19-liter volume of the MABR, and was mixed in 5-gallon polycarbonate bottles with DI water to meet the correct volume. The media was then covered and mixed for 20 minutes using a magnetic stirrer and stir bar. For the anoxic reactor analysis, the media was replicated for simultaneous comparisons. After mixing, the media was pumped into the MABR, and initial samples were taken for analysis. The wall mounted air pressure gauge connected to the air supply was set at a constant pressure of 15-psi. This air pressure was used due to the occurrence of leaks within the air feed lines at higher gauge pressures. The MABR was than inoculated with $25-\mathrm{mL}$ of returned activated sludge (RAS) from the Reclamation Facility. The MABR was than sampled daily and analyses were conducted for ammonia, nitrate, nitrite, and DO concentrations for each run from start to finish.

\subsubsection{Continuous Experiments}

The continuous run experiments were conducted from the months of April, 2008 through August, 2008. The continuous experiments used minimal media and also wastewater from the Reclamation Facility in separate experiments based on the varied mixtures of the wastewater (Table 3.3Error! Reference source not found.). The minimal media ammonia concentrations varied between $5 \mathrm{mg} / \mathrm{L}$ and $25 \mathrm{mg} / \mathrm{L}$ as $\mathrm{NH}_{4}^{+}$, and the wastewater received from the Reclamation Facility had varying ammonia concentrations due to daily natural fluctuations. The continuous run experiments were studied to 
replicate real-life use for the MABR, and the reaction run-times were determined by media availability and attempts to reach steady-state conditions within the MABR. The reaction run-times varied between 43.5 and 384 hours. 
Table 3.3: Continuous Experiments Specifications

\begin{tabular}{cccc}
\hline Experiment & $\begin{array}{c}\text { Total Run } \\
\text { Hours }\end{array}$ & Media Type & $\begin{array}{c}\text { Inlet Ammonia } \\
\text { Concentration as } \\
\mathbf{N H}_{4}^{+}(\mathbf{m g} / \mathbf{L})\end{array}$ \\
\hline C1 & 72 & Minimal media & 5 \\
C2 & 66 & Minimal media & 10 \\
C3 & 73 & Minimal media & 25 \\
C4 & 101 & Minimal media & 10 \\
C5 & 167 & Minimal media & 5 \\
C6 & 43.5 & Minimal media & 10 \\
CW1 & 101.5 & Secondary Effluent & Variable \\
CW2 & 142 & Wastewater & Variable \\
CW3 & 154 & 100\% Nitrified Effluent & Variable \\
CW4 & 164 & Nitrified Effluent Mixture & Variable \\
CW5 & 384 & 25\% Primary, 75\% & Nitrified Effluent Mixture \\
\hline
\end{tabular}

During the initial, minimal media, continuous run experiments a 50-gallon PVC drum was used for storing inlet media. In some cases, 5-gallon polycarbonate bottles were used. The 50-gallon PVC drum was used for experiments $\mathrm{C} 1, \mathrm{C} 2, \mathrm{C} 3$, and $\mathrm{C} 4$. These first four tests were conducted by first creating a minimal media and DI mixture to meet the required ammonia concentration for the test. The large volume allowed for a multiday run to attempt to reach steady state within the MABR. However, the media remained in the drum for a long period of time for each experiment and biological growth was detected and influent concentrations of ammonia declined during the progression of the experiment. The tank growth was remedied by the use of 5-gallon polycarbonate bottles for the remaining experiments. The minimal media for the 5-gallon bottles was mixed daily to maintain new media feeding into the MABR, in an attempt to keep a constant ammonia inlet concentration and lessen the chance of microbial growth within the feed storage. Two 5-gallon bottles were used in order for the bottles to be cleaned between 
uses. The contents of the inlet feed were analyzed daily for nitrate, nitrite, and ammonia respectively.

The MABR tests using Reclamation Facility wastewater were conducted in the same manner as the 5-gallon bottle runs using the minimal media. The wastewater was collected from the Reclamation Facility daily by taking grab samples from the primary clarifier effluent and final clarifier nitrified effluent and stored in Nalgene ${ }^{\circledR}$ 5-gallon and 2.5-gallon bottles for transport. The amount of wastewater collected depended on necessary volumes needed for each individual run. The primary and nitrified effluents were then mixed in the 5-gallon feed storage bottles to obtain required nitrate concentrations and replaced daily to maintain inlet wastewater for the MABR. Sampling and analysis were conducted daily.

\subsection{Reactor Media}

The media used for each reaction was a minimal growth media. The initial compounds within the media included glucose, monopotassium phosphate $\left(\mathrm{KH}_{2} \mathrm{PO}_{4}\right)$, ferrous sulfate $\left(\mathrm{FeSO}_{4}\right)$, calcium sulfate $\left(\mathrm{CaSO}_{4}\right)$, thiamine, yeast extract, and ammonium sulfate $\left(\left(\mathrm{NH}_{4}\right)_{2} \mathrm{SO}_{4}\right)$ used as the nitrogen and ammonia source. However, the concentrations of these compounds varied based on different experiments. The concentrations in the various experiments are listed below. Some compounds were eliminated and replaced due to reactor complications. These will be explained in Results and Discussions, Chapter 4. When changes were made, the replacement compounds included calcium

chloride $\left(\mathrm{CaCl}_{2}\right)$, and ammonium chloride $\left(\mathrm{NH}_{4} \mathrm{Cl}\right)$. Also the use of thiamine was eliminated within our media due to the trace nitrate concentrations within the substance in order eliminate false nitrate concentration readings within the reactor. 


\subsubsection{Initial $50 \mathrm{mg} / \mathrm{L} \mathrm{NH}_{4}{ }^{+}$as $\mathrm{NH}_{4}{ }^{+}$minimal growth media}

For the first experiment conducted, a minimal media with an ammonium concentration of $50 \mathrm{mg} / \mathrm{L}$ was used. The remaining constituents used in the media are shown in Table 3.4.

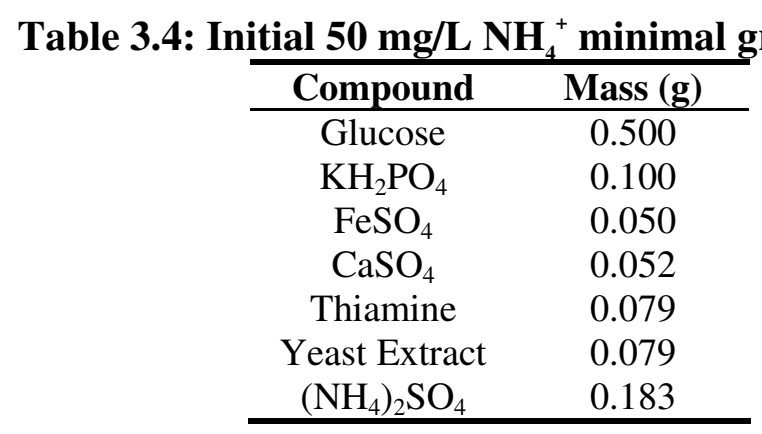

This media was used for experiment B1 that took place between February 18, 2008 and February 26, 2008. However, after conducting this experiment, odor issues and potential sulfide toxicity became a concern, and the media changed in order to remedy the concerns.

\subsection{2 $10 \mathrm{mg} / \mathrm{L} \mathrm{NH}_{4}{ }^{+}$minimal growth media}

This media differed from the initial $50 \mathrm{ppm}$ media due to the use of $\mathrm{NH}_{4} \mathrm{Cl}$, as the ammonium source, and $\mathrm{CaCl}_{2}$. The mass of the $\mathrm{CaCl}_{2}$ remained the same, and the $\mathrm{NH}_{4} \mathrm{Cl}$ was adjusted accordingly based on the desired ammonia concentration for the experiment (Table 3.5). The new minimal media was used for experiment B2 that took place between March 1, 2008 and March 8, 2008. 
Table 3.5: $10 \mathrm{mg} / \mathrm{L} \mathrm{NH}_{4}^{+}$minimal growth media

\begin{tabular}{cc}
\hline Compound & Mass $(\mathbf{g})$ \\
\hline $\mathrm{Glucose}$ & 0.500 \\
$\mathrm{KH}_{2} \mathrm{PO}_{4}$ & 0.100 \\
$\mathrm{FeSO}_{4}$ & 0.050 \\
$\mathrm{CaCl}_{2}$ & 0.052 \\
$\mathrm{Thiamine}$ & 0.079 \\
Yeast Extract & 0.079 \\
$\mathrm{NH}_{4} \mathrm{Cl}$ & 0.030 \\
\hline
\end{tabular}

The reason for altering the initial minimal media was due to odor issues within the reactor caused by anaerobic conditions and high amounts of sulfur compounds used in the media. Also, the opportunity for sulfide toxicity to the microorganisms within the reactor became a concern. I still desired sulfur to in the media, but a lower concentration seemed much more beneficial to the desired experiment.

For later experiments, we used a limited nutrient minimal media by lessening the media constituents and halving the glucose concentration (Table 3.6). This $10 \mathrm{mg} / \mathrm{L}$ ammonium media was used for the continuous experiment C2 between April 23, 2008 and April 26, 2008; experiment C3 between April 27, 2008 and May 1, 2008; experiment C5 between May 6, 2008 and May 10, 2008; and experiment C8 between June 30, 2008 and July 2, 2008.

Table 3.6: $10 \mathrm{mg} / \mathrm{L} \mathrm{NH}_{4}^{+}$minimal growth media using limited nutrients

\begin{tabular}{cc}
\hline Compound & Mass (g) \\
\hline $\mathrm{Glucose}$ & 0.25 \\
$\mathrm{KH}_{2} \mathrm{PO}_{4}$ & 0.026 \\
$\mathrm{FeSO}_{4}$ & 0.026 \\
$\mathrm{CaCl}_{2}$ & 0.026 \\
Yeast Extract & 0.0053 \\
$\mathrm{NH}_{4} \mathrm{Cl}$ & 0.03 \\
\hline
\end{tabular}


The use of thiamine was also eliminated due to trace concentrations of nitrate found in the substance, and might have caused false positives of the nitrate within the MABR. However, this media was not used until the April 1, 2008 experiments.

\subsection{3 $25 \mathrm{mg} / \mathrm{L} \mathrm{NH}_{4}{ }^{+}$minimal growth media}

The $25 \mathrm{mg} / \mathrm{L}$ ammonia media was used for experiment B3, which was conducted between March 8, 2008 and March 28, 2008 (Table 3.7)

Table 3.7: $25 \mathrm{mg} / \mathrm{L} \mathrm{NH}_{4}^{+}$minimal growth media

\begin{tabular}{cc}
\hline Compound & Mass (g) \\
\hline $\mathrm{Glucose}$ & 0.250 \\
$\mathrm{KH}_{2} \mathrm{PO}_{4}$ & 0.100 \\
$\mathrm{FeSO}_{4}$ & 0.050 \\
$\mathrm{CaCl}_{2}$ & 0.052 \\
Thiamine & 0.079 \\
Yeast Extract & 0.079 \\
$\mathrm{NH}_{4} \mathrm{Cl}$ & 0.151 \\
\hline
\end{tabular}

The $25 \mathrm{mg} / \mathrm{L}$ minimal growth media was used for both the MABR reactor and the anoxic reactor.

The other reaction that occurred using a $25 \mathrm{mg} / \mathrm{L}$ ammonia media was experiment $\mathrm{C} 4$ conducted between May 1, 2008 and May 4, 2008 (Table 3.8) using the limited nutrient concentration minimal media.

Table 3.8: $25 \mathrm{mg} / \mathrm{L} \mathrm{NH}_{4}^{+}$minimal growth media using limited nutrients

\begin{tabular}{cc}
\hline Compound & $\begin{array}{c}\text { Concentration } \\
(\mathbf{m g} / \mathbf{L})\end{array}$ \\
\hline $\mathrm{Glucose}$ & 0.250 \\
$\mathrm{KH}_{2} \mathrm{PO}_{4}$ & 0.026 \\
$\mathrm{FeSO}_{4}$ & 0.026 \\
$\mathrm{CaCl}_{2}$ & 0.026 \\
Yeast Extract & 0.0053 \\
$\mathrm{NH}_{4} \mathrm{Cl}$ & 0.151 \\
\hline
\end{tabular}




\subsection{4 $5 \mathrm{mg} / \mathrm{L} \mathrm{NH}_{4}{ }^{+}$minimal growth media}

The 5 ppm ammonia limited nutrient media was used for all experiments at this concentration (Table 3.9), including the MABR batch and anoxic experiment B4 for the dates of April 1, 2008 to April 8, 2008. The run experiment that also used this media were experiment C1 between April 16, 2008 and April 19, 2008; and experiment C6 between June 4, 2008 to June 11, 2008.

Table 3.9: $5 \mathrm{mg} / \mathrm{L} \mathrm{NH}_{4}^{+}$minimal growth media using limited nutrients

\begin{tabular}{cc}
\hline Compound & $\begin{array}{c}\text { Concentration } \\
(\mathbf{m g} / \mathbf{L})\end{array}$ \\
\hline $\mathrm{Glucose}$ & 0.250 \\
$\mathrm{KH}_{2} \mathrm{PO}_{4}$ & 0.026 \\
$\mathrm{FeSO}_{4}$ & 0.026 \\
$\mathrm{CaCl}_{2}$ & 0.026 \\
Yeast Extract & 0.0053 \\
$\mathrm{NH}_{4} \mathrm{Cl}$ & 0.015 \\
\hline
\end{tabular}

\subsection{Local Municipal Wastewater}

Wastewater from the City of San Luis Obispo (California) Water Reclamation Facility was used to test the MABR's effectiveness at nitrification and denitrification of municipal wastewater. The San Luis Obispo Water Reclamation Facility (Reclamation Facility) treats an average daily load of 4.5 million gallons of wastewater to tertiary treatment levels. For this investigation, three locations within the Reclamation Facility's treatment process were chosen to study the MABR's ability to nitrify and denitrify the wastewater. Three wastewater types were secondary effluent, nitrified effluent, and a mixture of nitrified and primary effluent. Grab samples were taken daily at each location and stored in 5-gallon and 2.5-gallon Nalgene ${ }^{\circledR}$ water containers for transport, which were then transferred to the 5-gallon storage bottles which fed the reactor. Analytical data from the Water Reclamation Facility Laboratory was used to calculate BOD, ammonia, nitrate, and nitrite concentrations of the wastewater media being used for the MABR 
experiments. Ammonia concentrations were determined by the Laboratory using the Ammonia-Selective Electrode Method number 4500, nitrate and nitrite concentrations were determined by $\mathrm{HACH}$ methods 8153 and 8039, and BOD concentrations were determined using a BOD correlation to total suspended solids (TSS) determined in the Reclamation Facility lab. The TSS value was multiplied by a factor of 1.2 to find the BOD concentration.

\subsubsection{Secondary Effluent Sample}

The secondary effluent sample was taken as a grab sample from an equalization tank located after the secondary clarifier and prior to the activated sludge tank (Figure 3.6).

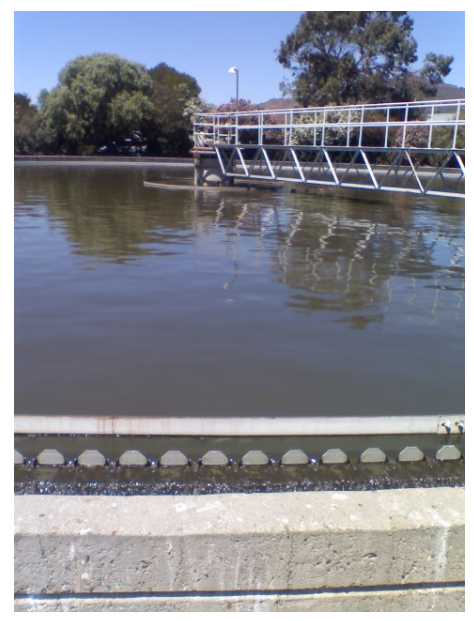

\section{Figure 3.6: Secondary Clarifier Effluent San Luis Obispo Water Reclamation Facility}

This sample was used for experiment CW1, and run through the MABR between July 15, 2008 and July 19, 2008, injected daily. The Reclamation Facility measured the ammonia concentrations between 11.6 and $16.5 \mathrm{mg} / \mathrm{L}$ as $\mathrm{NH}_{4}^{+}$, BOD concentrations between 45.6 and $70.8 \mathrm{mg} / \mathrm{L}$, and nitrate and nitrite concentrations were negligible and were determined to be non-detect (ND) (Table 3.10).

Table 3.10: Secondary Effluent Constituent Concentrations (Experiment CW1) 


\begin{tabular}{ccccc}
\hline \multirow{2}{*}{ Day } & $\begin{array}{c}\text { Ammonia as } \\
\mathbf{N H}_{4}^{+}(\mathbf{m g} / \mathbf{L})\end{array}$ & $\begin{array}{c}\text { Nitrate as } \\
\mathbf{N O}_{3}^{-}(\mathbf{m g} / \mathbf{L})\end{array}$ & $\begin{array}{c}\text { Nitrite as } \\
\mathbf{N O}_{2}^{-}(\mathbf{m g} / \mathbf{L})\end{array}$ & BOD $(\mathbf{m g} / \mathbf{L})$ \\
\hline 1 & 12.4 & ND & ND & 70.8 \\
2 & 13.6 & ND & ND & 61.2 \\
3 & 16.5 & ND & ND & 48.0 \\
4 & 11.6 & ND & ND & 49.2 \\
5 & 11.9 & ND & ND & 45.6 \\
\hline Average & 13.2 & ND & ND & 55.0 \\
\hline
\end{tabular}

\subsubsection{Nitrified Effluent Sample}

The nitrified effluent sample was collected from the underground headworks diverting water from the final clarifier (Figure 3.7) towards sand filtration and cooling towers.

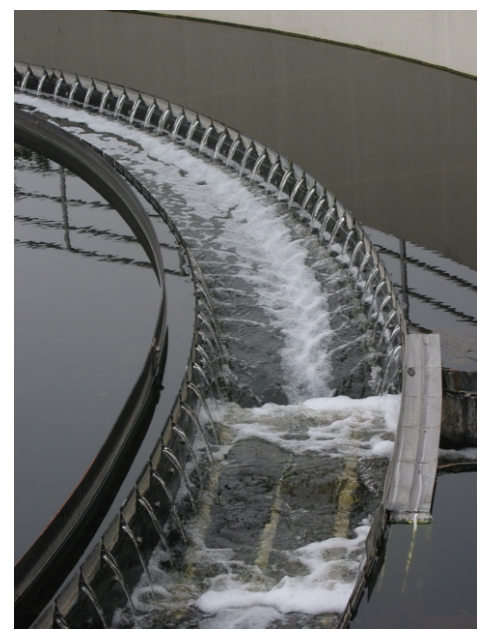

\section{Figure 3.7: Nitrified Effluent from Final Clarifier San Luis Obispo Water Reclamation Facility}

Prior to clarification, the wastewater had been processed through the activated sludge tanks for nutrient removal, which caused the nitrified effluent to have low ammonia concentrations and high nitrate concentrations (Table 3.11). This water was used for experiment CW2 between July 21, 2008 and July 27, 2008. The ammonia concentrations ranged from 0.125 to $3.080 \mathrm{mg} / \mathrm{L}$ as $\mathrm{NH}_{4}^{+}$, nitrate concentrations ranged from 51.40 to $78.85 \mathrm{mg} / \mathrm{L}$ as $\mathrm{NO}_{3}^{-}$, nitrite between 0 and $2.96 \mathrm{mg} / \mathrm{L}$ as $\mathrm{NO}_{2}^{-}$, and $\mathrm{BOD}$ concentrations between 9.6 and $23.5 \mathrm{mg} / \mathrm{L}$.

Table 3.11: Nitrified Effluent Constituent Concentrations (Experiment CW2) 


\begin{tabular}{ccccc}
\hline Day & $\begin{array}{c}\text { Ammonia as } \\
\mathbf{N H}^{+}(\mathbf{m g} / \mathbf{L})\end{array}$ & $\begin{array}{c}\text { Nitrate as } \\
\mathbf{N O}_{\mathbf{3}}^{-}(\mathbf{m g} / \mathbf{L})\end{array}$ & $\begin{array}{c}\text { Nitrite as } \\
\mathbf{N O}^{-}(\mathbf{m g} / \mathbf{L})\end{array}$ & $\begin{array}{c}\mathbf{B O D} \\
(\mathbf{m g} / \mathbf{L})\end{array}$ \\
\hline 1 & 0.159 & 73.98 & 0.99 & 12.5 \\
2 & 0.125 & 77.08 & 0.99 & 13.9 \\
3 & 0.180 & 51.40 & 0 & 12.0 \\
4 & 0.827 & 75.31 & 0 & 23.5 \\
5 & 3.080 & 65.56 & 0 & 17.3 \\
6 & 0.480 & 78.85 & 0.99 & 21.6 \\
7 & 0.277 & 75.75 & 2.96 & 9.6 \\
\hline Average & 0.733 & 71.13 & 0.85 & 15.8 \\
\hline
\end{tabular}

\subsubsection{Nitrified and Primary Effluent Mixtures}

For the next set of experiments, the effluent from the primary clarifiers was combined with the nitrified effluent from the final clarifiers. The purpose of the combining of the two streams was to use the primary effluents as the external carbon source to promote heterotrophic nitrification. The primary effluent experiments consisted of 5\%,15\%, and $25 \%$ by volume primary wastewater mixtures, with the nitrified effluent percentages being $95 \%, 85 \%$, and $75 \%$ by volume mixtures, respectively. Primary effluent samples collected were grab samples taken from the primary clarifier effluent prior to entering the headworks and pump station directing the wastewater to the trickling filters for secondary treatment at the Reclamation Facility (Figure 3.8).

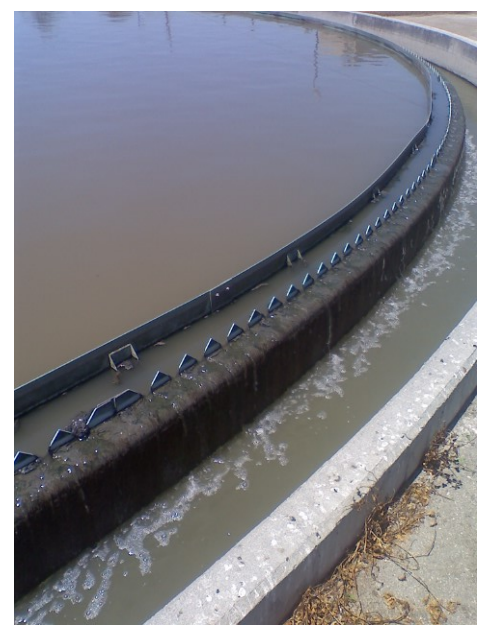




\section{Figure 3.8: Primary Effluent from Primary Clarifier of San Luis Obispo Water Reclamation Facility}

The primary effluent concentrations of BOD and ammonia were much higher when compared to the nitrified effluent, which offered higher concentrations of BOD and ammonia for the MABR influent. The primary and nitrified effluent mixtures were used during the end of July and the entire month of August tests (Table 3.12). 
Table 3.12: Primary Effluent Constituent Concentrations

\begin{tabular}{ccc}
\hline Day & $\begin{array}{c}\text { Ammonia as } \\
\mathbf{N H}_{4}^{+}(\mathbf{m g} / \mathbf{L})\end{array}$ & BOD (mg/L) \\
\hline 1 & 28.6 & 46.8 \\
2 & 38.2 & 48.0 \\
3 & 38.5 & 60.0 \\
4 & 32.1 & 74.4 \\
5 & 37.6 & 37.2 \\
6 & 31.5 & 36.0 \\
7 & 33.4 & 32.4 \\
8 & 30.5 & 38.4 \\
9 & 33.8 & 68.4 \\
10 & 40.3 & 86.4 \\
11 & 24.7 & 64.8 \\
12 & 34.7 & 49.2 \\
13 & 37.8 & 37.2 \\
14 & 41.2 & 34.8 \\
15 & 28.4 & 85.2 \\
16 & 29.7 & 32.4 \\
17 & 48.1 & 32.4 \\
18 & 36.2 & 66.0 \\
19 & 32.7 & 72.0 \\
20 & 30.6 & 63.6 \\
21 & 38.8 & 85.2 \\
22 & 27.2 & 62.4 \\
23 & 32.5 & 32.4 \\
24 & 41.3 & 32.4 \\
25 & 39.5 & 56.4 \\
26 & 43.0 & 54.0 \\
27 & 36.4 & 44.4 \\
28 & 32.4 & 49.2 \\
29 & 39.1 & 40.8 \\
30 & 52.0 & 42.0 \\
31 & 29.7 & 45.6 \\
\hline
\end{tabular}

The 5\% primary, $95 \%$ nitrified effluent mixture was used for experiment $\mathrm{CW} 3$ in a seven day test between July 29, 2008 and August 4, 2008. The ammonia concentrations for the mixture during the test period ranged from 1.68 and $2.33 \mathrm{mg} / \mathrm{L}$ as $\mathrm{NH}_{4}^{+}$, the nitrate concentrations ranged from 13.60 and $18.60 \mathrm{mg} / \mathrm{L}$ as $\mathrm{NO}_{3}^{-}$, nitrite concentrations ranged from 0.00 and $0.90 \mathrm{mg} / \mathrm{L}$ as $\mathrm{NO}_{2}^{-}$, and $\mathrm{BOD}$ ranged between 10.56 and $16.54 \mathrm{mg} / \mathrm{L}$ (Table 3.13). 
Table 3.13: 5\% Primary, 95\% Nitrified Effluent Mixture Constituents Concentrations (Experiment CW3)

\begin{tabular}{ccccc}
\hline Day & $\begin{array}{c}\mathbf{A m m o n i a}^{+} \text {as } \\
\mathbf{N H}_{4}^{+}(\mathbf{m g} / \mathbf{L})\end{array}$ & $\begin{array}{c}\text { Nitrate as }_{\mathbf{N O}_{3}^{-}(\mathbf{m g} / \mathbf{L})} \\
\mathbf{N O}_{2}^{-}(\mathbf{m g} / \mathbf{L})\end{array}$ & $\begin{array}{c}\text { NoD } \\
(\mathbf{m g} / \mathbf{L})\end{array}$ \\
\hline 1 & 1.68 & 16.80 & 0.30 & 16.48 \\
2 & 2.33 & 14.90 & 0.90 & 16.54 \\
3 & 2.20 & 16.80 & 0.90 & 10.75 \\
4 & 1.78 & 16.10 & 0.90 & 10.56 \\
5 & 2.09 & 18.30 & 0.60 & 15.08 \\
6 & 1.76 & 13.60 & 0.00 & 12.74 \\
7 & 1.85 & 18.60 & 0.30 & 13.93 \\
\hline Average & 1.96 & 16.44 & 0.56 & 13.73 \\
\hline
\end{tabular}

The $25 \%$ primary, $75 \%$ nitrified effluent mixture was used for experiment CW4 which was an eight day analysis period between August 4, 2008 and August 12, 2008. The ammonia concentrations for this testing period ranged from 9.44 to $10.36 \mathrm{mg} / \mathrm{L}$ as $\mathrm{NH}_{4}^{+}$, the nitrate concentrations ranged from 15.90 to $18.60 \mathrm{gm} / \mathrm{L}$ as $\mathrm{NO}_{3}^{-}$, nitrite concentrations ranged between 0.00 and $0.30 \mathrm{mg} / \mathrm{L}$ as $\mathrm{NO}_{3}^{-}$, and $\mathrm{BOD}$ concentrations ranged between 17.8 and $72.96 \mathrm{mg} / \mathrm{L}$ (Table 3.14).

Table 3.14: 25\% Primary, 75\% Nitrified Effluent Mixture Constituents Concentrations (Experiment CW4)

\begin{tabular}{ccccc}
\hline Day & $\begin{array}{c}\mathbf{A m m o n i a}^{+} \mathbf{\text { as }} \\
\mathbf{N H}_{4}^{+}(\mathbf{m g} / \mathbf{L})\end{array}$ & $\begin{array}{c}\text { Nitrate as } \\
\mathbf{N O}^{-}(\mathbf{m g} / \mathbf{L})\end{array}$ & $\begin{array}{c}\text { Nitrite as } \\
\mathbf{N O}_{2}^{-}(\mathbf{m g} / \mathbf{L})\end{array}$ & $\begin{array}{c}\mathbf{B O D} \\
(\mathbf{m g} / \mathbf{L})\end{array}$ \\
\hline 7 & 10.19 & 18.60 & 0.30 & 17.8 \\
8 & 9.44 & 15.90 & 0.00 & 72.96 \\
9 & 10.36 & 16.00 & 0.30 & 36.18 \\
10 & 10.2 & 14.90 & 0.00 & 36.36 \\
11 & 6.26 & 15.00 & 0.30 & 28.8 \\
12 & 8.75 & 16.20 & 0.30 & 22.38 \\
13 & 9.51 & 18.80 & 0.90 & 20.1 \\
14 & 12.14 & 14.20 & 0.30 & 19.14 \\
\hline Average & 9.61 & 16.2 & 0.30 & 31.72 \\
\hline
\end{tabular}

The $15 \%$ primary, $85 \%$ nitrified effluent mixture was used for experiment CW5 to conduct an extended reaction period. The reaction ranged from August 15, 2008 to August 31, 2008. Based on the lab analysis conducted by the Reclamation Facility, the ammonia concentrations ranged between 4.37 and $8.33 \mathrm{mg} / \mathrm{L}$ as $\mathrm{NH}_{4}^{+}$, nitrate 
concentrations ranged from 16.0 to $26.6 \mathrm{mg} / \mathrm{L}$ as $\mathrm{NO}_{3}$, nitrite concentrations ranged from 0.00 to $1.20 \mathrm{mg} / \mathrm{L}$ as $\mathrm{NO}_{2}^{-}$, and $\mathrm{BOD}$ concentrations ranged between 11.39 and 23.39 $\mathrm{mg} / \mathrm{L}$ (Table 3.15).

Table 3.15: 15\% Primary, 85\% Nitrified Effluent Mixture Constituents Concentrations (Experiment CW5)

\begin{tabular}{ccccc}
\hline Date & $\begin{array}{c}\mathbf{A m m o n i a}^{\mathbf{N}} \mathbf{N H}_{4}{ }^{(\mathbf{m g} / \mathbf{L})} \\
\mathbf{N O}_{3}{ }^{-}(\mathbf{m g} / \mathbf{L})\end{array}$ & $\begin{array}{c}\text { Nitrate as } \\
\mathbf{N O}_{2}{ }^{-}(\mathbf{m g} / \mathbf{L})\end{array}$ & $\begin{array}{c}\text { BOD } \\
(\mathbf{m g} / \mathbf{L})\end{array}$ \\
\hline 15 & 8.33 & 23.60 & 0.90 & 23.39 \\
17 & 6.46 & 20.80 & 0.60 & 15.88 \\
18 & 7.47 & 17.60 & 0.30 & 13.43 \\
19 & 5.47 & 19.50 & 0.00 & 17.65 \\
20 & 4.94 & 21.80 & 1.20 & 21.82 \\
21 & 4.63 & 22.00 & 0.00 & 20.96 \\
22 & 6.16 & 26.60 & 0.90 & 20.94 \\
23 & 4.37 & 16.20 & 0.60 & 17.52 \\
24 & 4.92 & 23.90 & 0.00 & 11.39 \\
25 & 6.23 & 18.80 & 0.90 & 14.24 \\
26 & 6.71 & 16.00 & 0.00 & 18.25 \\
27 & 6.49 & 19.60 & 0.30 & 15.44 \\
28 & 5.49 & 12.70 & 0.00 & 13.19 \\
29 & 4.89 & 18.60 & 0.00 & 17.58 \\
30 & 5.90 & 21.10 & 0.60 & 15.10 \\
31 & 7.82 & 23.70 & 0.60 & 16.91 \\
\hline Average & 4.49 & 21.80 & 0.00 & 18.67 \\
\hline
\end{tabular}

\subsection{Media Sampling and Analysis}

Ammonia, nitrate and nitrite were analyzed daily during both the batch experiments and continuous experiments. Also, dissolved oxygen (DO) concentrations, and volumetric flow rate were calculated.

Sample extraction from the reactor was done using 60-mL PVC syringes and plungers, with 6-inch and 12-inch steel hypodermic needles. The syringe and hypodermic needles were injected through the silicone septum of each sample port along the MABR, and approximately $35-\mathrm{mL}$ of liquid was extracted for analysis. The sample collection from 
inlet media and wastewater was collected by grab samples from the 5-gallon storage bottles using similar syringes and plungers. After extraction from the sample ports, the samples were placed into a $40-\mathrm{mL}$ glass beaker, and $\mathrm{pH}$ and temperature were analyzed using an OAKTON, Acorn Series $\mathrm{pH}$ and temperature probe. The samples were then filtered using $0.45-\mu \mathrm{m}$ Fisher glass fiber filters prior to any further analysis, and also $0.2-$ $\mu \mathrm{m}$ Fisher membrane filters for nitrate and nitrite analysis. The purpose of the $0.45-\mu \mathrm{m}$ filtering of all samples was to eliminate suspended solids or biomass that would interfere with spectrophotometric analysis. The samples were then separated into sealed glass vials for ammonia, nitrate and nitrite analyses. The DO concentrations were measured using a SensIon 6 DO meter, and flow rate was determined by timing the filling of a graduated cylinder with $100-\mathrm{mL}$ reactor effluent.

\subsubsection{Ammonia Analysis}

Two methods were used for ammonia analysis. The initial method was based on the Standard Method 4500- $\mathrm{NH}_{3}$ F, Ammonia-Selective Electrode Method (APHA, 1992). This method uses a hydrophobic gas-permeable membrane to separate the sample solution from an electrode internal solution of ammonium chloride, and the dissolved ammonia in the analyzed samples was converted to aqueous ammonia by raising the $\mathrm{pH}$ to above 11 with a strong base. The internal $\mathrm{pH}$ within the electrode changes when it contacts the solution, and the electrode tracks these changes (APHA, 1992). The selective ammonia probe used was an Orion 9512 Ammonia Probe, and the $\mathrm{pH}$ adjusting solution was an Ammonia pH electrode, Ionic Strength Adjusting (ISA) solution. 2-mL of the ISA solution was added per $100-\mathrm{mL}$ of sample, and additional ISA solution could have been added until the correct $\mathrm{pH}$ for ammonia measurement was reached. The 
electrode readings were in millivolts, and in order to determine the corresponding concentrations a 3 to 5-point calibration curve was made for each analysis using known ammonia concentrations. Ammonia concentrations as ammonia for the calibration curve included 1, 5, 10, 50 and 100-mg/L. The three concentrations used for calibration were determined based on expected ammonia concentrations for each analysis.

The ammonia-selective electrode method was used throughout the batch run experiments and a few of the continuous run experiments. However, due to its eventual malfunction, the HACH Method 8155: Salicylate Method was used for the remaining continuous run experiment to calculate the ammonia concentrations. The HACH method used Ammonia Salicylate Reagent Powder Pillows and Ammonia Cyanurate Powder Pillows added to a mixture of $4.5-\mathrm{mL}$ of DI water and $0.5-\mathrm{mL}$ of $0.45-\mu \mathrm{m}$ filtered MABR samples. After addition of the Powder Pillows, the sample mixture was allowed to react for 20 minutes to produce a green color. The sample was than analyzed for absorbance in a Hitachi: U3010 Spectrophotometer at a $655-\mathrm{nm}$ wavelength. The concentration was determined by making a three-point calibration curve of known ammonia concentrations with the 0.5$\mathrm{mL}$ sample and 4.5-mL DI samples. For low-anticipated ammonia concentrations a concentrated solution calibration curve was made by making a 3 to 5-point calibration curve using 5-mL of known ammonia concentration samples and no DI dilution.

\subsubsection{Nitrate Analysis}

The nitrate analysis was conducted using two different methods for redundancy comparison. The first nitrate analysis technique used ion chromatography. Ion chromatography uses ion exchange of compounds bound to a solid surface being replaced by compounds in solution being analyzed, and the concentration of the compounds in the 
samples are than determined based on their corresponding conductivity readings. The analyzed samples were initially filtered using 0.22- $\mu \mathrm{m}$ Millipore Membrane filters and 60-mL HDPE syringes and plungers. The filtered samples were then placed in 5-mL Dionex Polyvials and sealed with $0.2-\mu$ m Dionex plain filter caps. If the samples could not be analyzed the same day of filtering and storage in the Polyvials, the samples were stored in a freezer with temperatures below $4{ }^{\circ} \mathrm{C}$. For analysis, the samples were injected individually into an eluent, electrolyte solution stream and passed through an ion exchange separator column within a Dionex: DX-120 Ion Chromatograph with internal pressure maintained between 2000 and 2300 psi. The eluent was an AS22 Eluent Concentrate with a 4.5-mM sodium carbonate and a 1.4-mM sodium bicarbonate concentration after the required 100X dilution, and was pressurized to a constant pressure of $60 \mathrm{psi}$ with a constant flow rate of $1.20-\mathrm{mL} / \mathrm{min}$. Prior to connection to the ion chromatograph, the eluent was degassed using Ultra High Purity helium for 20-minutes. Within the Ion Chromatograph, the ions were than separated based on their affinities for an ion exchange resin contained in the separator column, which was a Dionex RFIC IonPac ${ }^{\circledast}$ AS22 4x250-mm separation column. The eluent and sample mixture was then passed through a suppressor that eliminated the background conductivity of the eluent, so the conductivity that remained was based on the ions found in the sample. After passing through the suppressor, the solution reached a conductivity cell and electrical conductivity was measured using Dionex Chromeleon software. The separate ions conductivities and concentrations were based on the retention times through the separation column and compared to a calibration curve with known ion concentrations using a Dionex Seven Anion Standard II (Lot \#: 38-15AS). The nitrate concentration within the Seven Anion Standard was $100 \mathrm{mg} / \mathrm{L}$ as sodium, which is equivalent to a 
nitrate concentration of $269.6 \mathrm{mg} / \mathrm{L}$ as nitrate within the solution. The solution was than diluted to different concentrations to create a 3-point calibration curve for the anions analyzed. The dilutions used were 50\%, 10\%, 5\% and 1\% dilutions, and the corresponding nitrate concentrations include $134.8 \mathrm{mg} / \mathrm{L}, 26.96 \mathrm{mg} / \mathrm{L}, 13.48 \mathrm{mg} / \mathrm{L}$ and $2.696 \mathrm{mg} / \mathrm{L}$ as nitrate respectively. The most appropriate 3-point calibration points used depended on expected nitrate concentrations within the analyzed samples.

The second method followed the HACH Method 8039: Cadmium Reduction Method. This method used a NitraVer 5 Nitrate Reagent Powder Pillow that mixed with 10-mL of a $0.45-\mu \mathrm{m}$ filtered sample. The Powder Pillow was added to the sample, rigorously shaken for one minute, and then was allowed a five minute reaction time. Samples containing nitrate resulted in a brown color. After five minutes, the absorbance was measured using the Hitachi: U-3010 Spectrophotometer at a 500-nm wavelength. The absorbance readings were converted to corresponding concentrations using a 3 to 5-point calibration curve using known ammonia concentrations.

\subsubsection{Nitrite Analysis}

Two methods were also used for the analysis of nitrite. The first was the Ion Chromatography method that was used for the nitrate analysis. The nitrite analysis differed based on the nitrites shorter retention time within the separation column. The nitrite concentration that corresponded to the conductivity reading produced by the ion exchange was determined based on a 3 to 5-point calibration curve using the Dionex Seven Anion Standard II. The nitrite concentration within the Seven Anion Standard II was $100-\mathrm{mg} / \mathrm{L}$ as sodium for the sodium nitrite compound. This corresponds to a nitrite concentration of $200-\mathrm{mg} / \mathrm{L}$ as nitrite. The known nitrite concentrations used for the 3 to 
5-point calibration curve included 50\%, 10\%, 5\%, and 1\% dilutions of the Seven Anion Standard II solution. The corresponding concentrations to the dilutions include 100, 20, 10, and 2-mg/L as nitrite respectively. The most appropriate concentrations for the calibration curve were used based on the expected concentrations within the samples being analyzed.

The second analysis method was the HACH Method 8153: Ferrous Sulfate Method. This method used a NitriVer 2 Reagent Powder Pillow and a 10-mL, 0.45- $\mu$ m filtered sample. The Reagent Powder Pillow was added to the sample and mixed by shaking. The prepared sample has a ten minute reaction time, and if nitrite was present a greenishbrown color developed. After the ten minutes, the samples were than analyzed in the Hitachi: U-3010 Spectrophotometer at a 585-nm wavelength. The absorbance reading is than corresponded to a known concentration using a 3 to 5-point calibration curve. The known concentrations used for the calibration curve were determined based on expected concentrations for the samples being analyzed. 


\section{CHAPTER 4: RESULTS AND DISCUSSION}

\subsection{Batch Experiment Results}

The goal of the batch experiments was to analyze ammonia, nitrate and nitrite concentration changes. The ammonia concentrations were expected to decline due to nitrification, and nitrate and nitrite concentrations would hopefully have an initial increase and then decline by the time denitrification (Table 4.1).

Table 4.1: Batch Process Specifications

\begin{tabular}{ccc}
\hline Experiment & $\begin{array}{c}\text { Total Run } \\
\text { Hours }\end{array}$ & $\begin{array}{c}\text { Ammonia } \\
\text { Concentration } \\
\text { as } \mathbf{~ N H}_{4}^{+}(\mathbf{m g} / \mathbf{L})\end{array}$ \\
\hline B1 & 192 & 50 \\
B2 & 172 & 10 \\
B3 & 476 & 25 \\
B4 & 160.5 & 5 \\
\hline
\end{tabular}

Each reaction performed differently however, and changing initial ammonia concentrations produced varying results throughout the batch experiments.

\subsubsection{Batch Experiment B1 Results}

This batch reaction ran for a total of eight days, using the $50 \mathrm{mg} / \mathrm{L}$ initial ammonium concentration in a minimal medium. The temperature fluctuated a few degrees throughout the entire reaction, and the changes were based on the ambient temperature changes. The $\mathrm{pH}$ was attempted to be maintained between 7 and 8 throughout the reaction, but the unpredictability of the changing biological reactions it was readjusted to these levels when measured too low (Figure 4.1). The initial $\mathrm{pH}$ drop was likely due to the biological reaction with the carbon source glucose within the MABR. The $\mathrm{pH}$ was adjusted back to between 7 and 8 by the addition of 1 to $3-\mathrm{mL}$ of $10-\mathrm{N}$ sodium hydroxide $(\mathrm{NaOH})$ to the $19-\mathrm{L}$ reactor. 


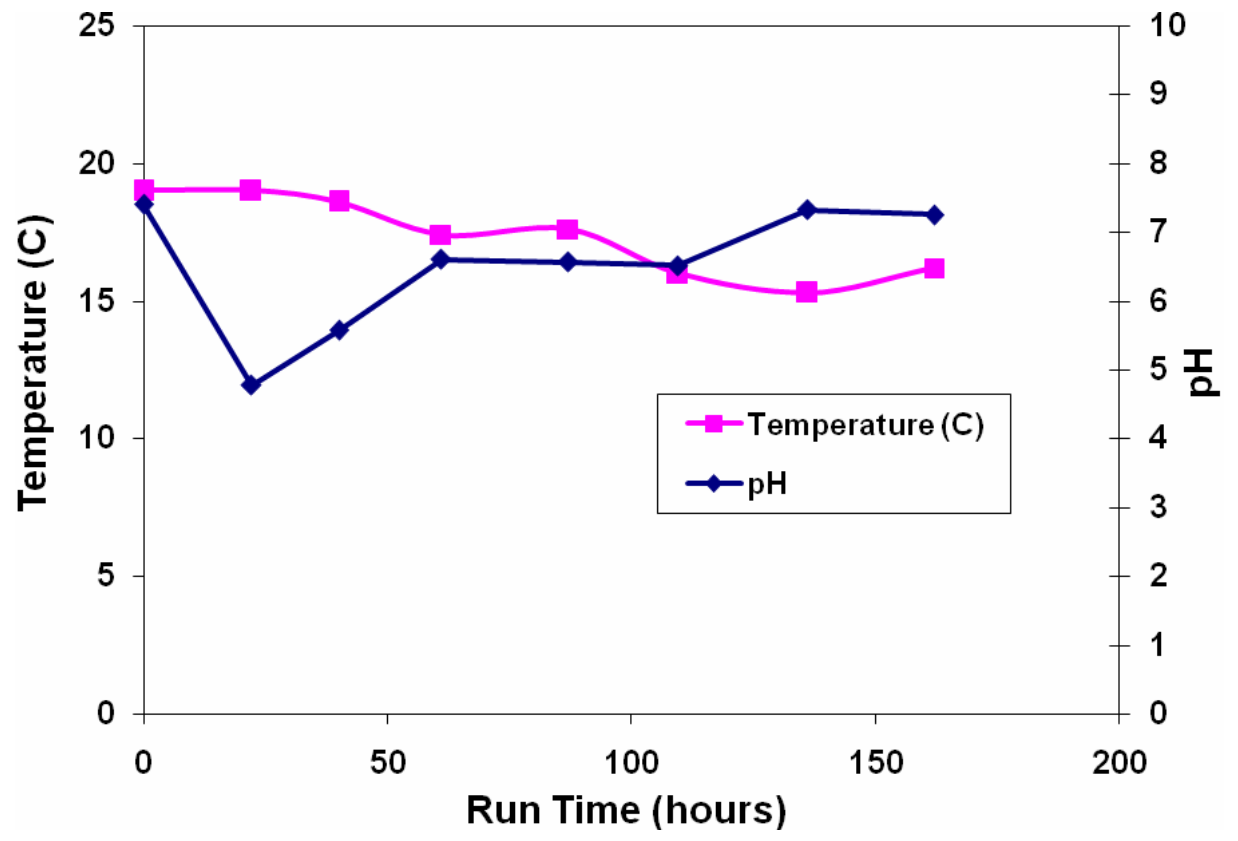

Figure 4.1: pH and Temperature Profile for Experiment B1

The ammonia, nitrate and nitrite fluctuations throughout the batch reaction showed promising results during the beginning of the reaction. The ammonia readings initially were higher than the proposed $50 \mathrm{mg} / \mathrm{L}$ ammonium concentrations $(56.23 \mathrm{mg} / \mathrm{L}$ as $\mathrm{N})$, but the trends of the decreasing ammonia and increasing nitrate levels followed anticipated trends. The ammonia concentration decreased to $24.9 \mathrm{mg} / \mathrm{L}$ as $\mathrm{N}$ within the first four days of the reaction. The first nitrate peak reached a total nitrate concentration of $30.2 \mathrm{mg} / \mathrm{L}$, which seems high, but based on stoichiometric molar ratios the nitrate concentration can reach up to 3.4 times the initial ammonium concentration (Figure 4.2). This means that the with the initial ammonium concentrations reading $56.23 \mathrm{ppm}$, this could coincide an eventual nitrate concentration to reach almost $191.2 \mathrm{mg} / \mathrm{L}$ as $\mathrm{N}$. This is not the case however, since all the ammonia was not exhausted within the MABR (Figure 4.2). With the change of ammonium being a $31.3 \mathrm{ppm}$ decrease, the corresponding nitrate increase could potentially reach up to $106.4 \mathrm{mg} / \mathrm{L}$ as N. The result of $106.4 \mathrm{ppm}$ seemed promising in that respect. However, the $31.3 \mathrm{ppm}$ decrease in ammonium 
concentration never increased any greater than that, so the nitrate concentration that reached $49.2 \mathrm{mg} / \mathrm{L}$ as $\mathrm{N}$ near the $150^{\text {th }}$ hour of the reaction was higher than expected (Figure 4.2). Also, the nitrite concentration never reached significantly high levels throughout the reaction, and it is assumed that the nitrite was quickly converted to nitrate within the MABR.

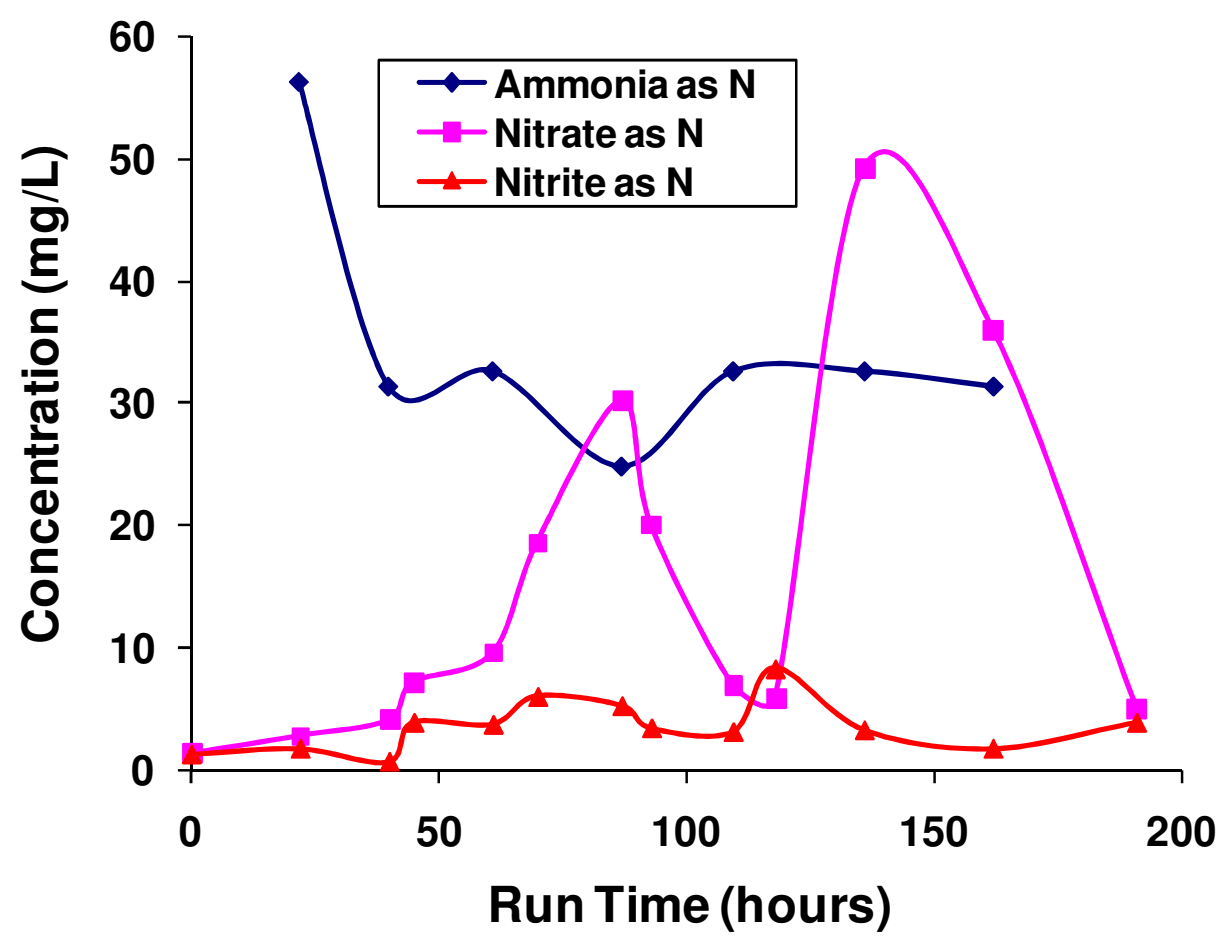

Figure 4.2: Ammonia, Nitrate and Nitrite Concentrations during Experiment B1

After two days of this batch reaction we noticed a darkening of the media within the MABR, which eventually became so severe, that the silicone tubing could not be seen. It was assumed to be a precipitate formed due to the anoxic conditions being formed within the bulk liquid of the reactor. Also due to the anoxic bulk liquid, the reactor liquid sampled was very malodorous and was determined to be the excess sulfur within our media compounds. The eventual ammonia concentration plateau near $32 \mathrm{mg} / \mathrm{L}$ as $\mathrm{N}$ (Figure 4.2) could have been due to sulfide toxicity experienced by the possible $\mathrm{H}_{2} \mathrm{~S}$ 
formation. The darkening of the bulk liquid also was determined to cause the sudden drastic increase in the nitrate concentration near the end of the reaction. Therefore, the last three data-points for the very high nitrate concentration are suspected outliers. Since there was no additional glucose added during the reaction the reactor was assumed to be exhausted and the nitrifying run experiment had ceased, due to the plateau of ammonium concentrations and the sudden decrease on the nitrate concentration near the $100^{\text {th }}$ hour (Figure 4.2).

\subsubsection{Batch Experiment B2 Results}

For this $10 \mathrm{mg} / \mathrm{L}$ ammonium reaction, the reaction lasted seven days. This reaction was the first to use a minimal media with less sulfur compounds, in a hope to decrease the formation of malodorous compounds. During the first 24-hours the reaction experienced a quick drop in $\mathrm{pH}$, and reached a $\mathrm{pH}$ of 3.92 before being adjusted using the $10-\mathrm{N} \mathrm{NaOH}$ (Figure 4.3). Though the initial $\mathrm{pH}$ of the reactor was at 9.07, the $\mathrm{pH}$ for the entire reaction was maintained between 7 and 8.5. Temperature changed with ambient temperatures in the surrounding area. 


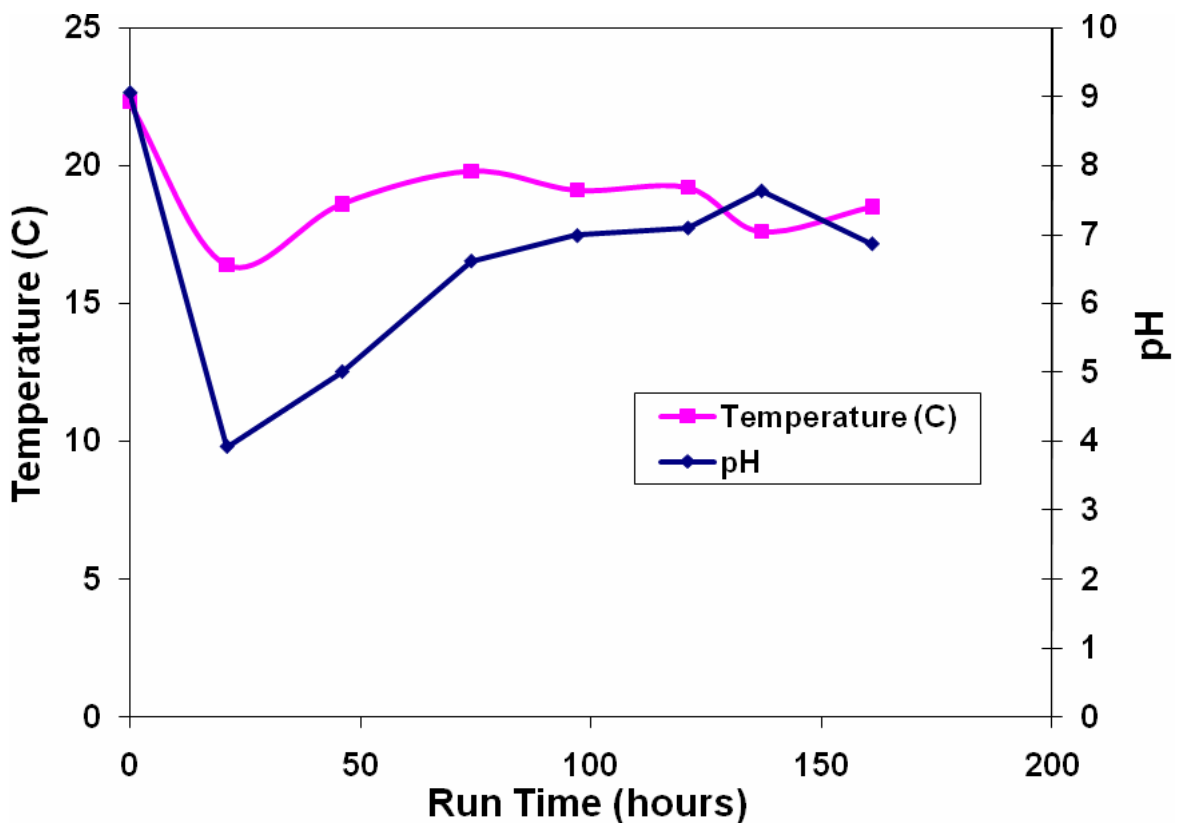

Figure 4.3: pH and Temperature Profile for Experiment B2

As in the previous reaction, the intended initial ammonia concentration was $10 \mathrm{mg} / \mathrm{L}$, but the concentration calculated was slightly lower at $4.85 \mathrm{mg} / \mathrm{L}$ as $\mathrm{N}\left(6.23 \mathrm{mg} / \mathrm{L}\right.$ as $\left.\mathrm{NH}_{4}^{+}\right)$. Both nitrate and nitrite also showed positive initial concentrations. This could have been due to the thiamine used in the minimal media, or be residual concentrations from the previous reaction (Figure 4.4). Based on the stoichiometric molar ratios the expected nitrate concentrations could have reached approximately $16.5 \mathrm{mg} / \mathrm{L}$ as $\mathrm{N}$, and nitrite concentrations could have reached $12.5 \mathrm{mg} / \mathrm{L}$ as $\mathrm{N}$. However, the nitrate concentration reached up to $9.26 \mathrm{mg} / \mathrm{L}$ as $\mathrm{N}$ near the $80^{\text {th }}$ hour of the seven day experiment (Figure 4.4). This could have been due to inaccurate initial ammonia readings, or due to the residual nitrate and nitrite compounds within the reactor at the beginning of the batch experiment. The nitrite concentration however reached a maximum peak of $4.79 \mathrm{mg} / \mathrm{L}$ as $\mathrm{N}$, which was within the stoichiometric possible range of expected concentrations. The nitrate and nitrite concentrations than decreased as expected and the ammonia concentration 
plateaued near $1.0 \mathrm{mg} / \mathrm{L}$ as $\mathrm{N}$ and the reaction was ended with final nitrate and nitrite concentrations of 2.32 and $2.05 \mathrm{mg} / \mathrm{L}$ respectively (Figure 4.4).

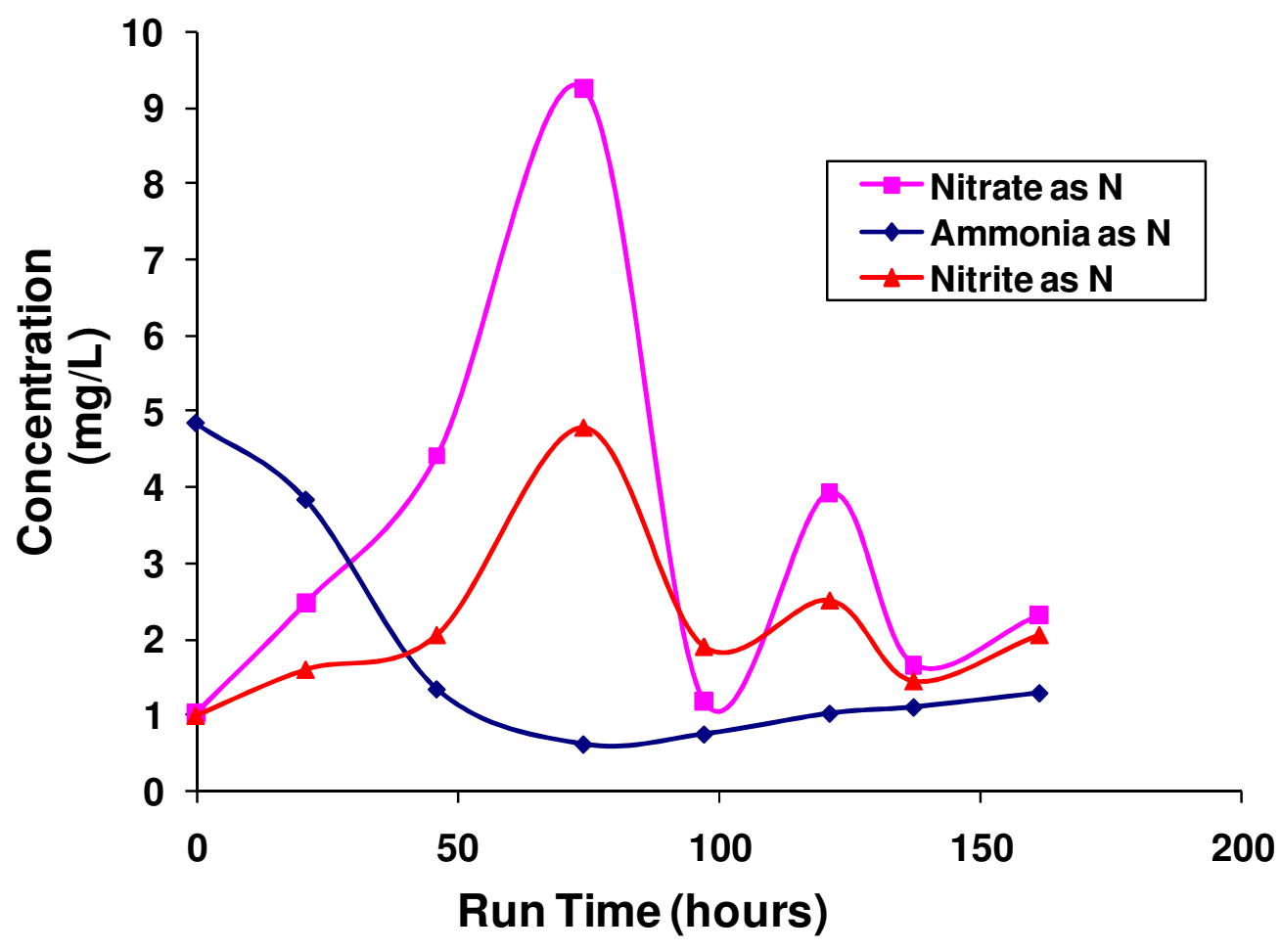

Figure 4.4: Ammonia, Nitrate and Nitrite Curves for Experiment B2

The degradation of ammonia during the first 50 hours of the reaction had a $79 \%$ degradation rate of ammonia. In order to determine the degradation rate constant, firstorder kinetics was used (Figure 4.5). The rate constant for the beginning of the experiment calculated to be -0.0284 hours $^{-1}$. 


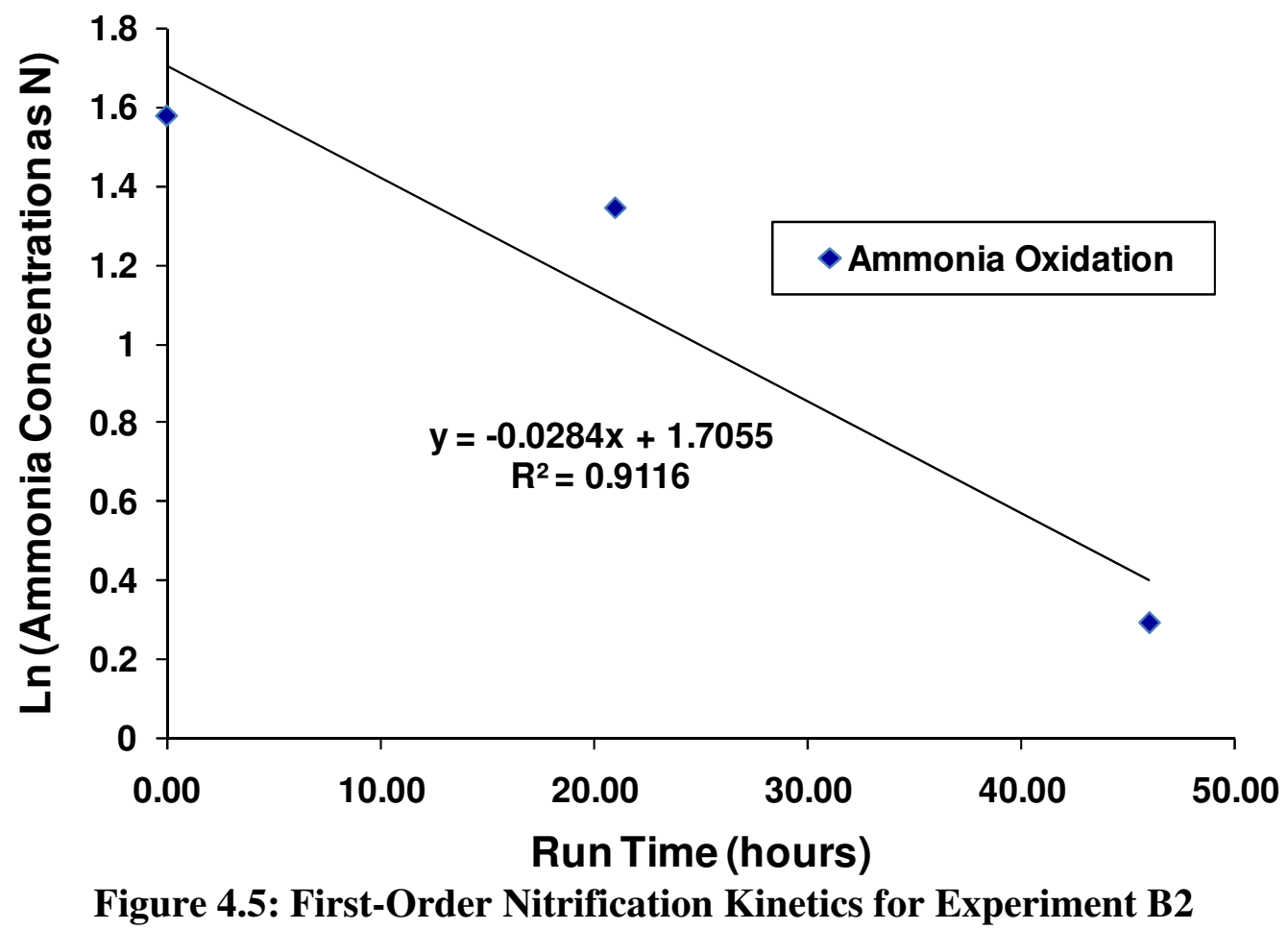

During this reaction, the contents of the reactor turned black similar to the previous experiment B1. As in the first reaction, it was caused by the formation of precipitates due to the anoxic conditions within the bulk liquid. There was still an extensive biofilm along the tubing, but the eventual darkening of the bulk liquid made it difficult to monitor the biofilm.

\subsubsection{Batch Experiment B3 Results}

This 20 day test was using an initial ammonia concentration of $25 \mathrm{mg} / \mathrm{L}$ as $\mathrm{NH}_{4}^{+}(19.4$ $\mathrm{mg} / \mathrm{L}$ as $\mathrm{N}$ ), and was conducted using both the MABR and an anoxic reactor in series. The $\mathrm{pH}$ and temperature followed similar paths with temperature changing with the ambient air temperature in the laboratory, and the initial $\mathrm{pH}$ decline was determined to be due to acid production from the glucose in the media. The $\mathrm{pH}$ readjustments were made with the addition of $10-\mathrm{N} \mathrm{NaOH}$ (Figure 4.6). Around the $130^{\text {th }}$ hour the $\mathrm{pH}$ did not 
require adjustment, which we determined to mean the glucose was exhausted within both reactors. To remedy this we added an additional 4.75-g $(0.25 \mathrm{~g} / \mathrm{L})$ of glucose to continue the experiment.

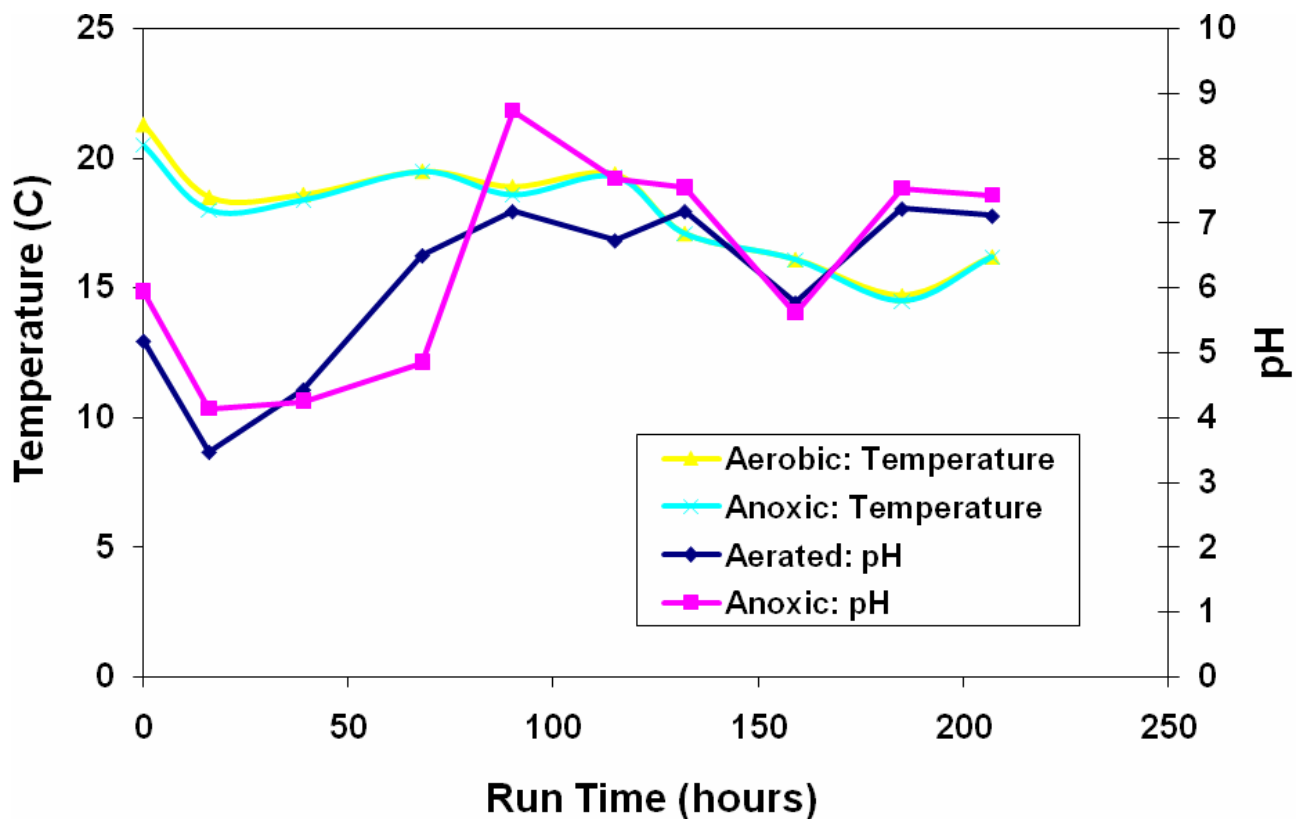

Figure 4.6: pH and Temperature Profile for Experiment B3

For the first 100 hours of the MABR reaction the data showed very positive results. The ammonia concentration decreased to half the initial concentration, nitrate increased to a peak of $7.0 \mathrm{mg} / \mathrm{L}$ as $\mathrm{N}$, and nitrite increased to $2.97 \mathrm{mg} / \mathrm{L}$ as $\mathrm{N}$ (Figure 4.7 ). While the reactor data showed a steep decline of nitrate concentrations, the ammonia concentration continued to decline until it reached a low concentration of $6.12 \mathrm{mg} / \mathrm{L}$ as $\mathrm{N}$ by the $159^{\text {th }}$ hour. The nitrate than had a second peak that reached $5.87 \mathrm{mg} / \mathrm{L}$ as $\mathrm{N}$ and nitrite reached a maximum concentration of $2.97 \mathrm{mg} / \mathrm{L}$ as $\mathrm{NO}_{2}^{-}$at 132 hours. The ammonia than inexplicably began to increase and the batch experiment was ended (Figure 4.7). 


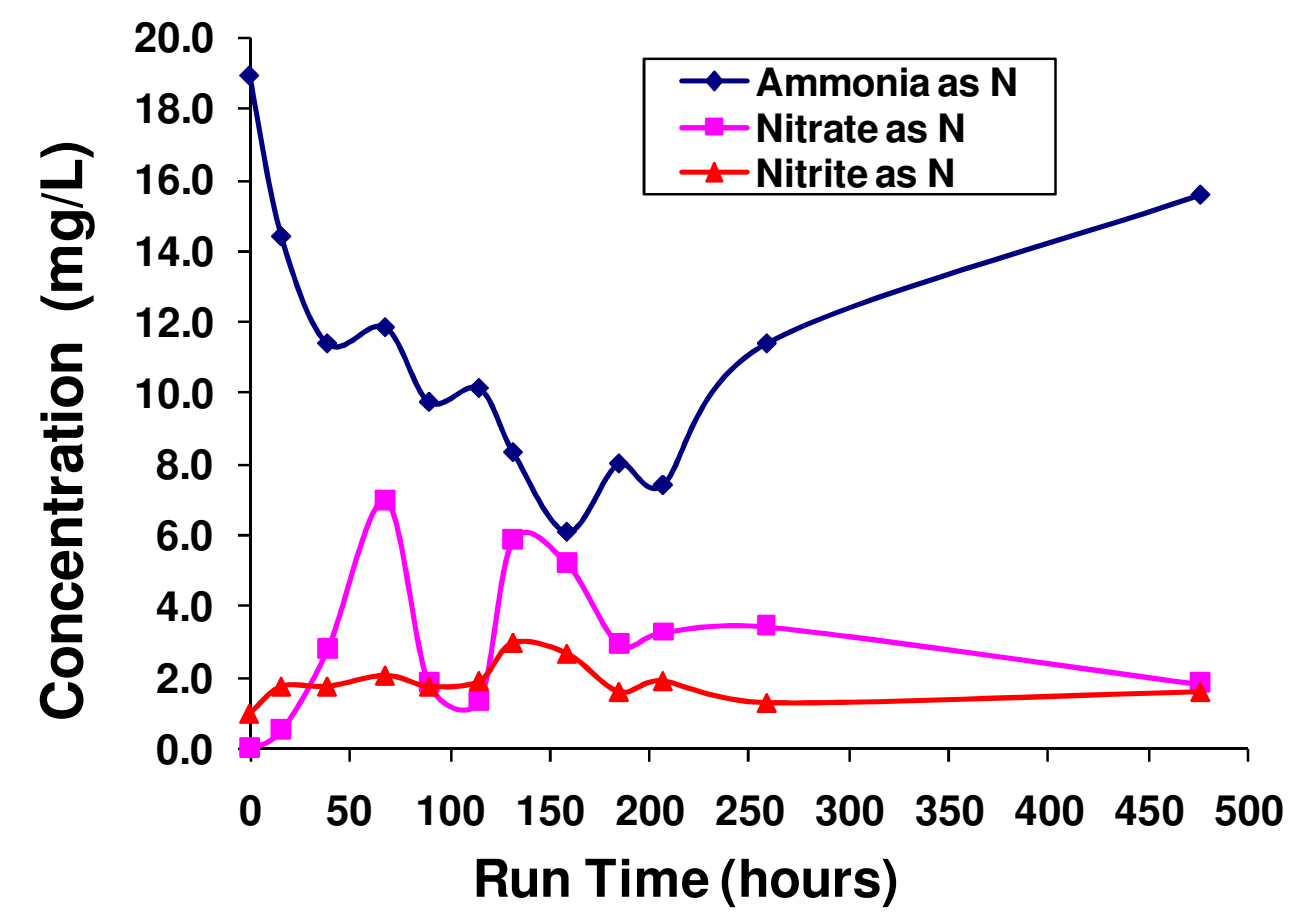

Figure 4.7: Ammonia, Nitrate and Nitrite Concentrations for Experiment B3 MABR Reactor

For the anoxic reactor the ammonia curves were very similar (Figure 4.8). The initial concentration was determined to be $17.5 \mathrm{mg} / \mathrm{L}$ as $\mathrm{N}$ and decreased to $4.82 \mathrm{mg} / \mathrm{L}$ by the $159^{\text {th }}$ hour of the reaction. The nitrate and nitrite data varied, and the nitrate concentrations were inconclusive during the first 132 hours of the reaction due to their negative values. However, it did have an eventual increase reaching a concentration of $6.68 \mathrm{mg} / \mathrm{L}$ as $\mathrm{N}$ by the $259^{\text {th }}$ hour and nitrite concentrations reached a maximum concentration of $2.05 \mathrm{mg} / \mathrm{L}$ as $\mathrm{N}$ at the $259^{\text {th }}$ hour (Figure 4.8 ). 


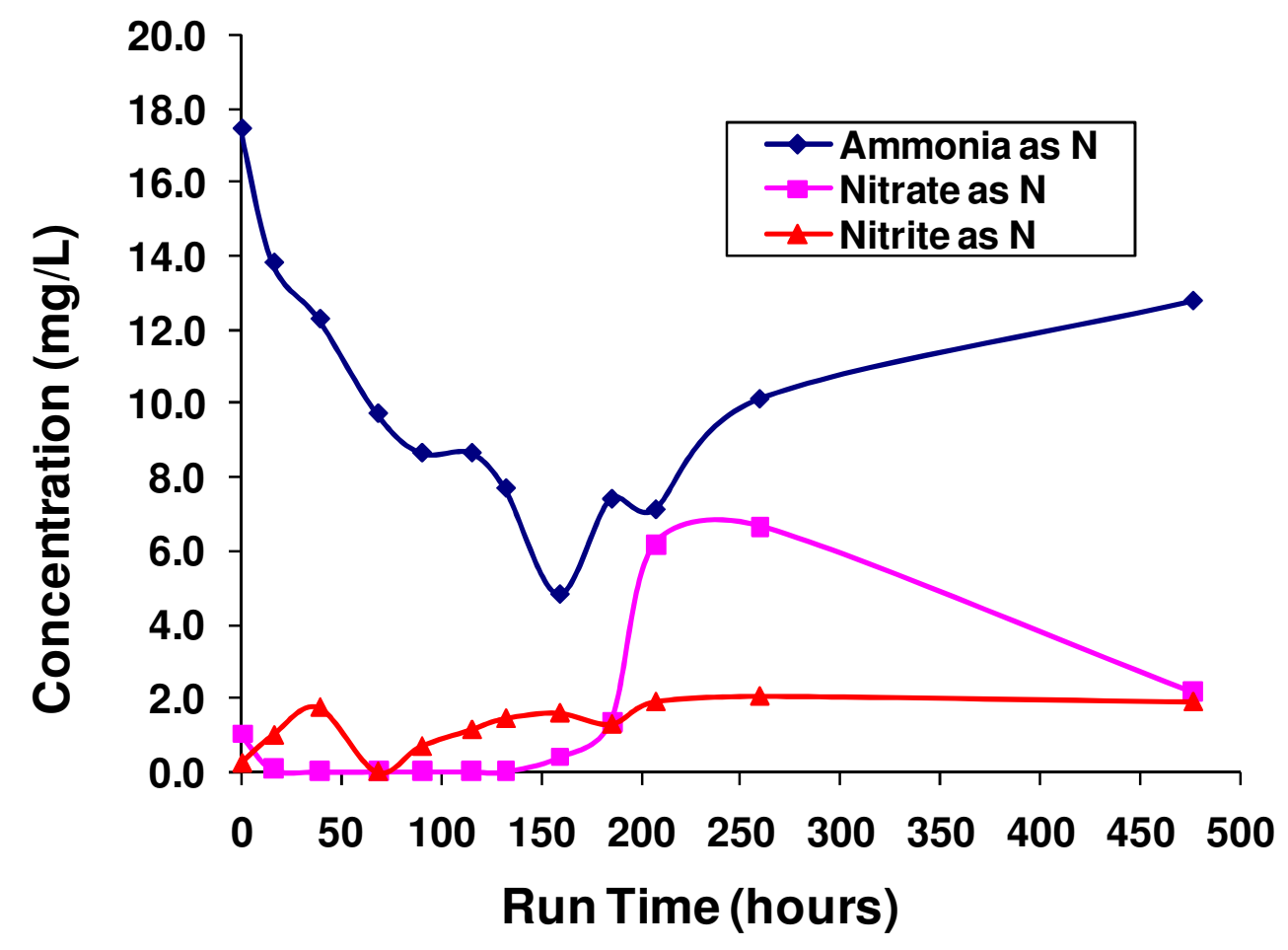

Figure 4.8: Ammonia, Nitrate and Nitrite Concentrations for Experiment B3 Anoxic Reactor

Both reactors showed similar ammonia concentration results, but the MABR showed positive results for nitrate and nitrite concentrations and changes. This helped back the belief that the MABR is more capable of performing both nitrification and denitrification within the same reactor. However with the positive results, the Ion Chromatograph reflected much smaller concentration increases of nitrate and nitrite. The nitrate concentrations ranged from 0 to $3 \mathrm{mg} / \mathrm{L}$, and nitrite concentrations ranged between 0 and $1 \mathrm{mg} / \mathrm{L}$. This brings into question the possibility of false positives for the HACH data collected (Figure 4.9). 


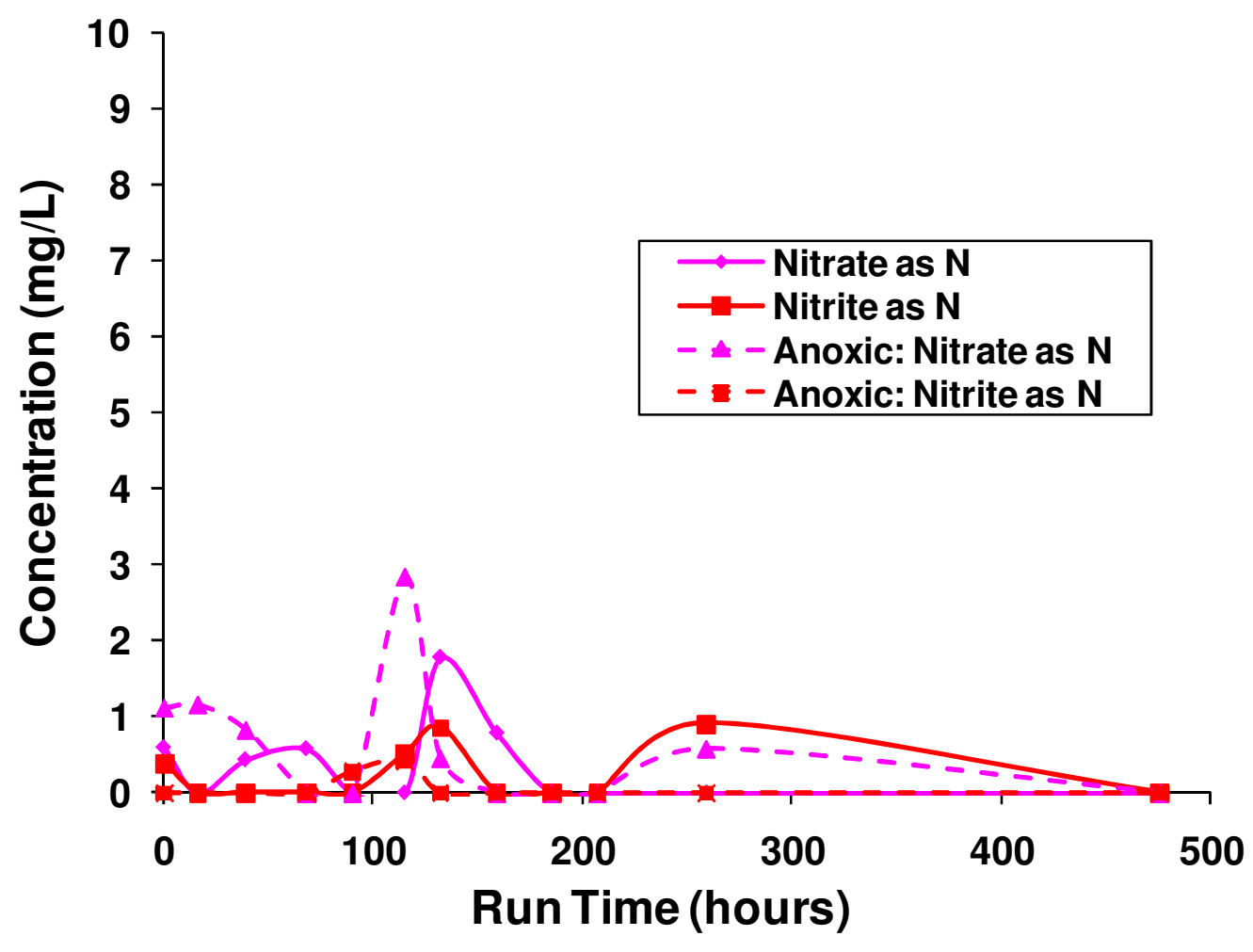

Figure 4.9: Nitrate and Nitrite IC Curves for Experiment B3

\subsubsection{Batch Experiment B4 Results}

The second MABR and anoxic comparison was done at an ammonia concentration of 5 $\mathrm{mg} / \mathrm{L}$ as $\mathrm{NH}_{4}^{+}(3.89 \mathrm{mg} / \mathrm{L}$ as $\mathrm{N})$. The reaction ran for 7 days, and temperature and $\mathrm{pH}$ followed similar paths during the entire reaction (Figure 4.10). The $\mathrm{pH}$ dropped initially as before in the previous run experiment, and the $\mathrm{pH}$ was adjusted with the $10-\mathrm{N} \mathrm{NaOH}$. 


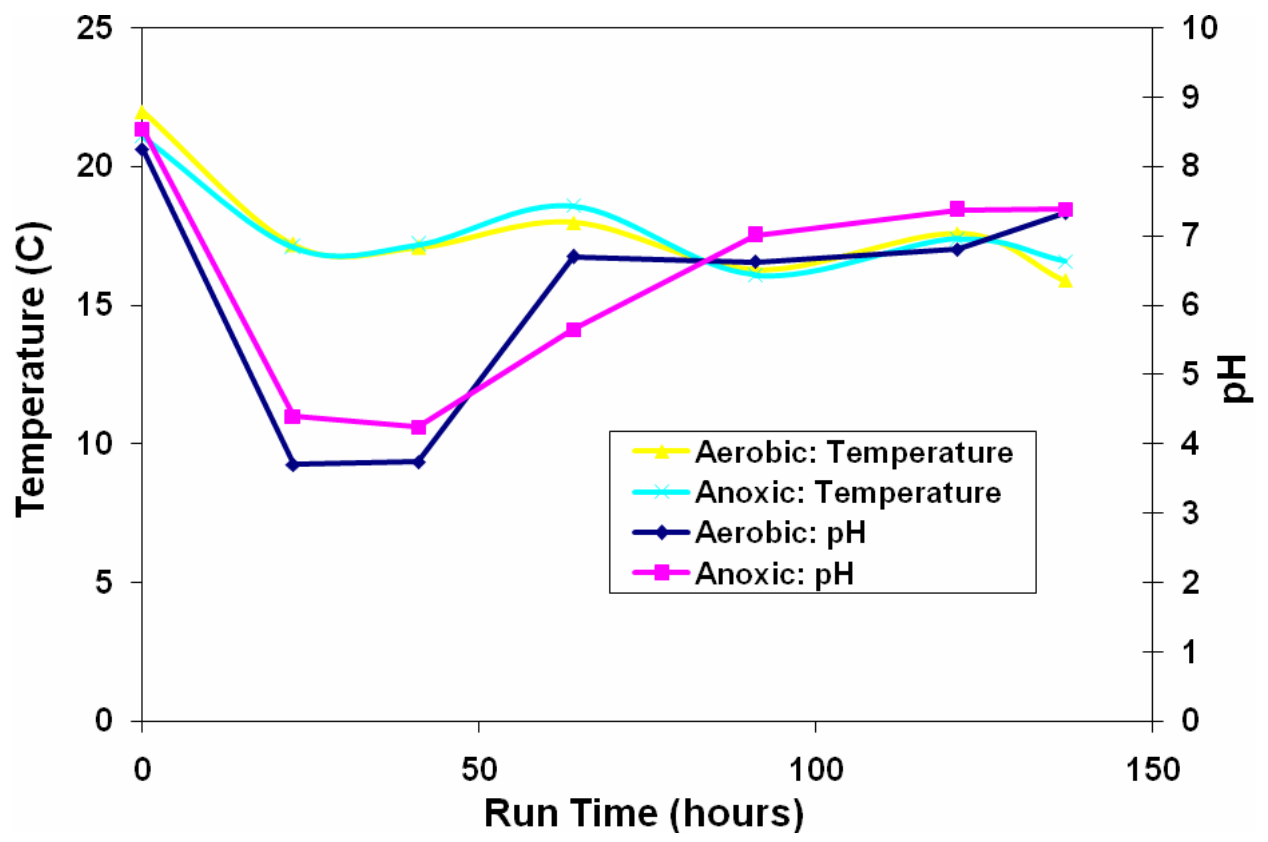

Figure 4.10: pH and Temperature Profile for Experiment B4

The MABR initial ammonia concentration reading was $3.03 \mathrm{mg} / \mathrm{L}$ as $\mathrm{N}$ (Figure 4.11), and the anoxic reactor had an initial reading of $3.42 \mathrm{mg} / \mathrm{L}$ as $\mathrm{N}$ (Figure 4.12). After the first 41 hours of the reaction, the MABR reached an ammonia concentration of $0.09 \mathrm{mg} / \mathrm{L}$ as $\mathrm{N}$ and the anoxic reactor reached a minimum of $0.22 \mathrm{mg} / \mathrm{L} \mathrm{as} \mathrm{NH}_{4}^{+}$, and the concentrations remained at these levels until the reaction completion. 


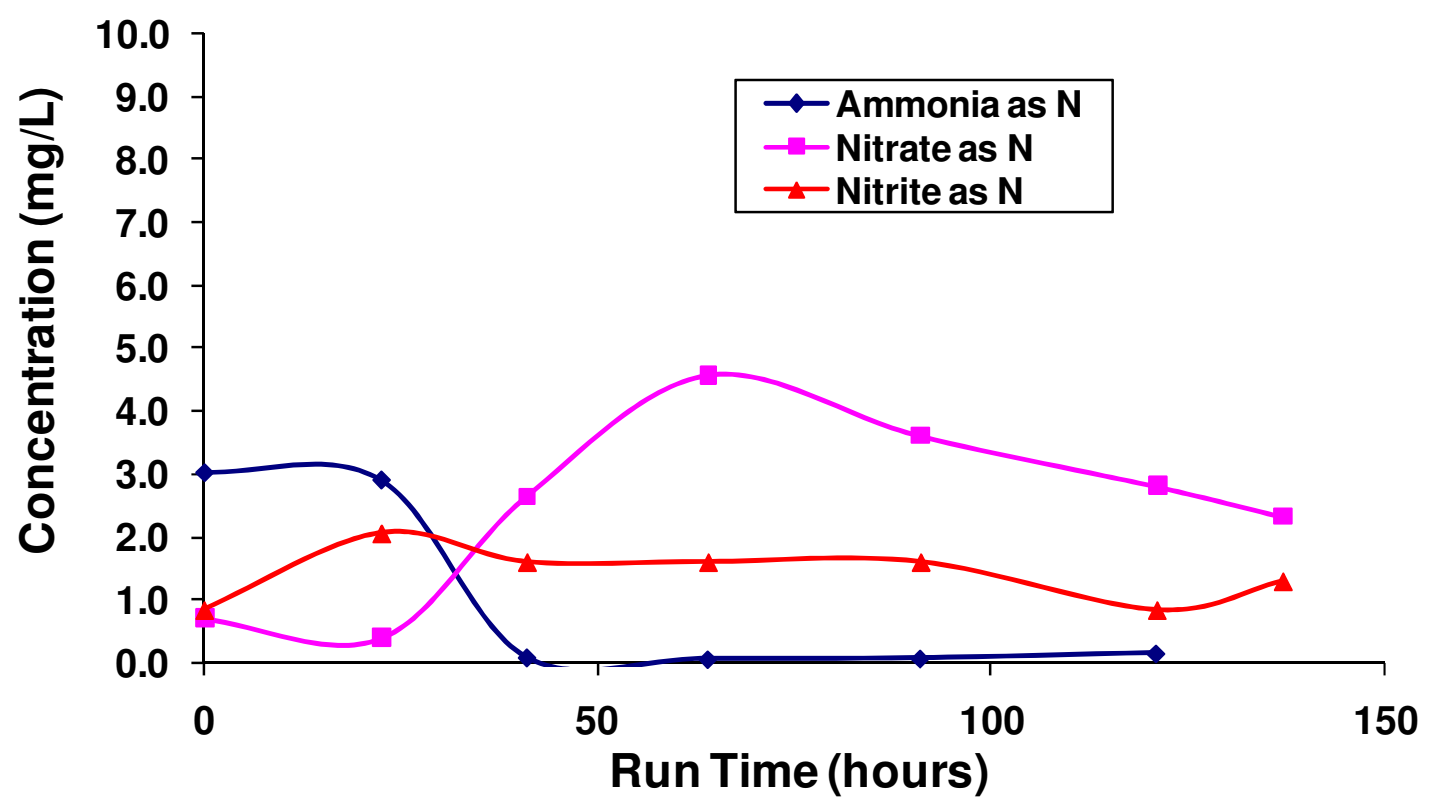

Figure 4.11: Ammonia, Nitrate and Nitrite Concentrations for Experiment B4 MABR Reactor

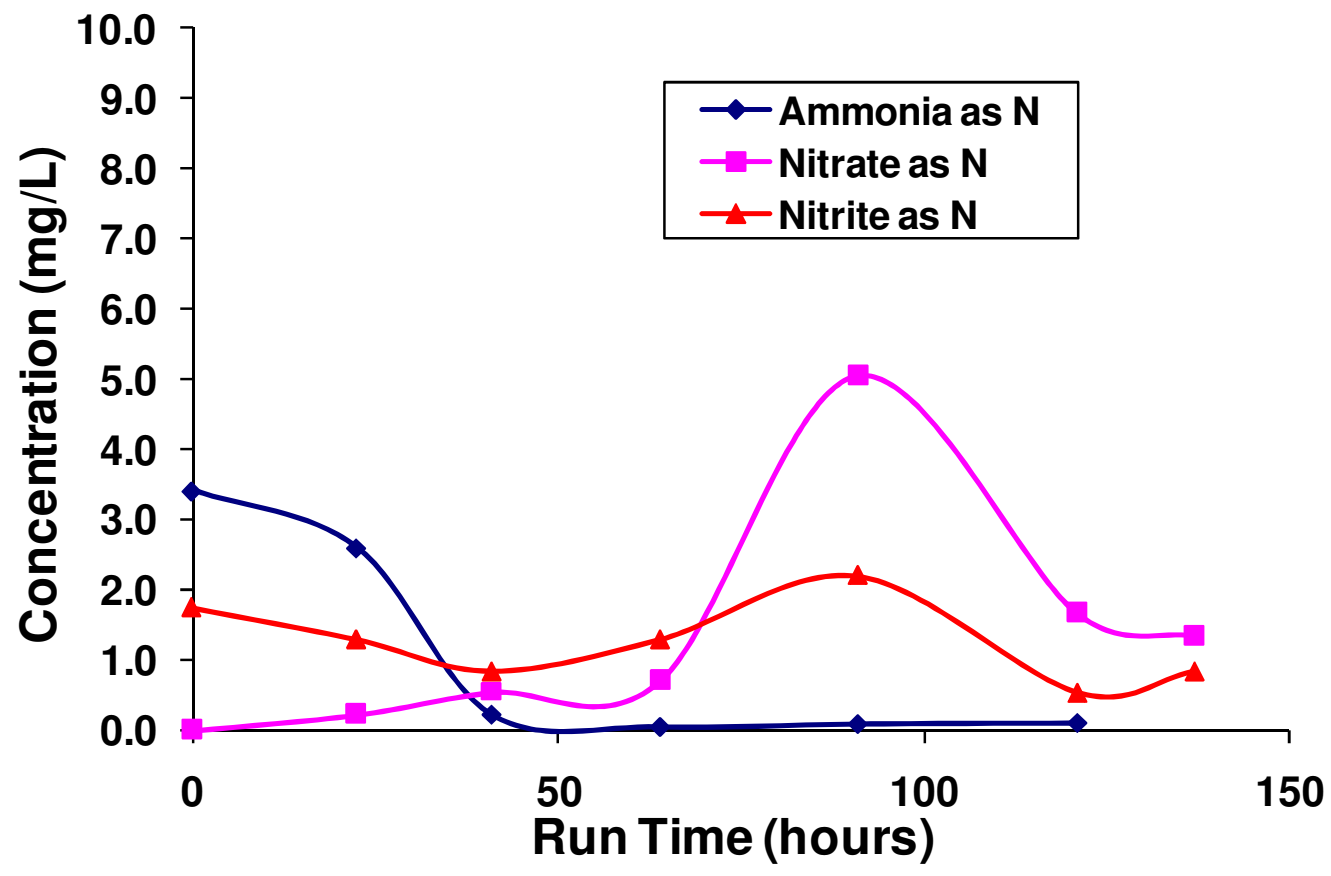

Figure 4.12: Ammonia, Nitrate and Nitrite Concentrations for Experiment B4 Anoxic Reactor

The similarities with the ammonia degradation were very similar again as in the previous $25 \mathrm{mg} / \mathrm{L}$ reaction. As in the previous example as well, the major differences were the 
results concerning nitrate and nitrite readings. For the MABR the nitrate concentration peaked at a concentration of $4.58 \mathrm{mg} / \mathrm{L}$ as $\mathrm{N}$ by the $64^{\text {th }}$ hour, and the nitrite concentration peaked after the $23^{\text {rd }}$ hour at $2.05 \mathrm{mg} / \mathrm{L}$ as $\mathrm{N}$ (Figure 4.11 ). The anoxic reactor showed inconclusive initial results, but reached a maximum nitrate concentration of $5.06 \mathrm{mg} / \mathrm{L}$ as $\mathrm{N}$ after 91 hours, and the nitrite concentration reached a maximum of $2.21 \mathrm{mg} / \mathrm{L}$ as $\mathrm{N}$ at the $91^{\text {st }}$ hour (Figure 4.12). Both reactors again had similar ammonia curves, but the MABR again showed more valid nitrate and nitrite results. However, confirmation samples were taken on April $1^{\text {st }}, 3^{\text {rd }}$, and $4^{\text {th }}$ for Ion Chromatograph confirmation samples and the results did not reflect the data found using the HACH method (Figure 4.13).

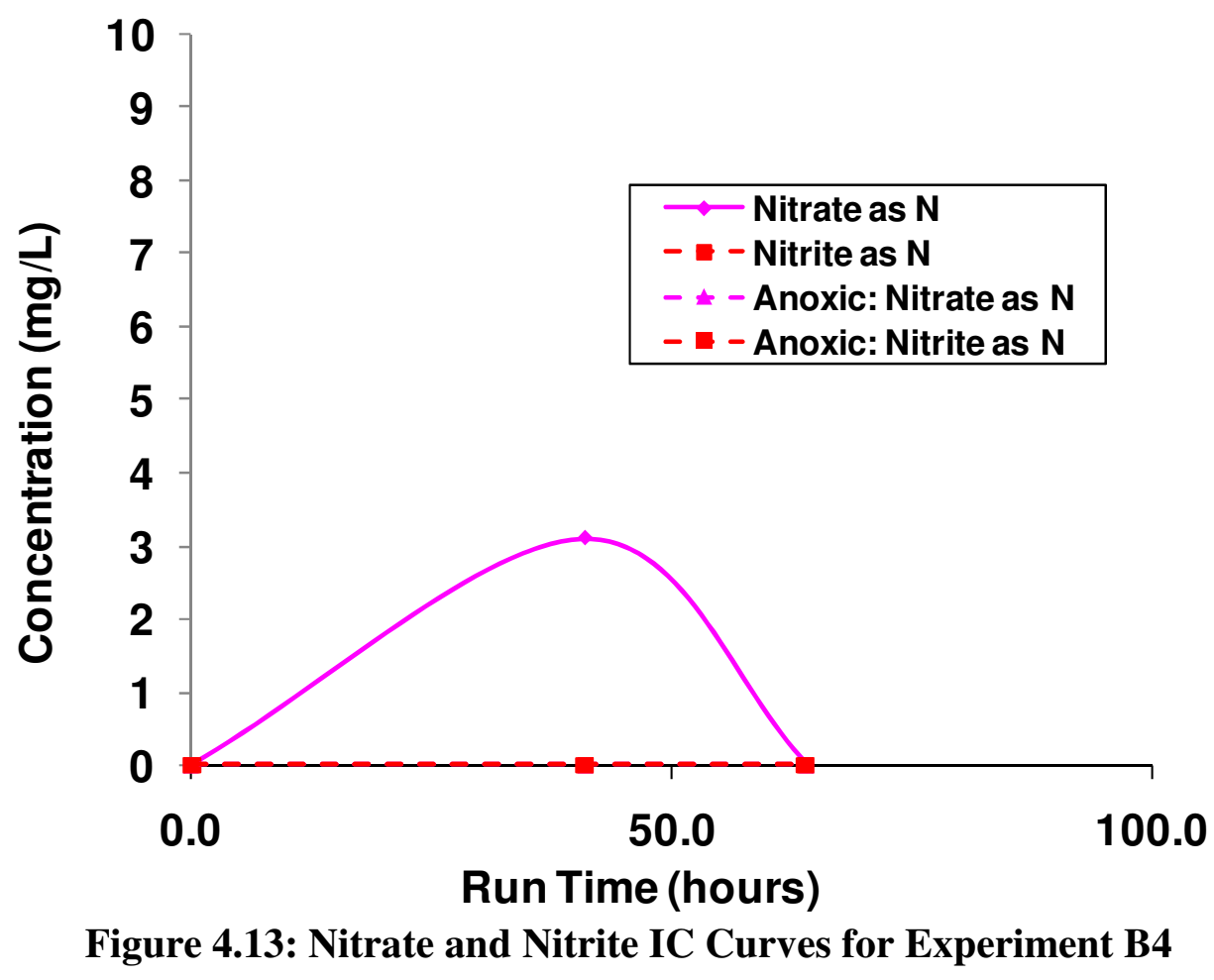

The MABR had the only positive result with a nitrate peak of $3 \mathrm{mg} / \mathrm{L}$ around the $50^{\text {th }}$ hour, while the rest of the data for nitrate and nitrite for both reactors showed 0 concentrations for the confirmation samples. Again this brings up the question of false positives or inaccuracies with the calculating of concentrations from the media collected. 


\subsection{Continuous - Flow Experiment Results}

The purpose of the continuous run experiment was to determine the MABR's ability to nitrify the chosen ammonia concentrations, and denitrify the nitrates and nitrites formed. The chosen flow rate was determined by maintaining the peristaltic pump to its lowest setting that was capable of overtaking the static head of the vertical reactor. However, the pump was as consistent as we could make it work, and there were slight differences between each experiment (Table 4.2).

Table 4.2: Continuous Process Specifications

\begin{tabular}{cccc}
\hline Experiment & $\begin{array}{c}\text { Total Run } \\
\text { Hours }\end{array}$ & Media Type & $\begin{array}{c}\text { Inlet Ammonia } \\
\text { Concentration as } \\
\mathbf{N H}_{4}^{+}(\mathbf{m g} / \mathbf{L})\end{array}$ \\
\hline C1 & 72 & Minimal media & 5 \\
C2 & 66 & Minimal media & 10 \\
C3 & 73 & Minimal media & 25 \\
C4 & 101 & Minimal media & 10 \\
C5 & 167 & Minimal media & 5 \\
C6 & 43.5 & Minimal media & 10 \\
\hline
\end{tabular}

The media was stored in a 50-gallon drum for the first four run experiment, until its eventual malfunction and biological growth problems caused for a new method that did not require so much stagnation of the media prior to pumping through the reactor. The 5gallon bottles were than chosen and media was needed to be made and added daily. The 5-gallon bottles were also used with the Reclamation Facility water samples. While the reactor was running, samples were taken from the sample ports, and analyzed for ammonia, nitrate and nitrite concentrations. Ion Chromatograph samples were also taken in order to have confirmation samples for the data calculated. As in the batch run experiment, each reaction acted very differently with the differing ammonia concentrations that were tested. 


\subsubsection{Continuous - Flow Experiment C1 Results}

The first continuous reaction used the 50-gallon drum and the minimal media used was made to have an ammonia concentration of $5 \mathrm{mg} / \mathrm{L}$ as $\mathrm{NH}_{4}^{+}(3.89 \mathrm{mg} / \mathrm{L}$ as $\mathrm{N})$. The average hydraulic residence time (HRT) for the reaction was 27.3 hours, which equaled an average flow rate of $11.6 \mathrm{~mL} / \mathrm{min}$. The $\mathrm{pH}$ showed slight changes within the reactor during the reaction, but the $\mathrm{pH}$ remained within the 4.5 and 3 ranges due to a decision that was made to not adjust the $\mathrm{pH}$ within the media (Figure 4.14). The temperature followed very similar paths throughout the reaction, and the fluctuations were based on the ambient temperature within the laboratory (Figure 4.14).

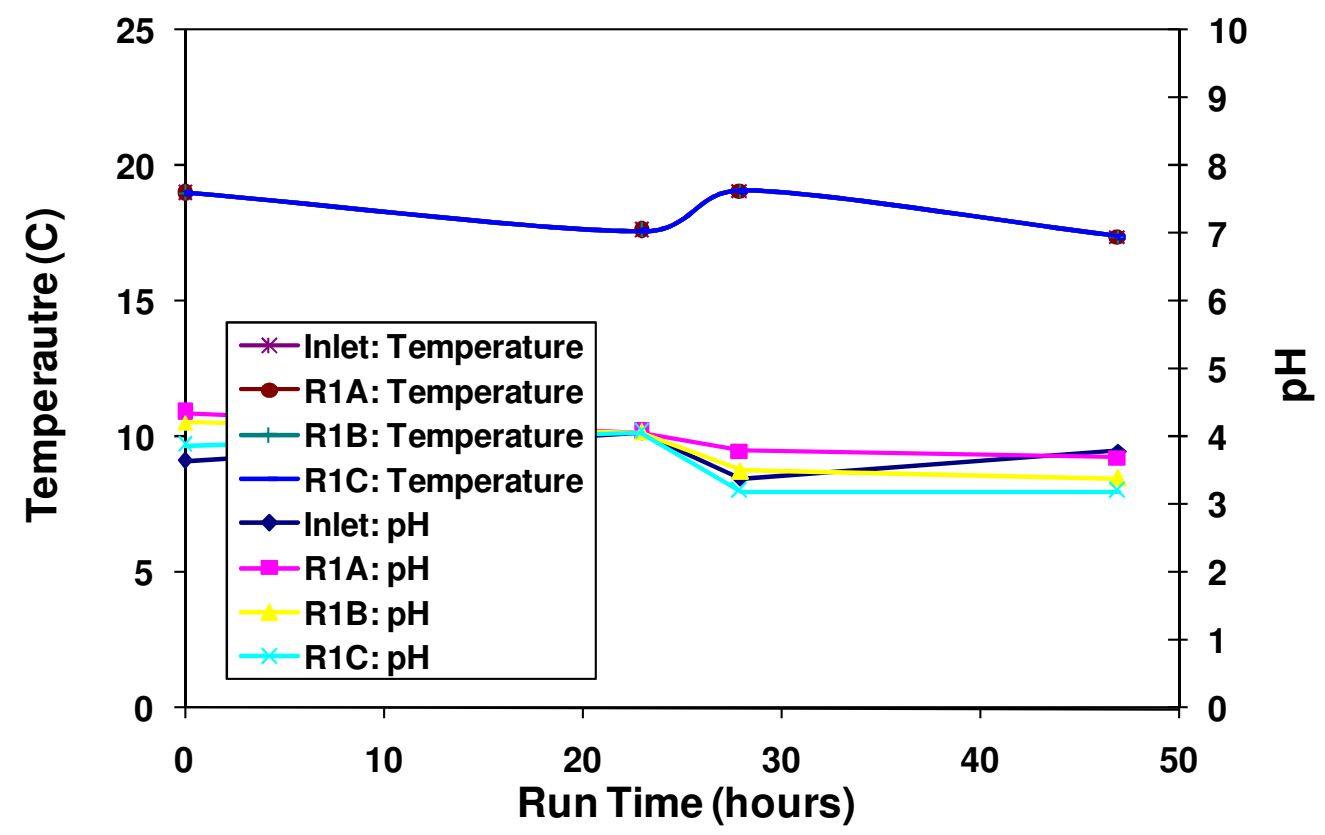

Figure 4.14: pH and Temperature Profile for Experiment C1

For the entire reaction, the influent ammonia concentration readings ranged between 1.3 and $2.5 \mathrm{mg} / \mathrm{L}$ as $\mathrm{N}$. The nitrate and nitrite concentrations were expected to be near zero for the influent of the minimal media, but the readings found for the nitrate concentration zero concentrations for the inlet and outlet data, and the nitrite levels remained at 1.9 $\mathrm{mg} / \mathrm{L}$ as $\mathrm{N}$ (Figure 4.15). 


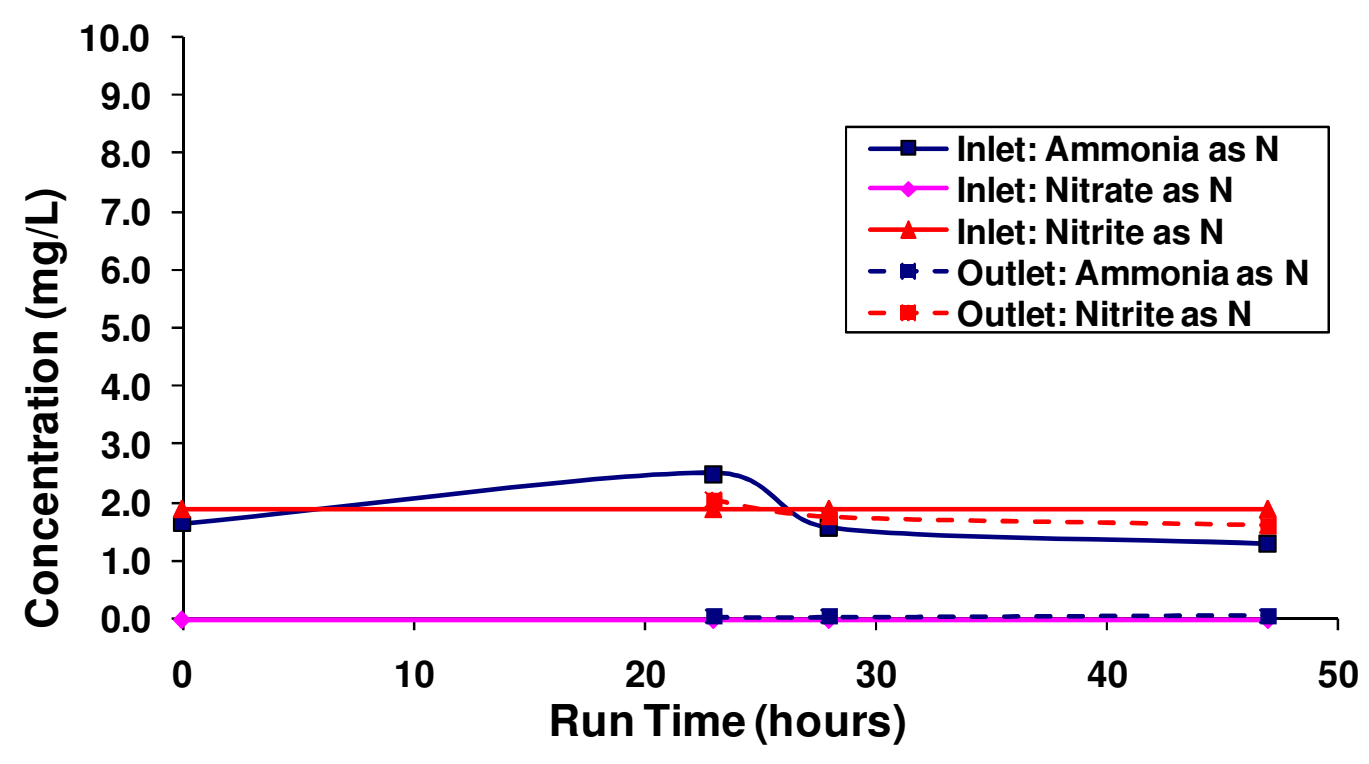

Figure 4.15: Ammonia, Nitrate and Nitrite Curves for Experiment C1

Within the first HRT for the MABR, the ammonia concentration dropped from the initial reading of $1.63 \mathrm{mg} / \mathrm{L}$ as $\mathrm{N}$ to a reading of $0.04 \mathrm{mg} / \mathrm{L}$ at the outlet. This concentration remained low throughout the remaining time of the 3 day reaction. However, nitrite levels within the reactor fluctuated between 1.6 and $2.36 \mathrm{mg} / \mathrm{L}$ as $\mathrm{NO}_{2}^{-}$and nitrate levels remained zero (Figure 4.15). Looking at the Ion Chromatograph data however, the readings for nitrate and nitrite were different. Nitrate concentrations reached a maximum concentration of approximately $3.3 \mathrm{mg} / \mathrm{L}$ as $\mathrm{N}$ by the final day of sampling, and nitrite levels were found to be zero throughout the reaction (Figure 4.16). 


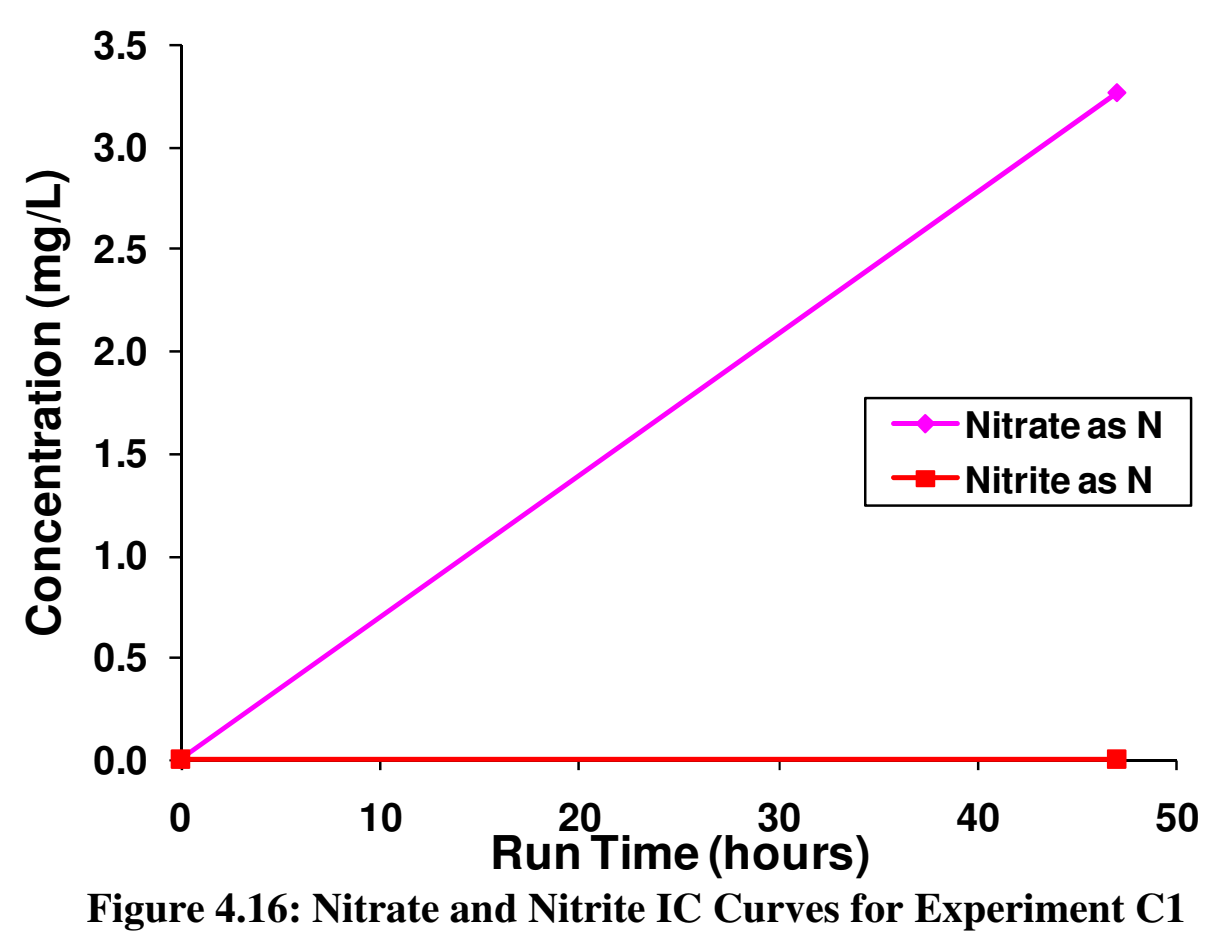

\subsubsection{Continuous - Flow Experiment C2 Results}

This reaction lasted for three days and used the 50-gallon drums for the entire reaction's media, and was intended to be a $10 \mathrm{mg} / \mathrm{L}$ ammonia media used for the MABR. The reaction had an average HRT of 27.4 hours, and an average flow rate of $11.65 \mathrm{~mL} / \mathrm{min}$. The Inlet $\mathrm{pH}$ for reaction was slightly lower than the $\mathrm{pH}$ within the reactor, but the changes in temperature within the reactor and with the effluent were all very similar (Figure 4.17). 


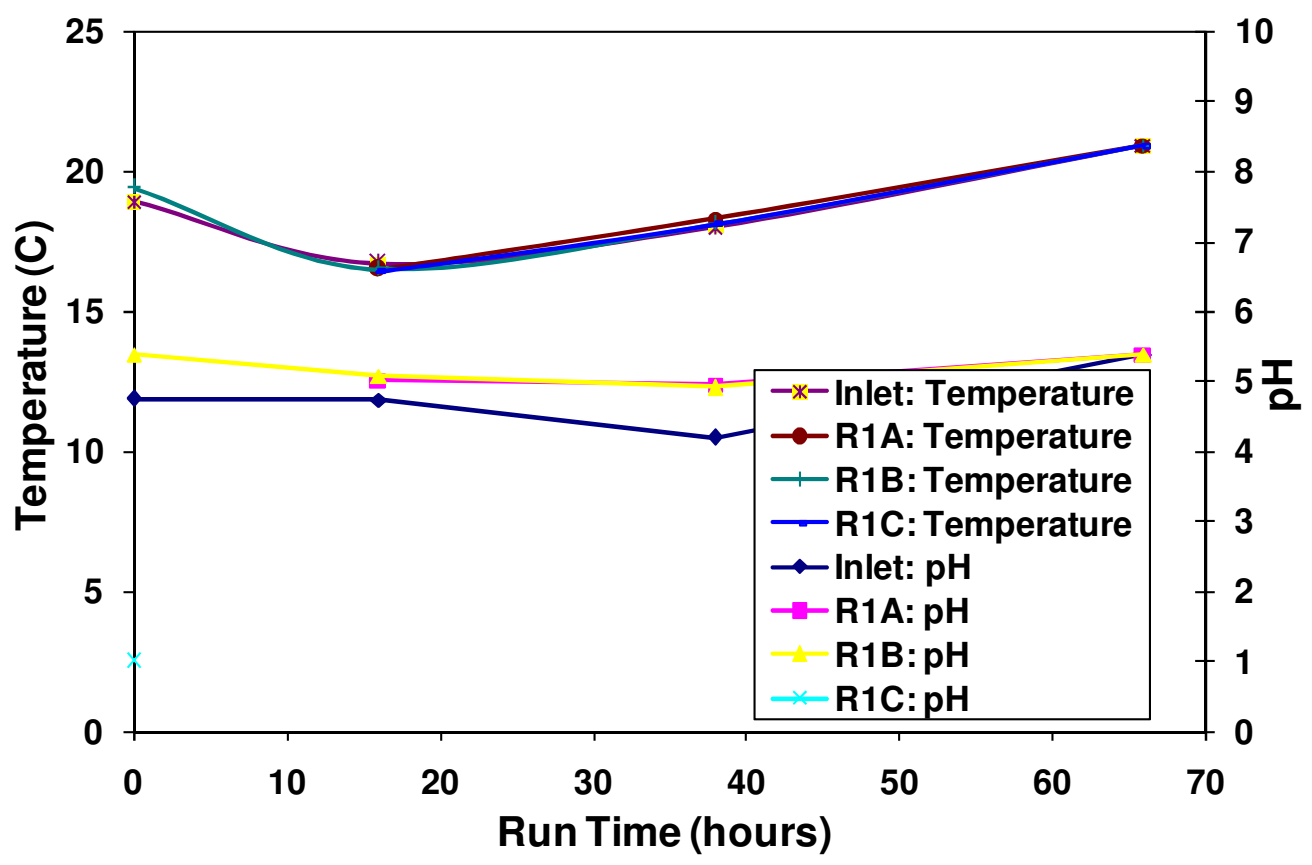

Figure 4.17: pH and Temperature Profile for Experiment C2

The initial inlet ammonia concentrations were measured to be around $4.28 \mathrm{mg} / \mathrm{L}$ as $\mathrm{N}$ $\left(5.5 \mathrm{mg} / \mathrm{L}\right.$ as $\left.\mathrm{NH}_{4}^{+}\right)$, though the intention was a media with a concentration of $10 \mathrm{mg} / \mathrm{L}$. The initial nitrate and nitrite concentrations were 0.87 as $\mathrm{N}$, and $1.14 \mathrm{mg} / \mathrm{L}$ as $\mathrm{N}$ respectively which were fairly high for initial concentrations due to their planned exclusion in the minimal media (Figure 4.18). Nevertheless, within the first 20 hours in the MABR the ammonia concentration decreased significantly to $0.47 \mathrm{mg} / \mathrm{L}$ as $\mathrm{N}$. The nitrate concentration decreased to $0.38 \mathrm{mg} / \mathrm{L}$ as $\mathrm{N}$ by the 16 th hour of the experiment, and had an increase to $0.71 \mathrm{mg} / \mathrm{L}$ by the 38 th hour. The concentration than decreased completely and nitrite had a slow and steady decrease throughout the rest of the reaction time to a concentration of $0.09 \mathrm{mg} / \mathrm{L}$ as $\mathrm{N}$. The nitrite concentration steadily decreased throughout the reaction, and by the end of the reaction the nitrite concentration reached $0.53 \mathrm{mg} / \mathrm{L}$ as $\mathrm{N}$ (Figure 4.18). 


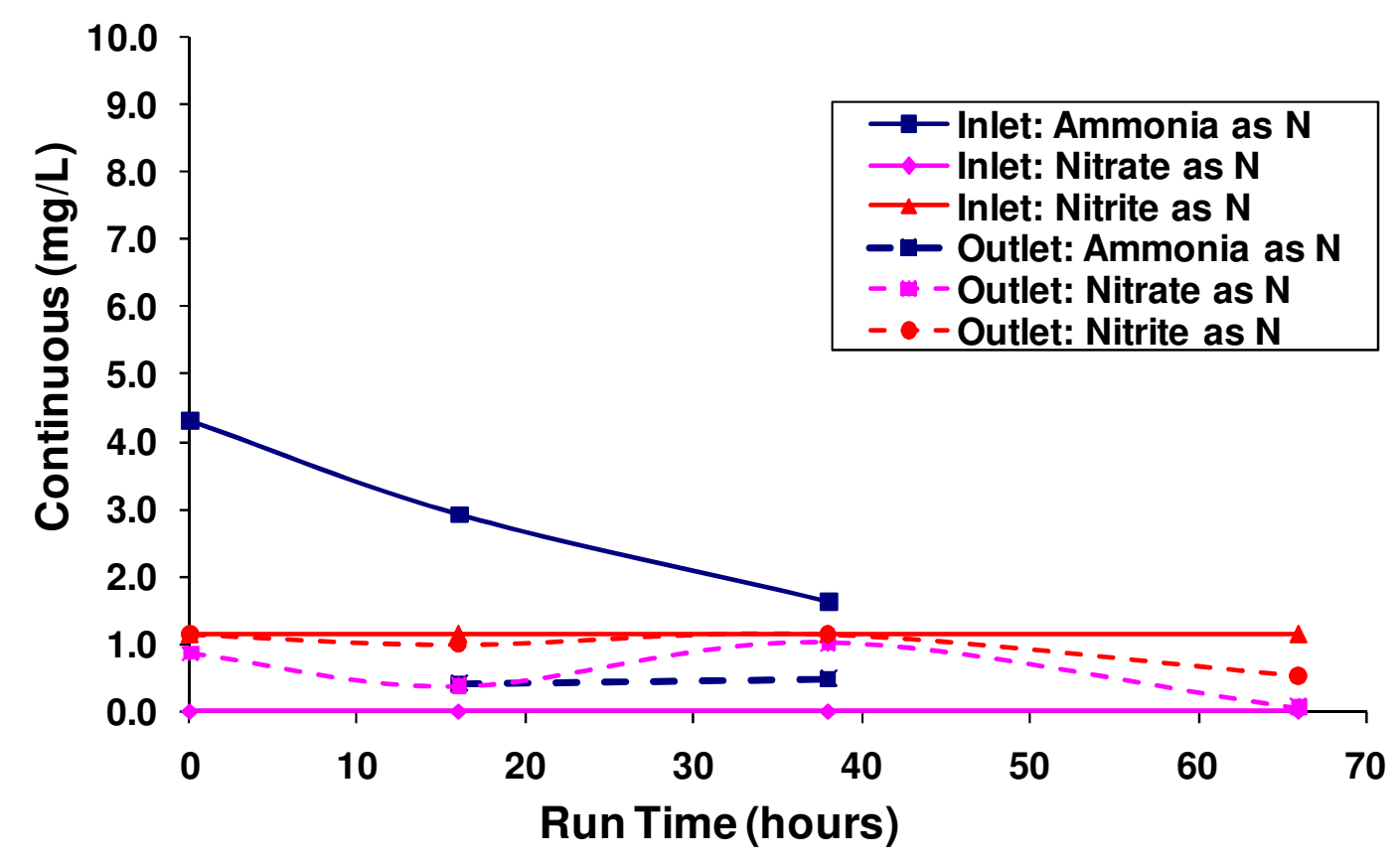

Figure 4.18: Ammonia, Nitrate and Nitrite Curves for Experiment C2

Confirmation samples were taken for analysis with the Ion Chromatograph, and as in the run experiment before, the nitrate and nitrite concentrations were quite different. The samples were taken from the initial sample and on the 16th hour, and the initial nitrate concentration was $0.5 \mathrm{mg} / \mathrm{L}$ as $\mathrm{N}$ and zero concentrations on the 16th hour, and nitrite concentrations did not show any occurrence of nitrite concentrations on either sampling event.

However, the inlet ammonia concentration was also decreasing during this time. Within 38 hours of the reaction, the inlet ammonia concentration decreased to $1.6 \mathrm{mg} / \mathrm{L}$ as $\mathrm{N}$. It was concluded that this was due to biological growth within the 50-gallon drum, and the drum was washed extensively to avoid the occurrence for future experiments. With the continuously different values for calculating concentrations within the reactor, it is difficult to make any valuable conclusions on the MABR effectiveness. The IC data was not included, since the nitrite concentrations were zero throughout the samples analyzed, 
and the nitrate concentration had an initial concentration of 0.5 while the remaining samples were zero.

\subsubsection{Continuous - Flow Experiment C3 Results}

For this three day reaction the intended initial ammonia concentration was $25 \mathrm{mg} / \mathrm{L}$ as $\mathrm{NH}_{4}^{+}(19.4 \mathrm{mg} / \mathrm{L}$ as $\mathrm{N})$. And prior to mixing the three days worth of media into the 50gallon drum, the drum was washed thoroughly to avoid biological growth. For this reaction the average HRT was 14.4 hours, and had a flow rate of $27.9 \mathrm{~mL} / \mathrm{min}$. This HRT was about half the normal HRT, and it was due to the use of a new peristaltic pump because the original needed to be replaced. For the entire reaction the $\mathrm{pH}$ and temperatures changes followed similar trends, and the large temperature flux was due to the ambient laboratory temperatures (Figure 4.19).

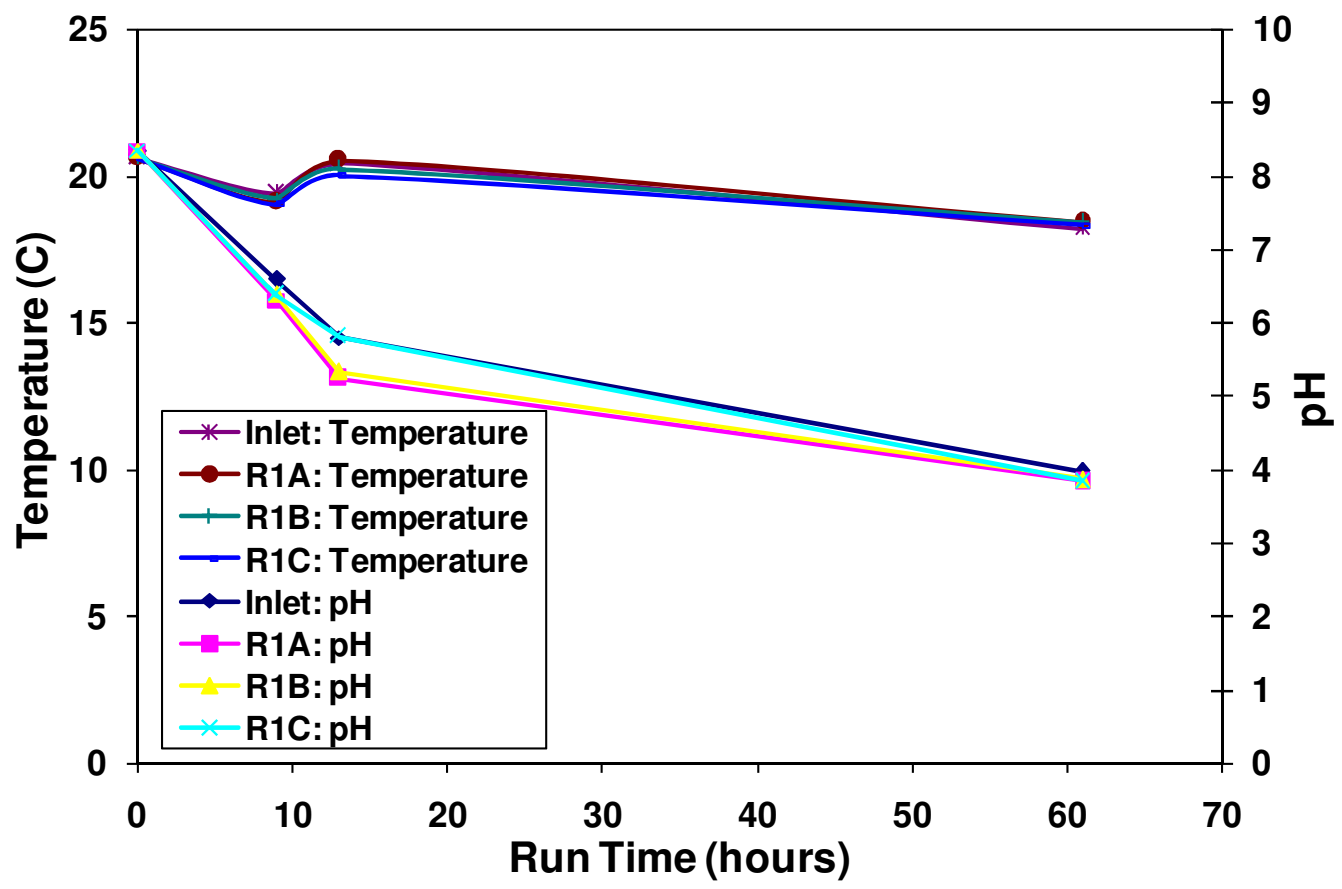

Figure 4.19: $\mathrm{pH}$ and Temperature Profile for Experiment C3

Throughout the reaction ammonia steadily decreased with an initial concentration of 13.3 $\mathrm{mg} / \mathrm{L}$ as $\mathrm{N}$. By the end of the reaction, the concentration had reached a concentration of 
$4.0 \mathrm{mg} / \mathrm{L}$. The nitrite concentration was maintained between 1.3 and $0.69 \mathrm{mg} / \mathrm{L}$ as $\mathrm{NO}_{2}$, and nitrate concentrations were inconclusive due to their negative values throughout the three day reaction (Figure 4.20).

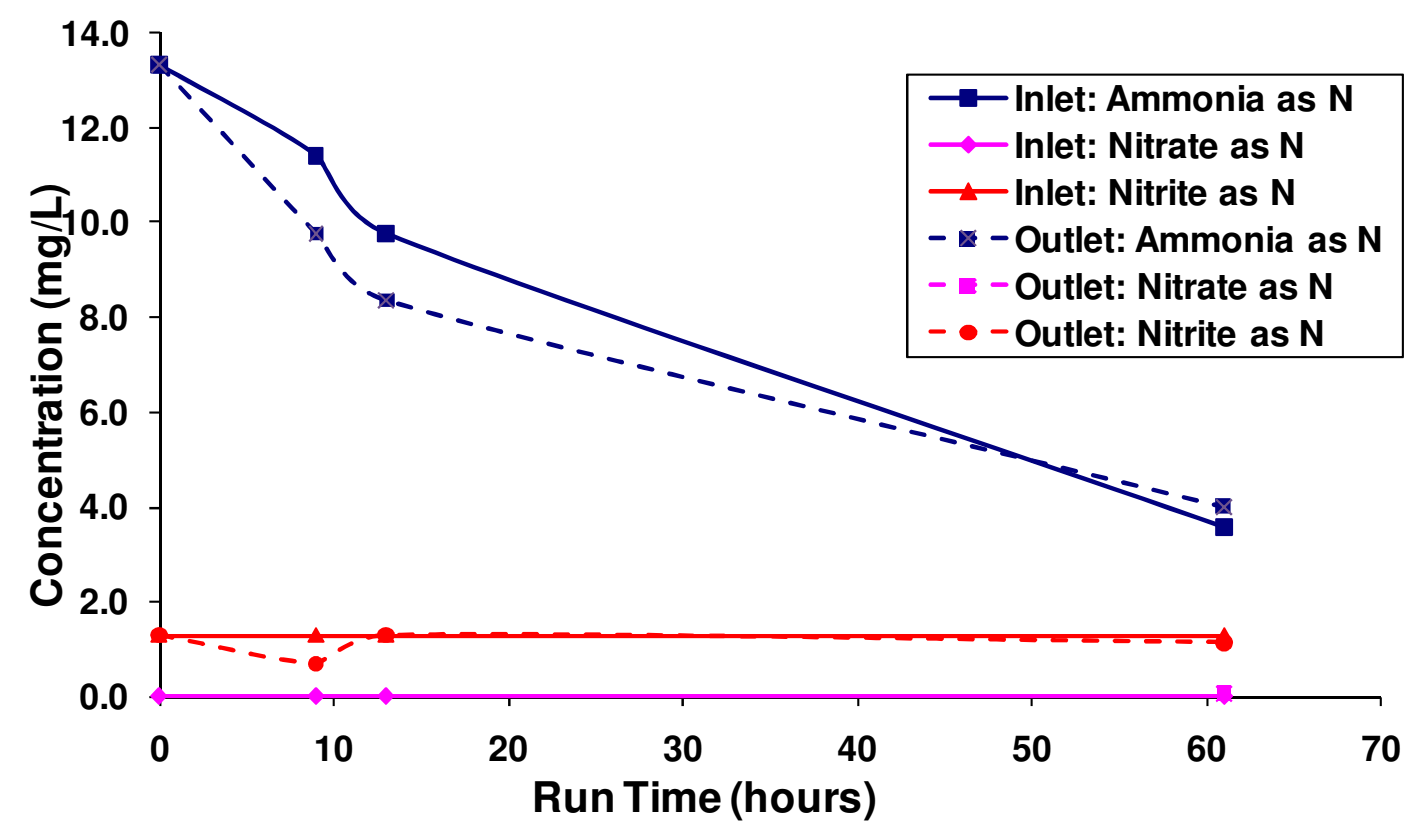

Figure 4.20: Ammonia, Nitrate and Nitrite Curves for Experiment C3

The largest issue with this reaction was the similar shape of the ammonia degradation curve to the inlet ammonia concentrations, and the similar nitrite curves from the 50gallon drum. The MABR did show some minor degradation of nitrate within the reactor, and the ammonia degradation was steeper within the MABR than when compared to the inlet ammonia concentrations. This showed some positive effects within the MABR, but the ammonia degradation within the storage drum was disconcerting. Also, the nitrate levels within the storage drum and the MABR were inconclusive and the increase of nitrate concentrations within the reactor that were hoped never showed up within our data analysis. When the data was compared to the Ion Chromatograph data collected, the results showed only an increase of approximately $2 \mathrm{mg} / \mathrm{L}$ as $\mathrm{N}$ during the second day of 
the reaction, and the nitrite levels remained at zero with all the confirmation samples (Figure 4.21).

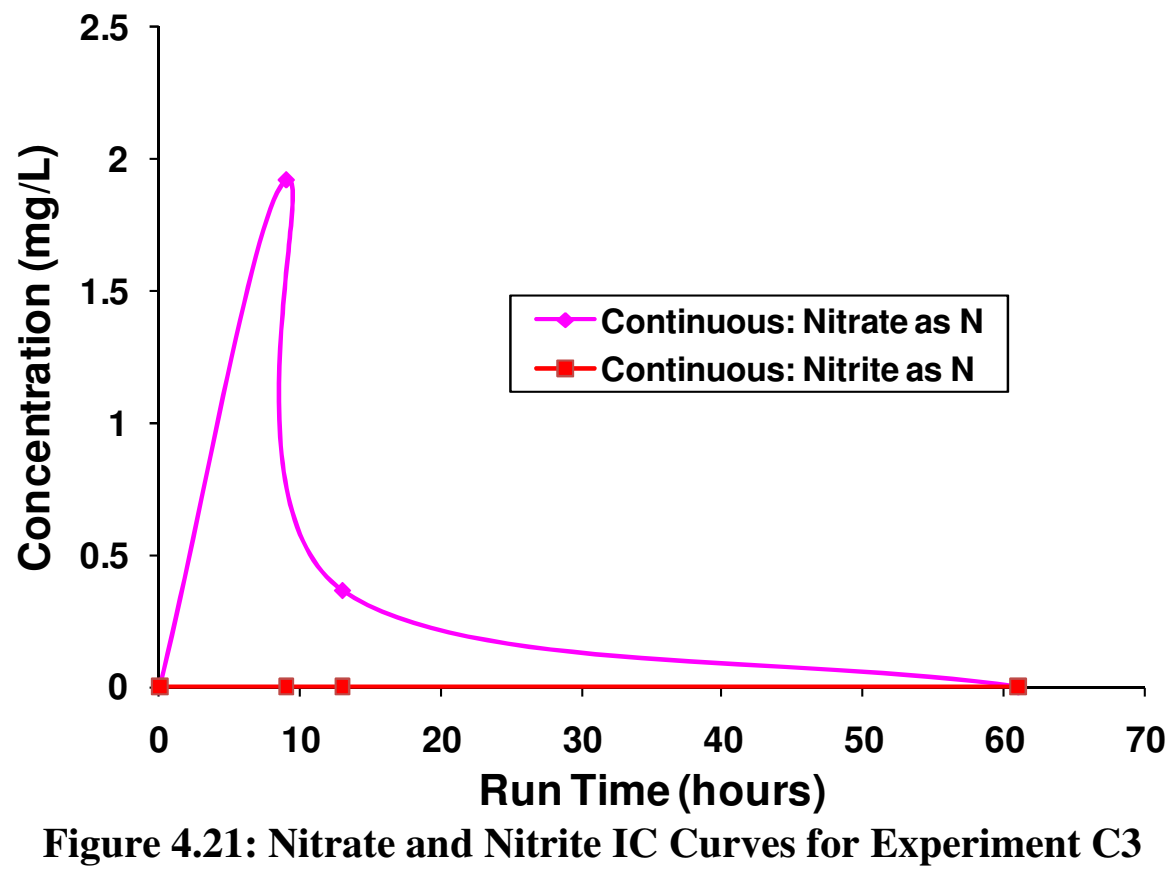

\subsubsection{Continuous - Flow Experiment C4 Results}

This four day reaction was the first reaction using the 5-gallon bottles for media storage. The new media was mixed daily and the use of two alternating bottles allowed each bottle to be cleaned and dried prior to the next day's use. This reaction used an ammonia concentration of $10 \mathrm{mg} / \mathrm{L}$ minimal media, and the new pump was also calibrated and to match the initial flow-rates through the reactor. The average HRT was 27.4 hours, and the average flow rate was $11.7 \mathrm{~mL} / \mathrm{min}$. The temperatures again followed similar fluctuations during the reaction, but the inlet $\mathrm{pH}$ stayed higher than the $\mathrm{pH}$ within the reactor throughout the reaction (Figure 4.22). The inlet $\mathrm{pH}$ ranged between 5.6 and 7.69 while the sample ports in the MABR had $\mathrm{pH}$ readings all near 4. 


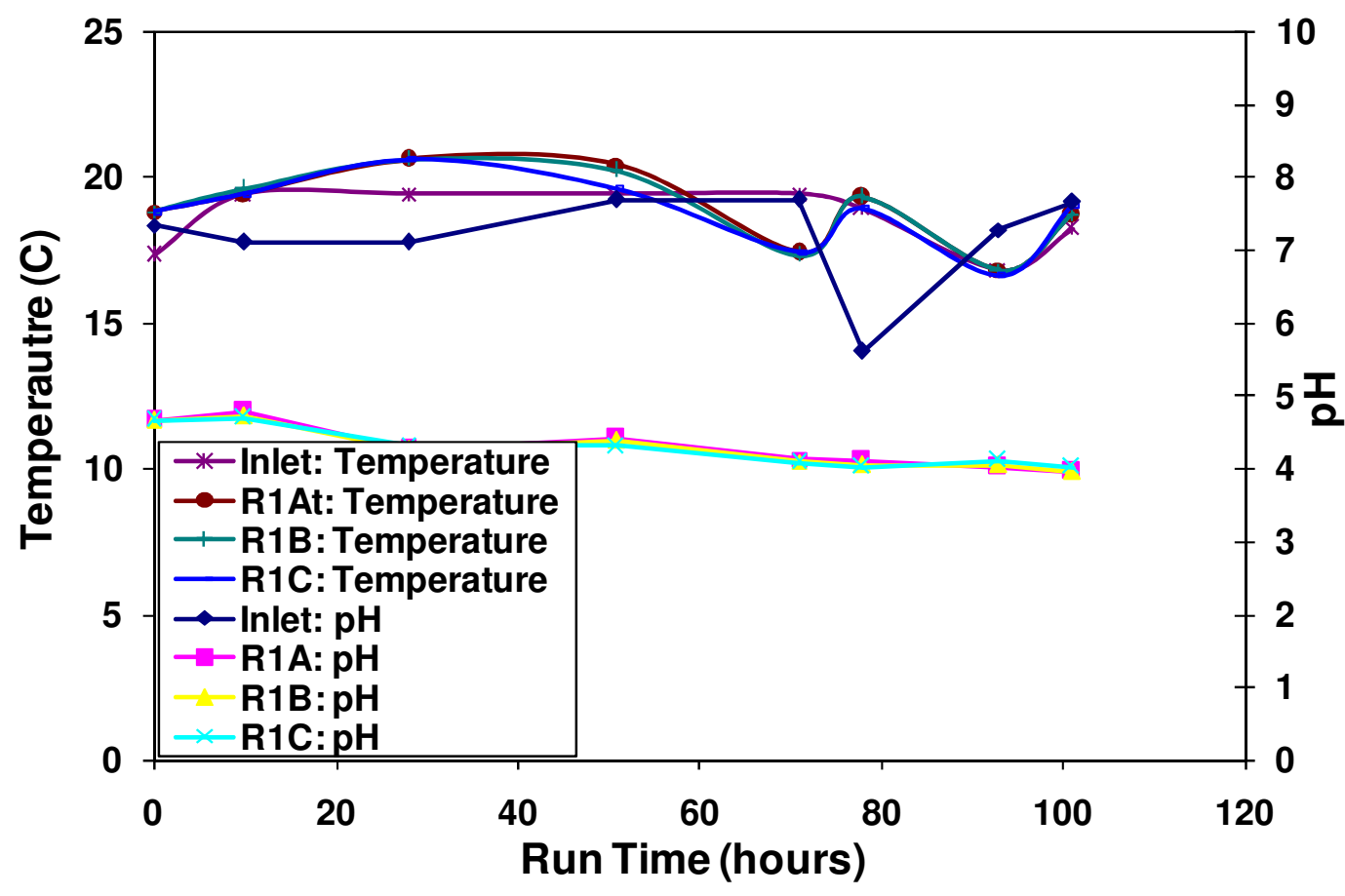

Figure 4.22: pH and Temperature Profile for Experiment C4

The ammonia concentration initially entering the MABR was measured to be $8.03 \mathrm{mg} / \mathrm{L}$ as $\mathrm{N}$, and within the first ten hours of the reaction it had fallen to $2.5 \mathrm{mg} / \mathrm{L}$ within the reactor. But by the time the reactor reached the end of the HRT, the concentration had increased to $6.14 \mathrm{mg} / \mathrm{L}$ as $\mathrm{N}$. This could have been due to mixing of the inlet media during the reaction time, which was maintained near the $10 \mathrm{mg} / \mathrm{L}$ as $\mathrm{NH}_{4}^{+}(7.78 \mathrm{mg} / \mathrm{L}$ as N) concentration for the first 45 hours of the reaction. It was not until the final 10 hours of the reaction did the inlet media concentration begin to become unexpectedly much higher. This media increase also was reflected with the ammonia concentrations within the MABR. The last 30 hours of the reaction showed an increase in ammonia concentration as it reached the effluent (Figure 4.23). Nitrate concentrations were much more variable, with the initial concentration being inconclusive due to its zero reading. However, the first 10 hours saw an increase that reached a nitrate concentration of 5.78 $\mathrm{mg} / \mathrm{L}$ as $\mathrm{N}$ (Figure 4.23). The readings than proceeded to decrease as expected, until they 
reached the negative range. Also, the final nitrate concentration reading was not used due to its unusually high reading of $174.1 \mathrm{mg} / \mathrm{L}$ as $\mathrm{N}$. The inlet nitrate concentration though stayed consistently zero. The nitrite concentrations maintained between 0.53 and 0.99 $\mathrm{mg} / \mathrm{L}$ as $\mathrm{N}$ except until the $93^{\text {rd }}$ hour of the reaction where the concentration dropped to $0.23 \mathrm{mg} / \mathrm{L}$ and than increased to $7.58 \mathrm{mg} / \mathrm{L}$ as $\mathrm{N}$ at the completion of the reaction as it was reaching the effluent of the reactor. This increase could have been due to the increased ammonia inlet concentration and the potential increase of nitrite production within the reactor, since the inlet nitrite concentration stayed constant at $1.36 \mathrm{mg} / \mathrm{L}$ as $\mathrm{N}$ (Figure 4.23).

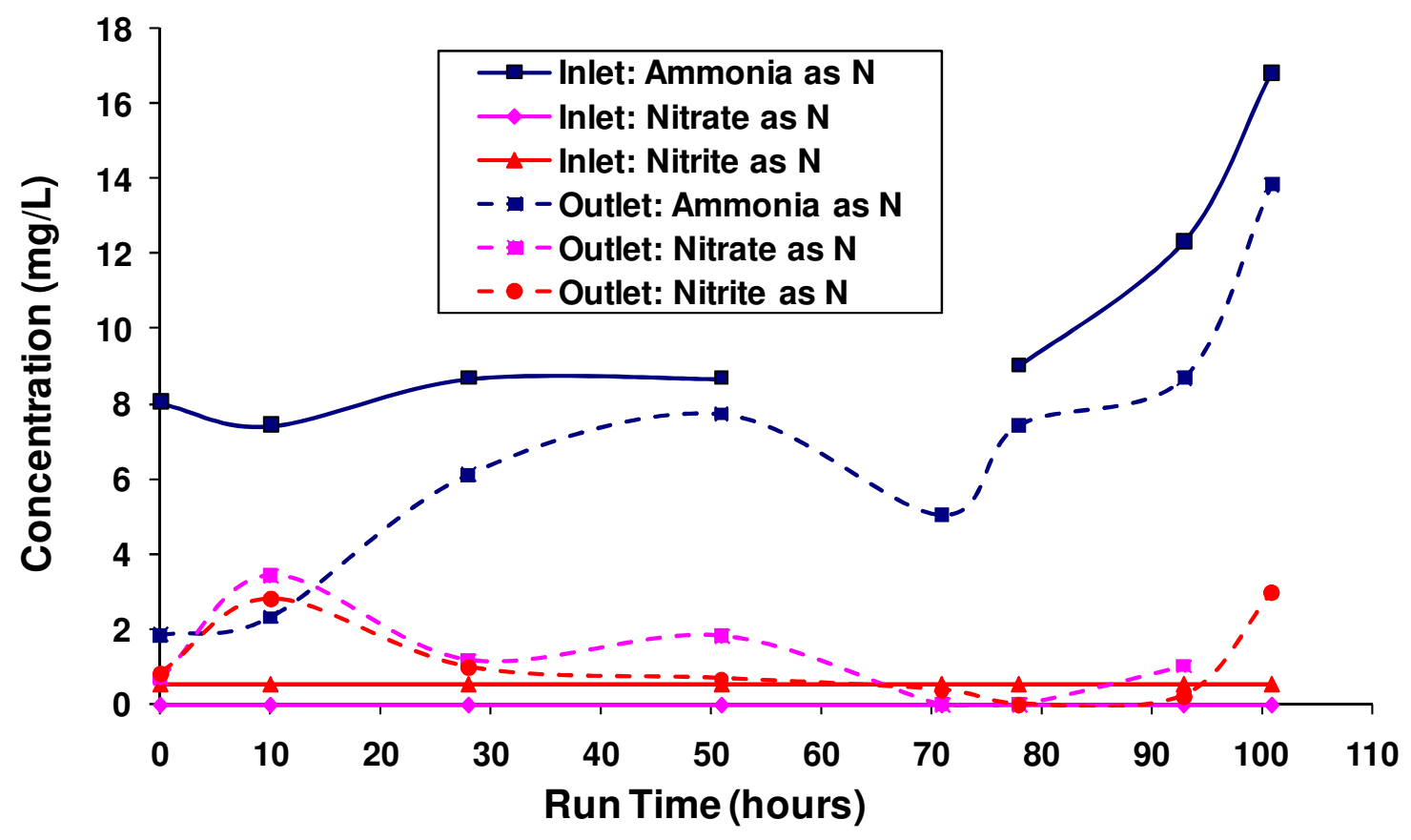

Figure 4.23: Ammonia, Nitrate and Nitrite Curves for Experiment C4

The Ion Chromatograph data showed minimal increases of nitrate and no nitrite production at all with the confirmation samples taken on May $6^{\text {th }}$, and $9^{\text {th }}$. The nitrate concentration peaked with an initial reading of $0.36 \mathrm{mg} / \mathrm{L}$. The rest of the samples for nitrate and nitrite were zero. 
After completion of this reaction, it was discovered that the air-line inlet was malfunctioning. The gauge readings read the desired air pressure of 15 psi within the line, but the actual air entering the silicone tubes from the laboratory air line was significantly lower. There was almost no air flow whatsoever. The initial thought was that the silicone tubes had experienced bio-fouling, but the tubes could not be cleaned significantly due to the lack of access to the tubes by the MABR's design. The silicone tubes were than replaced with new silicone tubes of the same length and diameter. The air line was than replaced and switched with a functioning air source.

\subsubsection{Continuous - Flow Experiment C5 Results}

This six day reaction was intended to have a $5 \mathrm{mg} / \mathrm{L}$ ammonium concentration. This was also the first reaction using a $\mathrm{HACH}$ method for detecting ammonia concentrations. This came after the malfunction of the ammonia probe used for the previous analysis. The average HRT throughout the reaction was 27.32 hours, and the average flow rate was $11.6 \mathrm{~mL} / \mathrm{min}$. With the limited $\mathrm{pH}$ and temperature readings taken, the temperatures followed similar paths, while the inlet $\mathrm{pH}$ stayed higher than the $\mathrm{pH}$ within the reactor until the final reading of the reaction (Figure 4.24). 


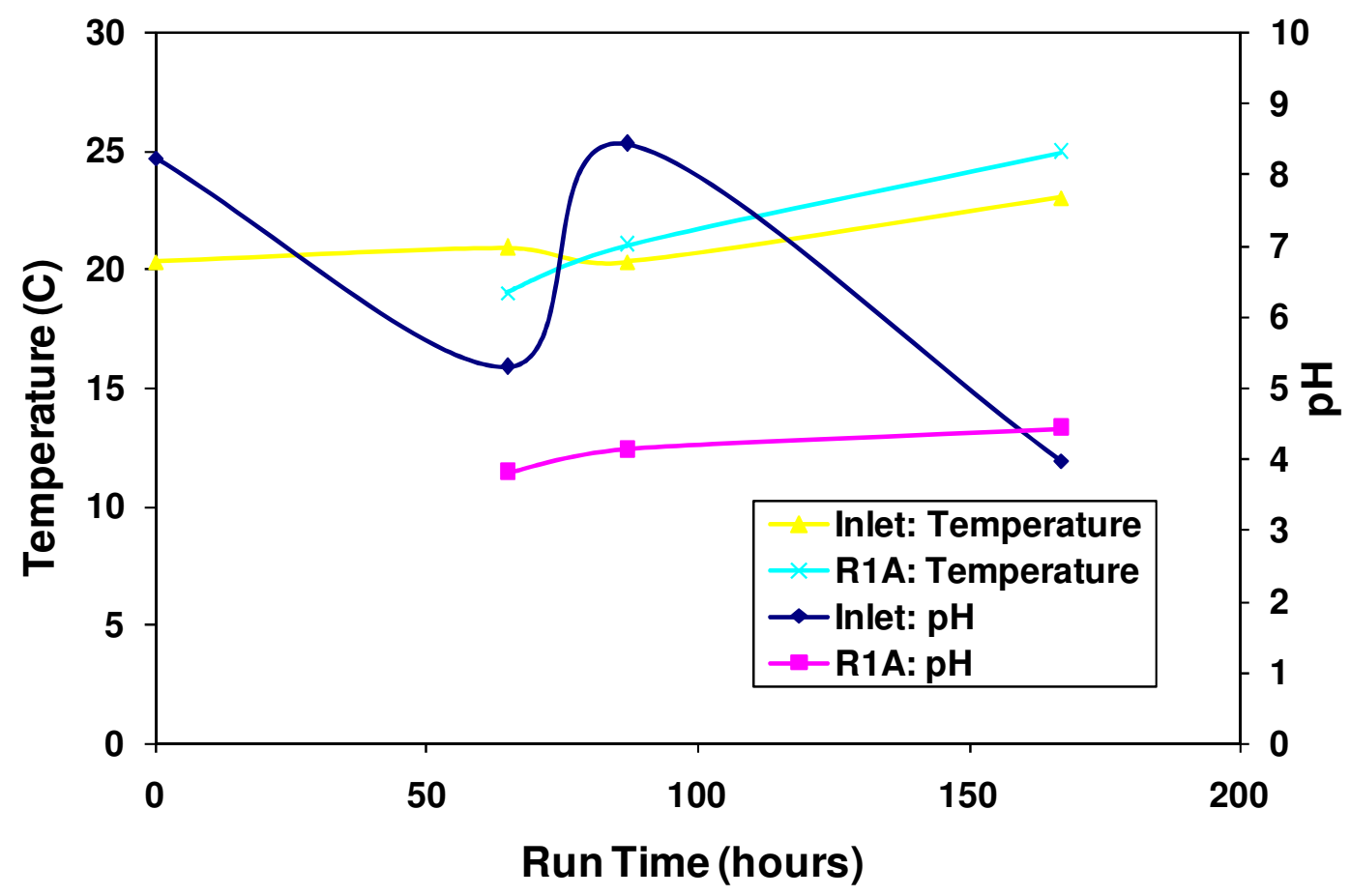

Figure 4.24: $\mathrm{pH}$ and Temperature Profile for Experiment C5

The only positive ammonia concentration was in the inlet minimal media, but the peak only showed a concentration of $0.58 \mathrm{mg} / \mathrm{L}$ as $\mathrm{N}$. Without any positive readings of ammonia, the positive nitrate and nitrite readings are fairly suspect. During the reaction time the nitrate concentration decreased from $0.71 \mathrm{mg} / \mathrm{L}$ to $0.39 \mathrm{mg} / \mathrm{L}$ as $\mathrm{N}$, and nitrite readings increased from $0.84 \mathrm{mg} / \mathrm{L}$ to $1.14 \mathrm{mg} / \mathrm{L}$ as $\mathrm{N}$ (Figure 4.25 ). The inlet concentrations for nitrate stayed consistently at $0.71 \mathrm{mg} / \mathrm{L}$ as $\mathrm{N}$, and nitrite inlet concentrations stayed at $0.84 \mathrm{mg} / \mathrm{L}$ as $\mathrm{N}$, which was unusual since the was not supposed to be any concentrations of either within the minimal media (Figure 4.25). 


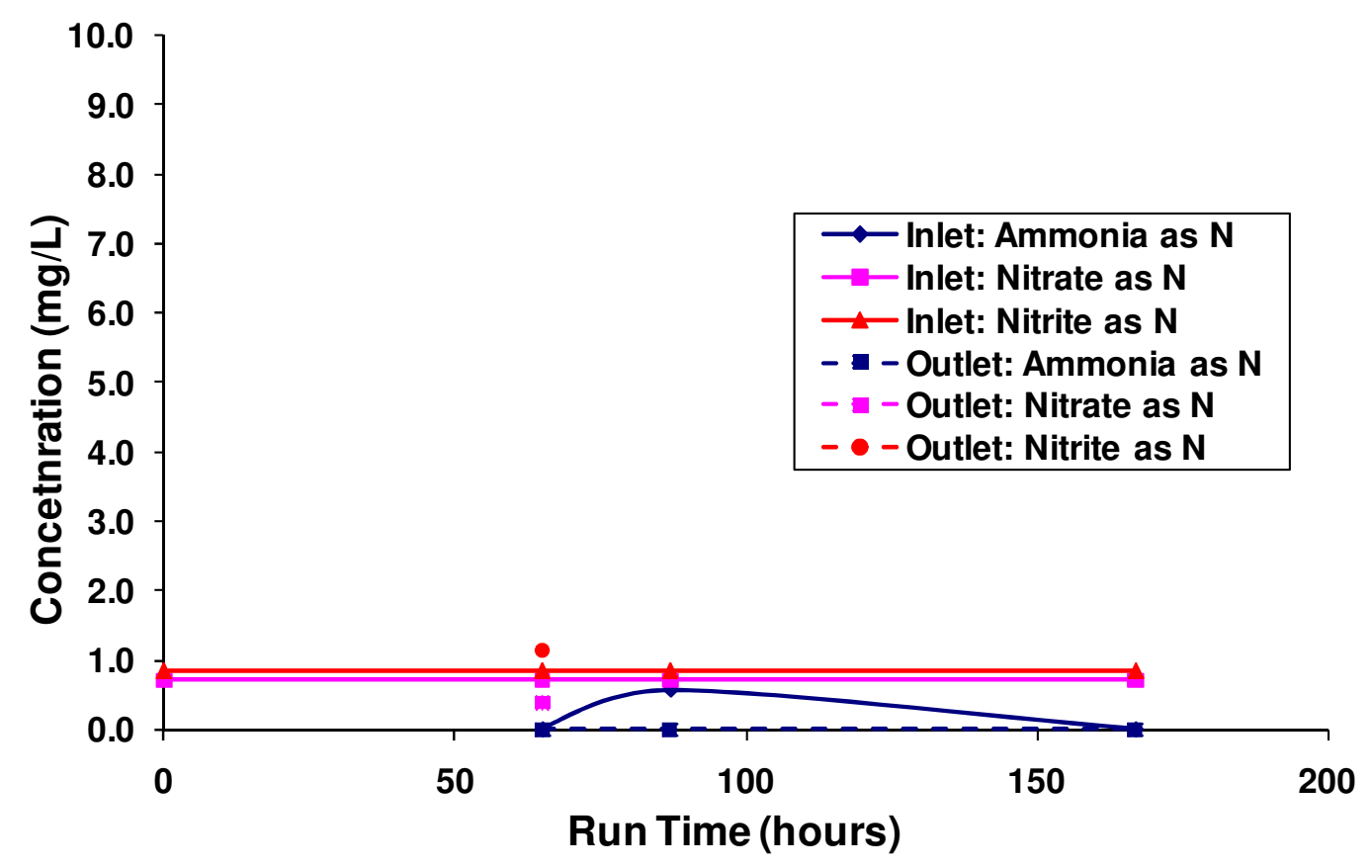

Figure 4.25: Ammonia, Nitrate and Nitrite Curves for Experiment C5

This run showed no successful results or MABR characteristics, and nitrate and nitrite concentrations within the MABR were determined to be due to residual compounds from previous run experiment. The media could have had positive readings of nitrates and nitrites due to some sort of contamination of the media or inaccurate readings and analysis. The Ion Chromatograph confirmation sample was taken on June $8^{\text {th }}$, the $87^{\text {th }}$ hour, and the nitrate and nitrite analysis showed no concentrations of nitrate or nitrite.

\subsubsection{Continuous - Flow Experiment C6 Results}

The three day reaction looked at a $10 \mathrm{mg} / \mathrm{L}$ concentration of ammonium $(7.78 \mathrm{mg} / \mathrm{L}$ as $\mathrm{N})$ in the media. The average HRT through the MABR was 25 hours, and the flow rate was $12.8 \mathrm{~mL} / \mathrm{min}$. Temperatures taken during the reaction followed similar paths, but sample port R1A showed greater fluctuations. Also, the inlet $\mathrm{pH}$ was greater than the $\mathrm{pH}$ taken 
from the sample ports. The inlet $\mathrm{pH}$ ranged between 7.74 and 6.55 while the reactor $\mathrm{pH}$ ranged from 4.61 to 4.39 (Figure 4.26).

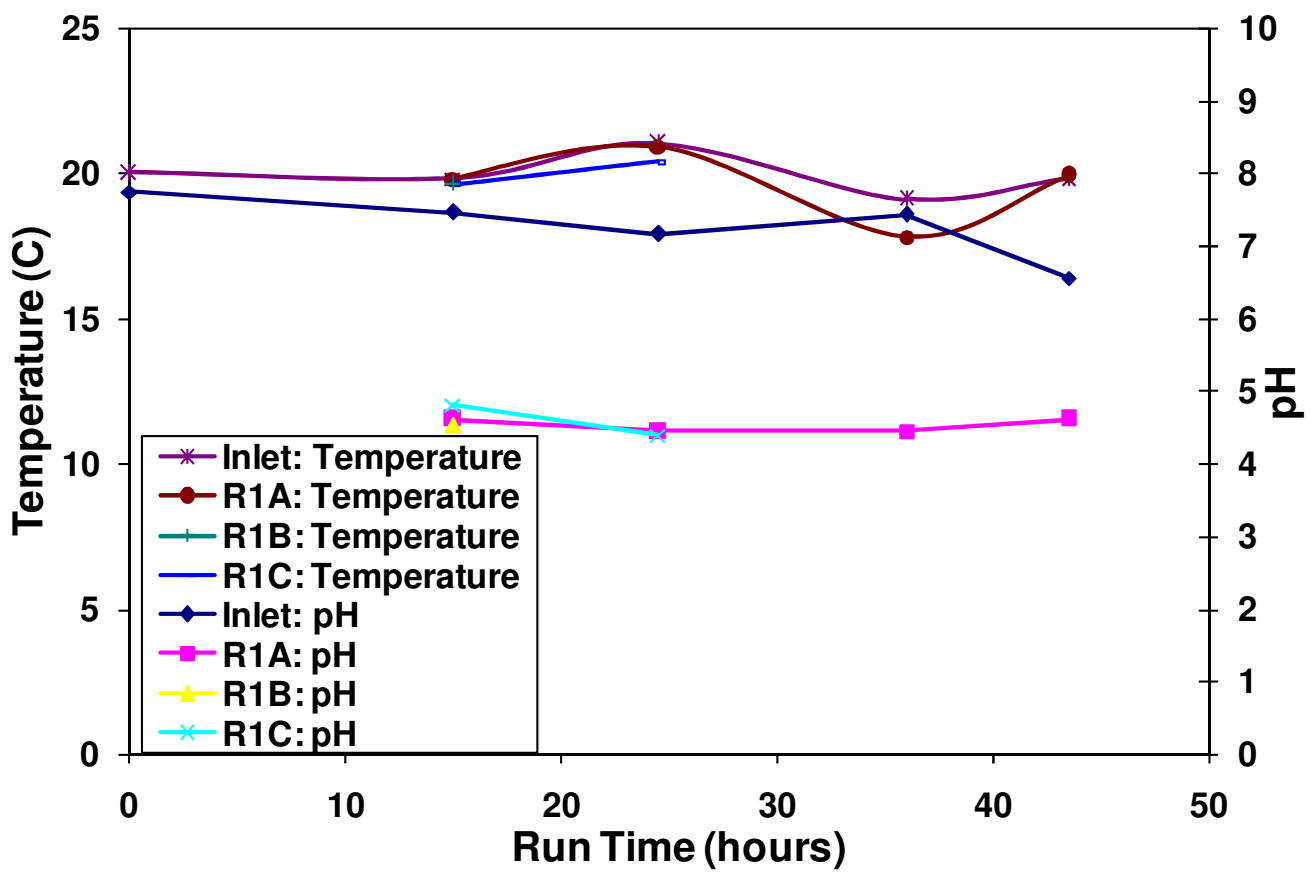

Figure 4.26: pH and Temperature Profile for Experiment C6

For the $\mathrm{C} 6$ experiment the initial ammonia concentration was calculated to be $7.33 \mathrm{mg} / \mathrm{L}$ as $\mathrm{N}$, and by the time it reached the top sample port R1A the concentration had decreased to $0.90 \mathrm{mg} / \mathrm{L}$ as $\mathrm{N}$ (Figure 4.27). Nitrate had an initial concentration of $2.0 \mathrm{mg} / \mathrm{L}$ as $\mathrm{N}$ inexplicably, and nitrite had an initial concentration of $1.9 \mathrm{mg} / \mathrm{L}$ as $\mathrm{N}$. However, the concentrations did decrease within the first 25 hours. The rest of the experiment showed a quick decrease in ammonium within the next 25 hours, but nitrate levels went from zero to a concentration of $1.07 \mathrm{mg} / \mathrm{L}$ as $\mathrm{N}$ and nitrite concentrations went from $0.23 \mathrm{mg} / \mathrm{L}$ to $0.076 \mathrm{mg} / \mathrm{L}$ as $\mathrm{N}$ (Figure 4.27). The initial decrease of ammonia concentration within the MABR during the first 25 hours of the reaction show an $86 \%$ decrease in ammonia concentration as it passes through the reactor, and eventually degradation rate slowly lessened. 


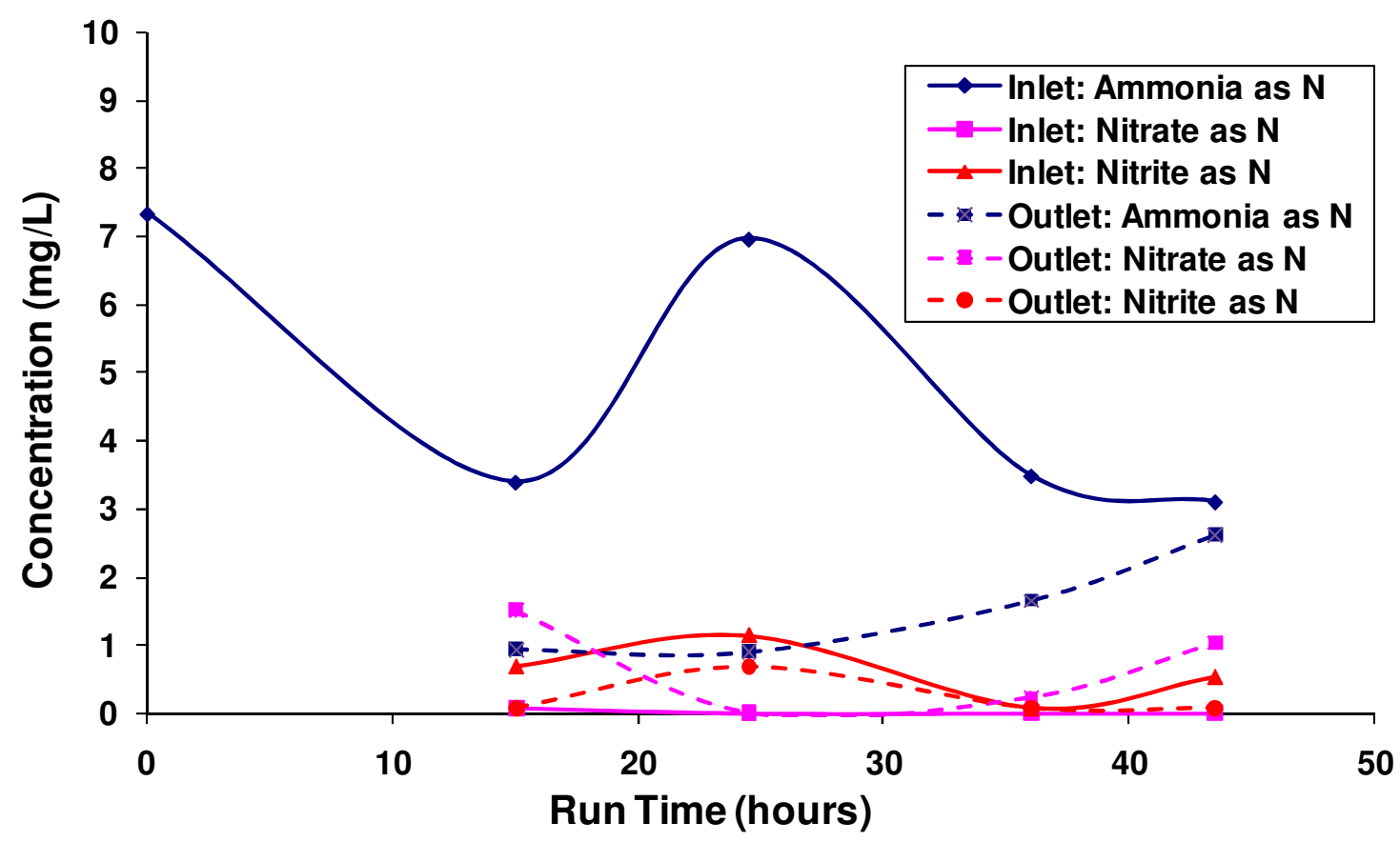

Figure 4.27: Ammonia, Nitrate and Nitrite Curves for Experiment C6

Inlet concentrations also began to experience fluctuations within each 5-gallon bottles used. Each peak of the ammonia inlet curve represented the initial concentration, and the decrease of the ammonia concentration was determined to be due to degradation of ammonia within the bottles, but nitrate concentrations were still very low and nitrite concentrations fluctuated between 1.14 and $0.076 \mathrm{mg} / \mathrm{L}$ as $\mathrm{N}$ (Figure 4.27). Due to the possible inaccuracies and confusion caused by the Ion Chromatograph, the analysis was not conducted for this experiment. 


\subsection{Local Municipal Wastewater Results}

The Local Municipal Wastewater reaction experiments used wastewater from different locations at the San Luis Obispo Reclamation Facility (Table 4.3). The samples were collected from the Reclamation Facility, transported to the laboratory and stored in the 5gallon bottles to run the wastewater through the MABR. While the wastewater traveled through the reactor, the ammonia, nitrate and nitrite concentrations were measured to track changes and determine the MABR's effectiveness.

Table 4.3: Continuous Wastewater Process Specifications

\begin{tabular}{cccc}
\hline Experiment & $\begin{array}{c}\text { Total Run } \\
\text { Hours }\end{array}$ & Media Type & $\begin{array}{c}\text { Ammonia } \\
\text { Concentration as } \\
\mathbf{N H}_{4}^{+}(\mathbf{m g} / \mathbf{L})\end{array}$ \\
\hline CW1 & 101.5 & $\begin{array}{c}\text { Secondary Effluent } \\
\text { Wastewater }\end{array}$ & Variable \\
CW2 & 142 & $\begin{array}{c}\text { 100\% Nitrified Effluent } \\
\text { 5\% Primary, 95\% }\end{array}$ & Variable \\
CW3 & 154 & $\begin{array}{c}\text { Nitrified Effluent Mixture } \\
\text { 25\% Primary, 75\% }\end{array}$ & Variable \\
CW4 & 164 & $\begin{array}{c}\text { Nitrified Effluent Mixture } \\
\text { 15\% Primary, 85\% }\end{array}$ & Variable \\
CW5 & 384 & Nitrified Effluent Mixture & Variable \\
\hline
\end{tabular}

\subsubsection{Secondary Effluent Experiment CW1 Results}

The secondary effluent experiment CW1 lasted for four days. The average HRT was 27.55 hours, and the average flow rate was $11.5 \mathrm{~mL} / \mathrm{min}$. The temperature curves for the influent and all the sample ports all followed common fluctuation trends throughout the run, but the inlet $\mathrm{pH}$ stayed higher than the $\mathrm{pH}$ from the sample ports. For sample port $\mathrm{R} 1 \mathrm{~A}$, the $\mathrm{pH}$ had dropped between 0.3 and $0.5 \mathrm{pH}$ units prior to reaching the effluent tubes (Figure 4.28). 


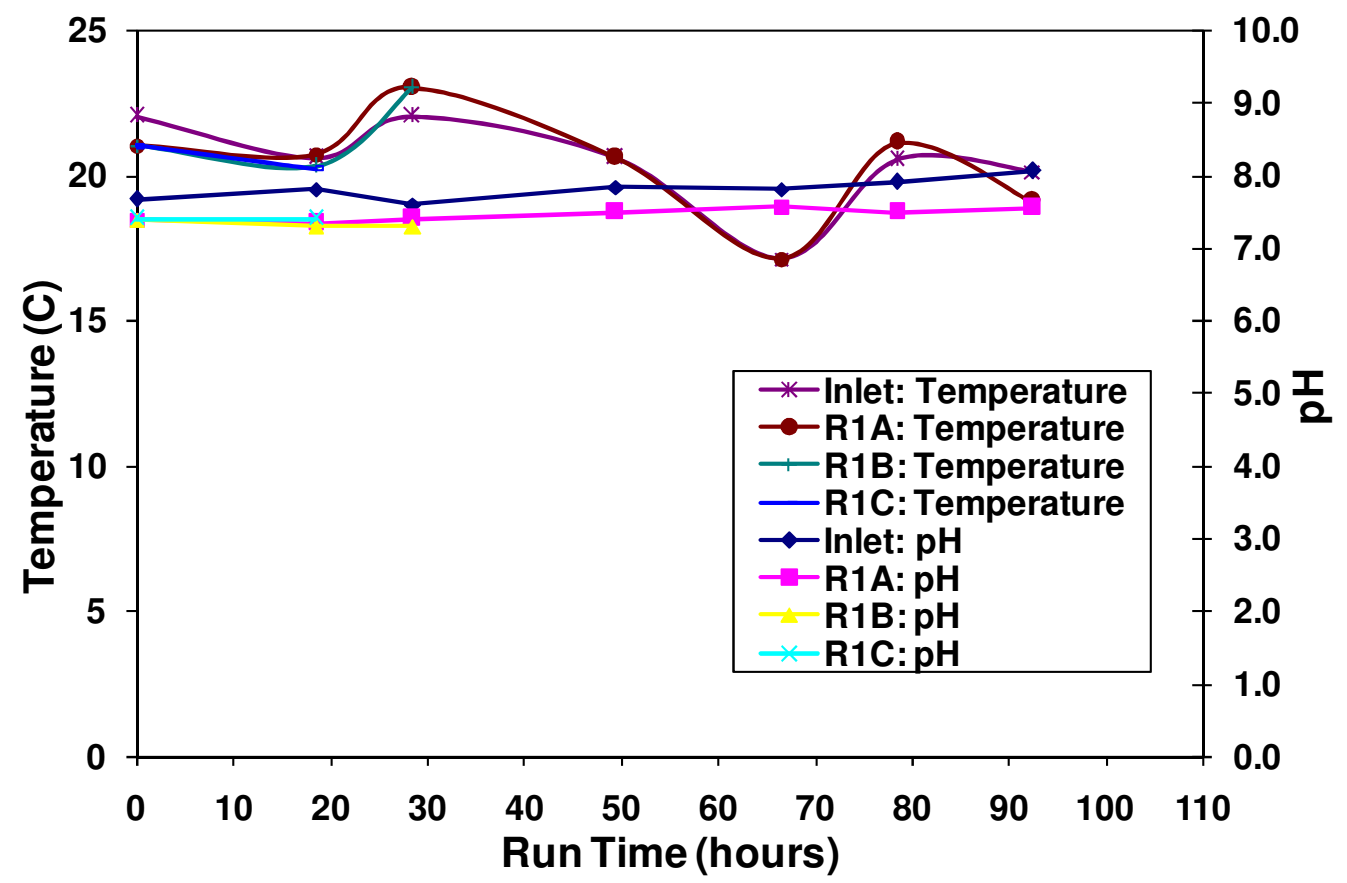

Figure 4.28: pH and Temperature Profile for Experiment CW1

For the continuous run, the change in concentration vs. change in time was broken up due to the inlet fluctuations of the wastewater, and the broken lines show each individual 5gallon wastewater sample as it traveled through the reactor. The three sections show the change of ammonia and nitrate concentrations based on their initial concentrations (Figure 4.29). The first 30 hours of the reaction showed a small decrease in nitrate concentration, but the ammonia concentration remained fairly stable. However, between the $30^{\text {th }}$ and $70^{\text {th }}$ hour of the reaction the concentrations of ammonia and nitrate showed major decreases. For the last 40 hours of the reaction, the ammonia concentration change leveled off and nitrate concentrations initially decreased and eventually had an increase (Figure 4.29). Nitrite concentrations were not analyzed the entire reaction or within the reactor, due to the lack of analysis supplies, and Ion Chromatograph data was not taken due to its previous issues and data inconsistencies. 


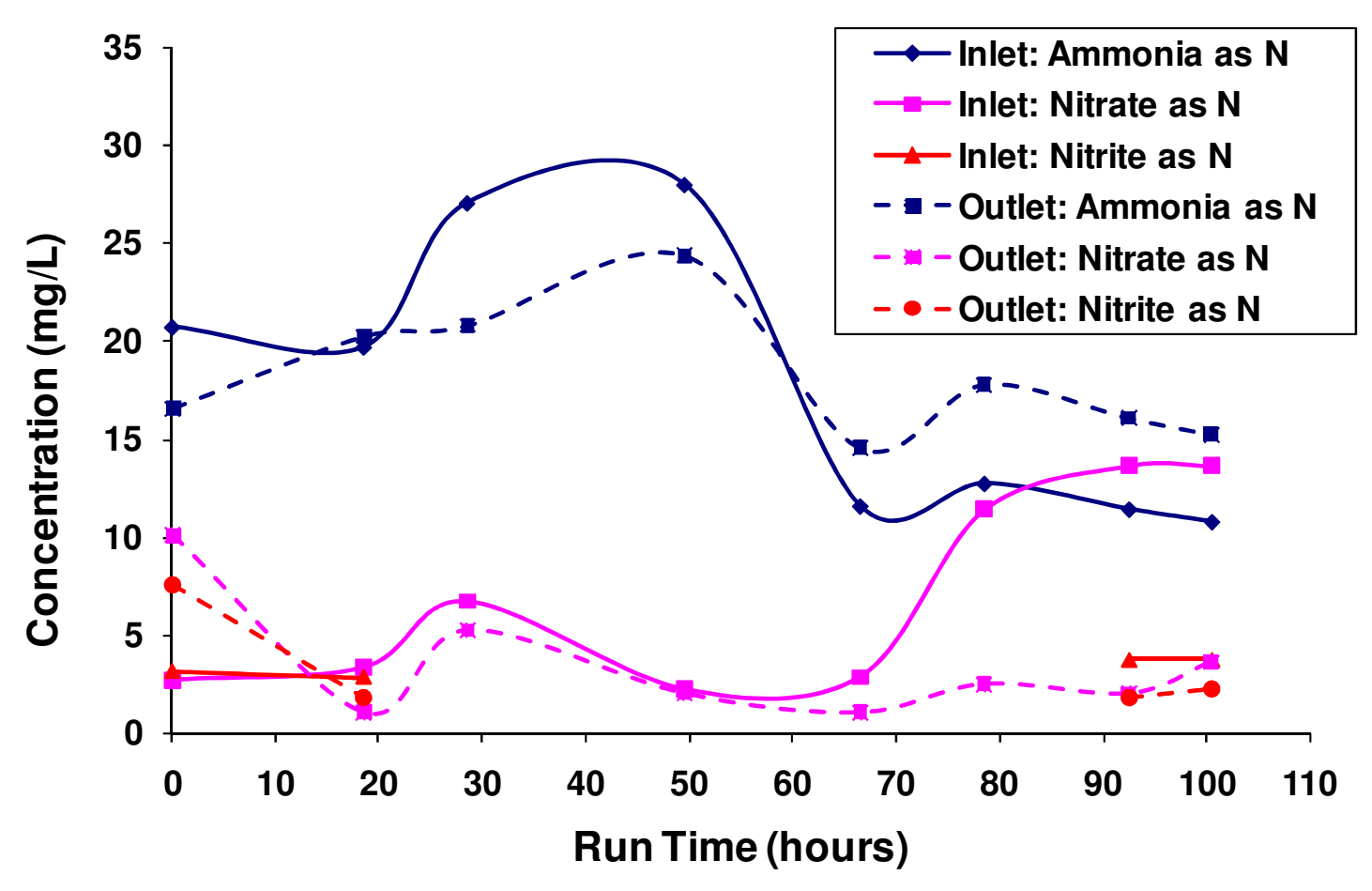

Figure 4.29: Ammonia, Nitrate and Nitrite Curves for Experiment CW1

Inlet concentrations from the Reclamation Facility did not have as drastic fluctuations as did our data analysis (Figure 4.29), which could have been due to changes occurring during transport or the possible different sampling times compared to the Reclamation facility laboratory analysis. The inconsistencies with constant concentrations of the influent were due to the natural daily fluctuations of the wastewater, even when it was sampled and transported around the same time every day. The changes within the MABR during this reaction showed positive results with the drop in ammonia and nitrate concentrations, but the run experiment were very inconsistent.

\subsubsection{0\% Nitrified Effluent Experiment CW2 Results}

The $100 \%$ nitrified effluent experiment CW2 lasted for 6 days. The average HRT for the reaction was 27.55 hours, and the average flow rate was $11.5 \mathrm{~mL} / \mathrm{min}$. Since the nitrified effluent is treated and clarified, the results of the experiment were expected to show 
minimal activity. The temperature data that was taken showed little changes within the reactor, but the $\mathrm{pH}$ within the reactor showed similar trends until the last 60 hours of the reaction (Figure 4.30). It showed a drop in $\mathrm{pH}$ from 7.25 in the influent to a $\mathrm{pH}$ of 6.95 in sample port R1A near the effluent. This led to the belief of unexpected microbiological activity.

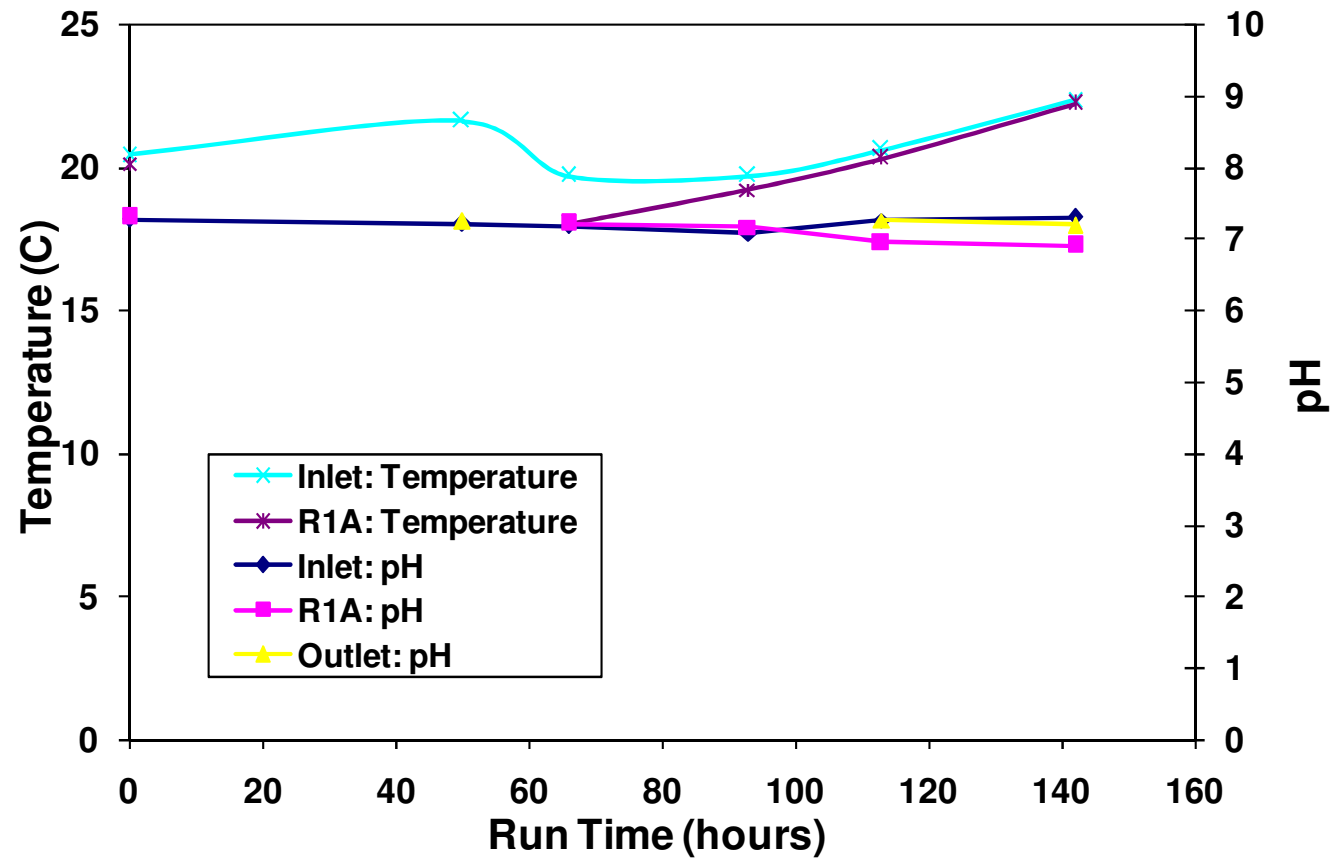

Figure 4.30: pH and Temperature Profile for Experiment CW2

The reaction analysis was again broken up based on influent changes, and each line indicates when the new day's media was added to the reactor (Figure 4.31). There were major fluctuations with nitrate concentration between $50^{\text {th }}$ and $100^{\text {th }}$ hour, and an even greater increase near the end of the reaction, but the ammonia levels remained very low, and there wouldn't be enough in the wastewater to cause these large fluctuations The trend however is very similar to the influent concentration changes of all three constituents: ammonia, nitrate, and nitrite (Figure 4.31). Ammonia and nitrite stayed very low, and it was determined that since the nitrate concentrations mimicked the 
influent concentrations that there was no run experiment and the constituents were just mixing within the reactor and passing through.

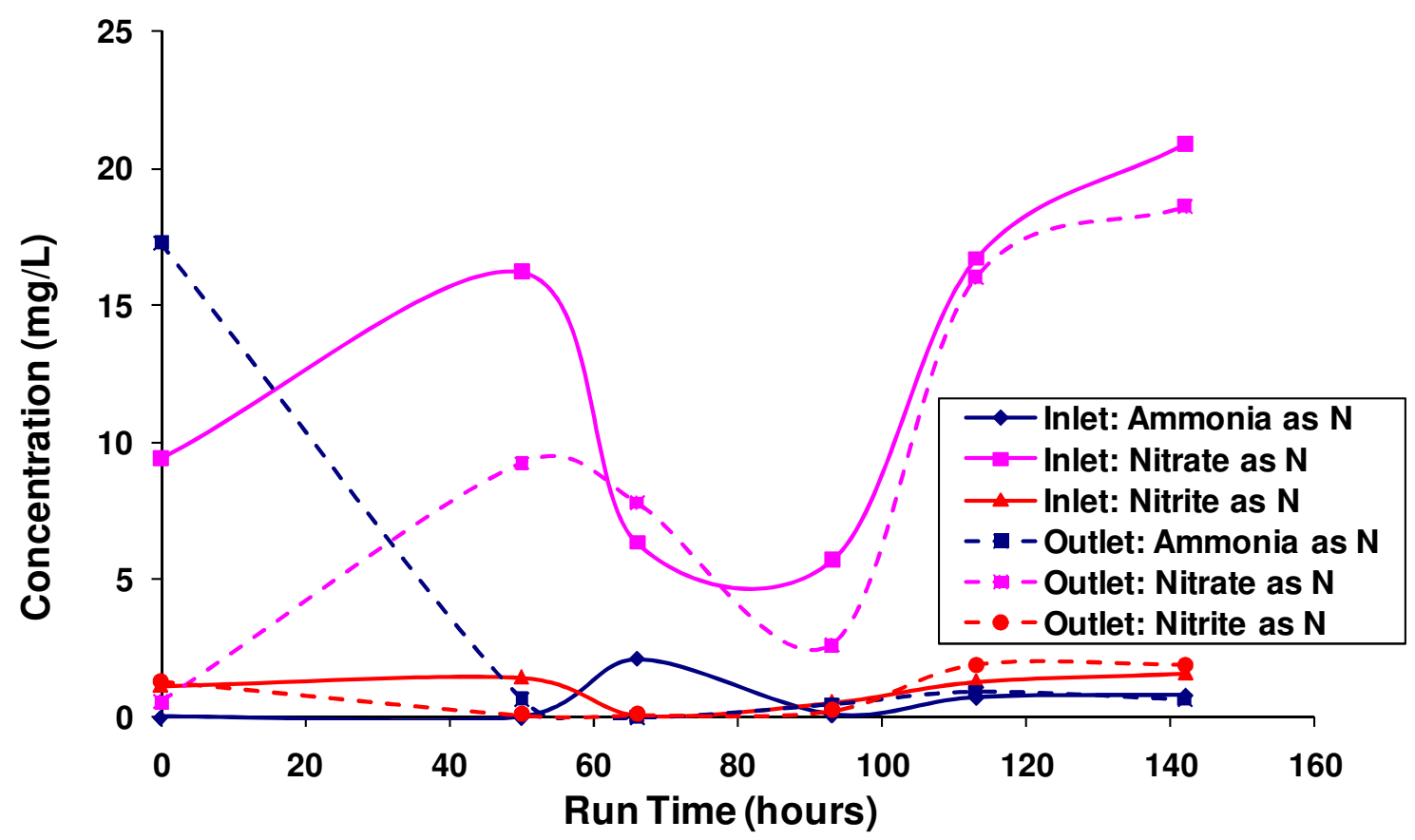

Figure 4.31: Ammonia, Nitrate and Nitrite Curves for Experiment CW2

\subsubsection{5\% Primary, 95\% Nitrified Effluent Experiment CW3 Results}

The $5 \%$ primary and $95 \%$ nitrified effluent mixture experiment lasted for six days. The average HRT was 27.84 hours, and the average flow rate was $11.4 \mathrm{~mL} / \mathrm{min}$. The temperature during the reaction in the effluent and within the reactor followed common trends. The $\mathrm{pH}$ trends initially showed similarities, but near the end of the reaction the $\mathrm{pH}$ had a drop of 0.5 at sample port $\mathrm{R} 1 \mathrm{~A}$ and began to increase in the effluent line (Figure 4.32). 


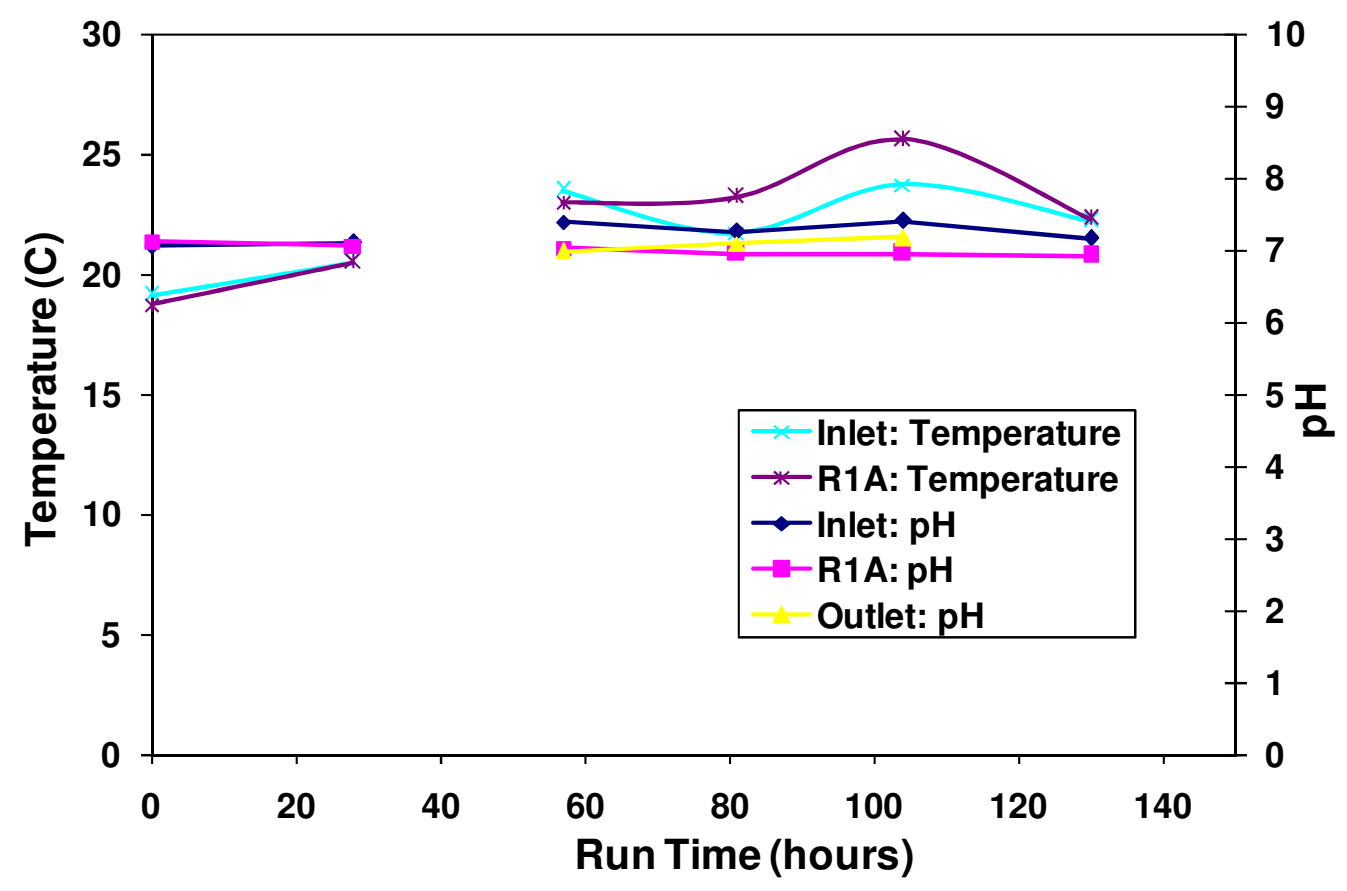

Figure 4.32: $\mathrm{pH}$ and Temperature Profile for Experiment CW3

For the entire reaction the ammonia concentration stayed low, and the nitrate concentration was very high. This was due to the fact that the wastewater samples were received after the nitrification at the Reclamation Facility, but the nitrates would hopefully be treated as they passed through the MABR (Figure 4.33). During the continuous reaction, the nitrate concentration fluctuated between 4.5 and $27.1 \mathrm{mg} / \mathrm{L}$ as $\mathrm{N}$, and each break represented the addition on influent with differing concentrations than previously added (Figure 4.33). During the time periods between the $50^{\text {th }}$ hour and the $125^{\text {th }}$ hour, the nitrate concentrations showed promising trends with the increase up to $27.01 \mathrm{mg} / \mathrm{L}$ as $\mathrm{N}$ and than decreased to $6.53 \mathrm{mg} / \mathrm{L}$ as $\mathrm{N}$. However, the ammonia and nitrite concentrations remained low throughout the fluctuations (Figure 4.33). 


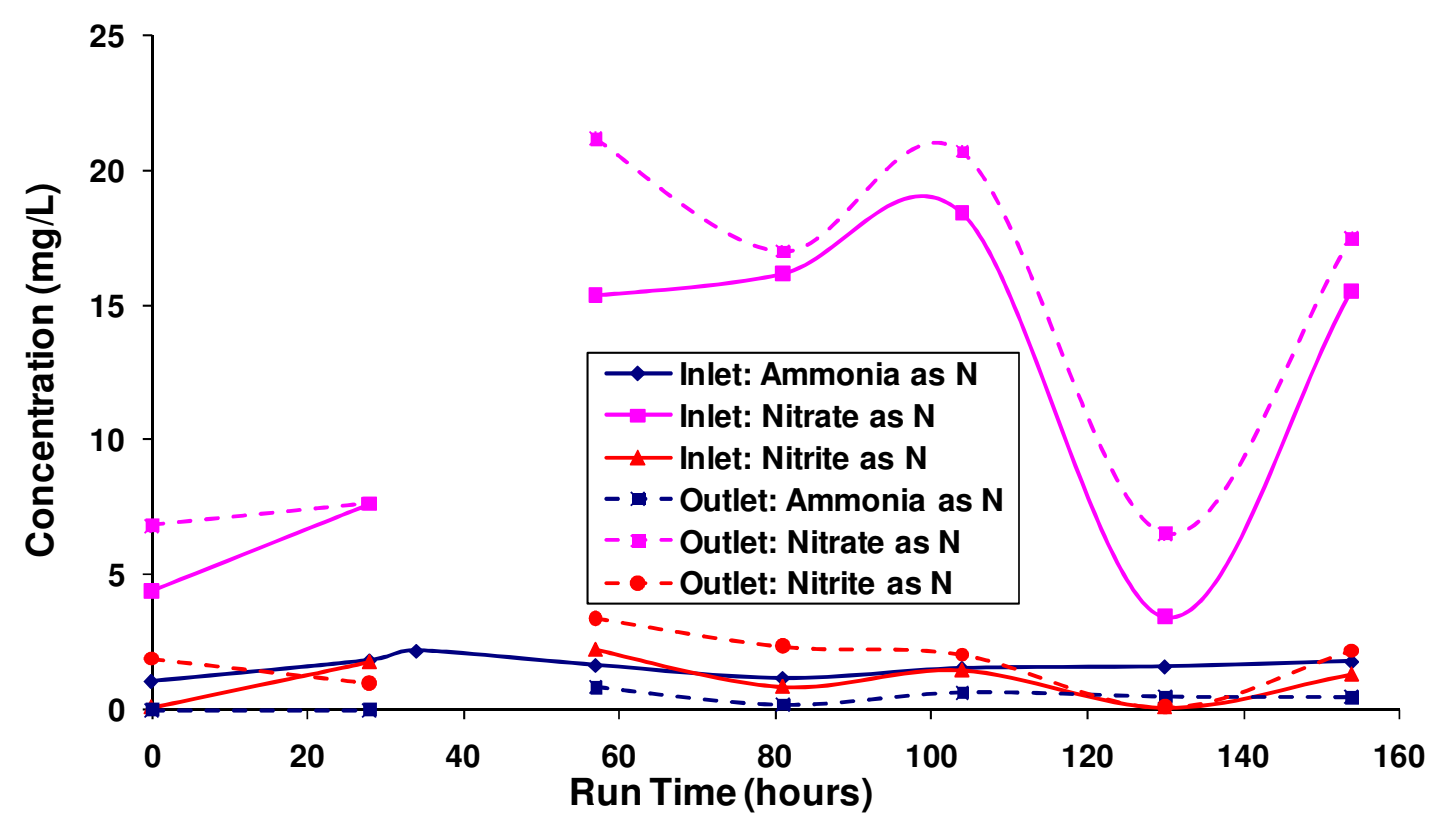

Figure 4.33: Ammonia, Nitrate and Nitrite Curves for Experiment CW3

The fact that the ammonia concentration remained low and the nitrate levels fluctuated so much were quite disconcerting. In comparison with the influent concentrations of ammonia, nitrate and nitrite the fluctuating trends were very similar (Figure 4.33). This lead to the possible conclusion as was the case in the previous test that the major fluctuations were due to mixing of the wastewater within the reactor. The peaks were larger in the continuous run analysis, but the ammonia concentrations ranged between 1.09 and $2.18 \mathrm{mg} / \mathrm{L}$ as $\mathrm{N}$ by our analysis, and this would not have had the ability to produce about $9.03 \mathrm{mg} / \mathrm{L}$ more of nitrate.

\subsubsection{5\% Primary, 75\% Nitrified Effluent Experiment CW4 Results}

The $25 \%$ primary and $75 \%$ nitrified effluent reaction lasted for 7 days, and the average HRT for the reaction was 28.14 hours, and the average flow rate was $11.3 \mathrm{~mL} / \mathrm{min}$. Both reactor and influent temperatures showed similar trends with similar decreases initially, and increases near the end of the reaction (Figure 4.34). The $\mathrm{pH}$ for the reaction did not 
show similar trends, with the lowest $\mathrm{pH}$ found from the R1A samples. The influent and effluent samples showed the highest $\mathrm{pH}$ with the two samples fluctuating between 7.1 and 7.5, while sample port $\mathrm{R} 1 \mathrm{~A}$ remained near the $\mathrm{pH} 7$ range. Though the $\mathrm{pH}$ samples were different, the changes don't show major significance to consider them changes due to microbial effects (Figure 4.34).

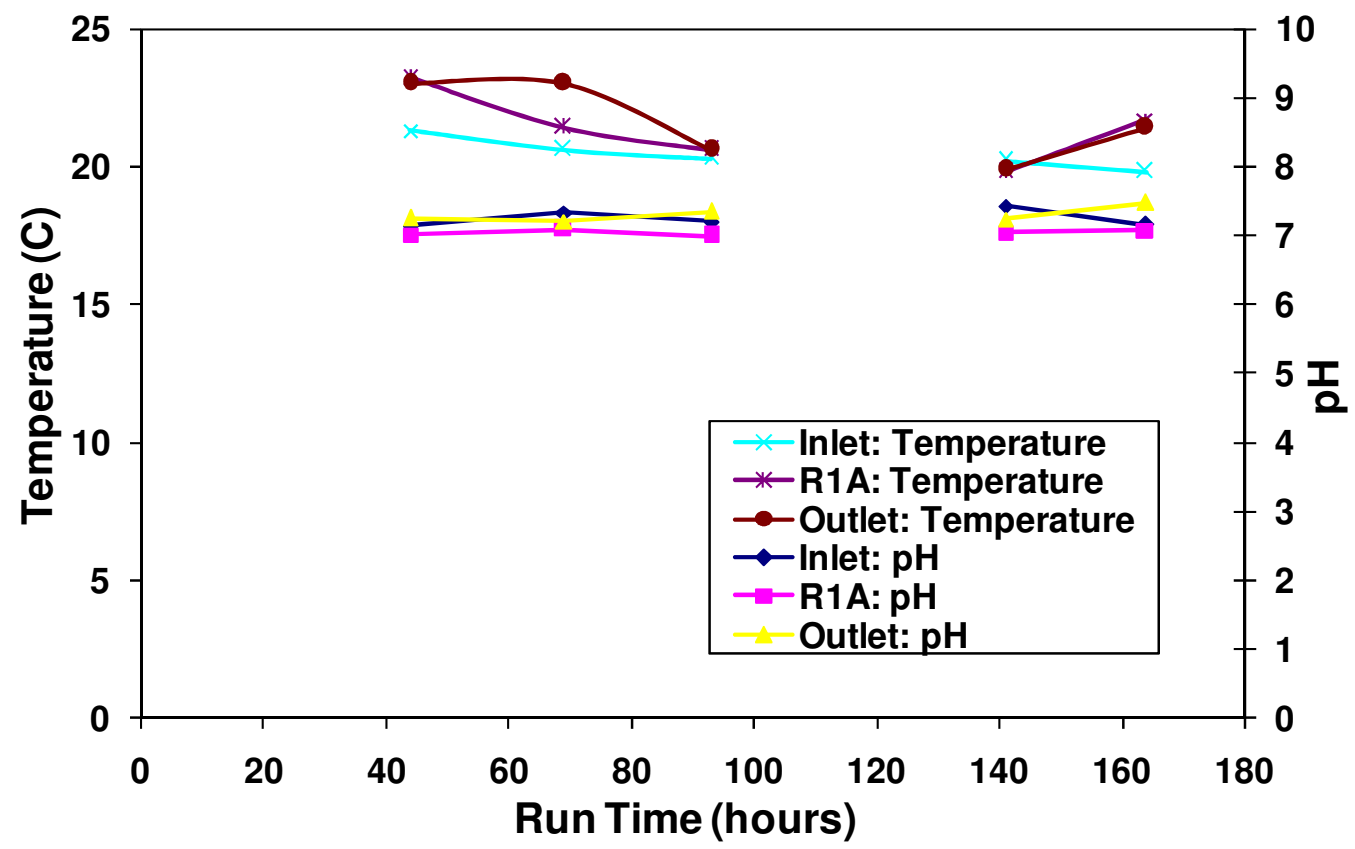

Figure 4.34: pH and Temperature Profile for Experiment CW4

For this continuous experiment, the ammonia and nitrite levels remained low compared to the nitrate levels. The ammonia concentrations were slightly higher in this reaction, due to the increased ammonia rich primary effluent added for this reaction (Figure 4.35). Initially, the increase in nitrate concentration from 19.1 to $23.3 \mathrm{mg} / \mathrm{L}$ as $\mathrm{N}$ looked promising and had the potential to be produced by the biofilm attached to the silicone tubes. Nitrite and ammonia concentrations stayed fairly consistent, and when the analyzed data for the wastewater traveling through the MABR was compared to the influent concentrations, the data again looked very similar (Figure 4.35). This leads to the conclusion that mixing and no microbial activity were occurring within the reactor 
still. The low concentrations were lower in the influent analysis, but the MABR concentrations analyzed had been mixed within the reactor but the flow was low enough to cause potentially a plug flow which would have the nitrate concentration peaks and valleys corresponding to the influent concentrations.

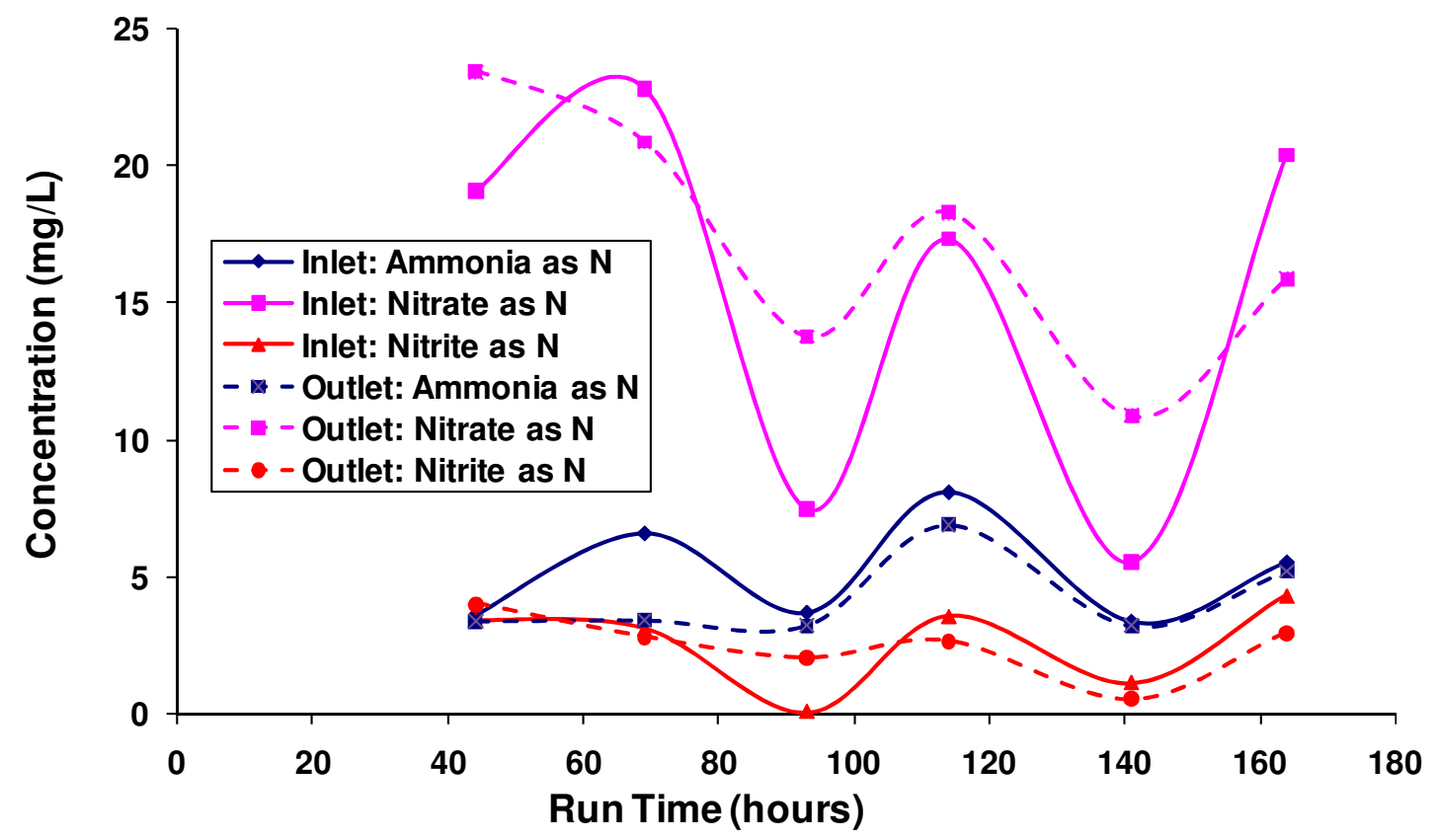

Figure 4.35: Ammonia, Nitrate and Nitrite Curves for Experiment CW4

Confirmation analysis was done again with the Ion Chromatograph, and samples had nitrate concentrations between 4.79 and $51.3 \mathrm{mg} / \mathrm{L}$ as $\mathrm{N}$. These concentrations were even higher than the samples analyzed using the $\mathrm{HACH}$, and the concentrations seemed abnormally high. Nitrite concentrations ranged between 0.61 and $2.13 \mathrm{mg} / \mathrm{L}$ as $\mathrm{N}$ and did correspond to the nitrite concentration changes during the continuous run, but the concentrations were still fairly different (Figure 4.36). 


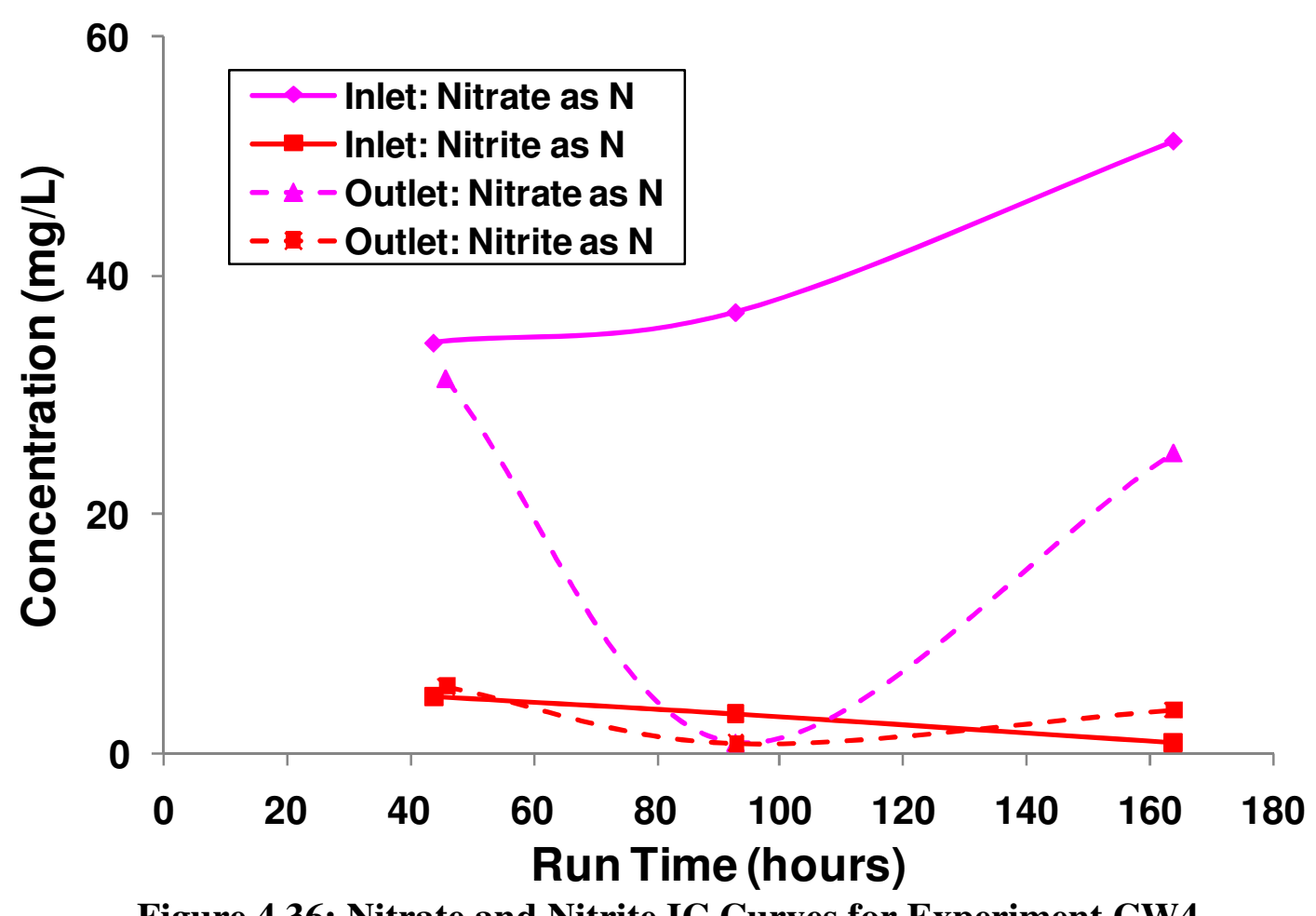

Figure 4.36: Nitrate and Nitrite IC Curves for Experiment CW4

\subsubsection{5\% Primary, 85 \% Nitrified Effluent Experiment CW5 Results}

For the final continuous reaction a $15 \%$ primary and $85 \%$ nitrified effluent mixture was used, and this reaction lasted for 15 days in order to find out if any steady state could be reached with the MABR. The average HRT was 28.01 hours, and the average flow rate was $11.3 \mathrm{~mL} / \mathrm{min}$. In order to attempt to decrease the daily fluctuations of the influent nitrate, nitrite and ammonia concentrations, we began taking larger samples from the Reclamation Facility and stored them in the laboratory prior to analysis. With this new method, the temperatures stayed constant, and the $\mathrm{pH}$ fluctuated between 7.7 and 6.8 , with the influent $\mathrm{pH}$ having the highest $\mathrm{pH}$. The rest of the sample ports and the effluent line stayed between ph of 7.2 and 6.8 (Figure 4.37). 


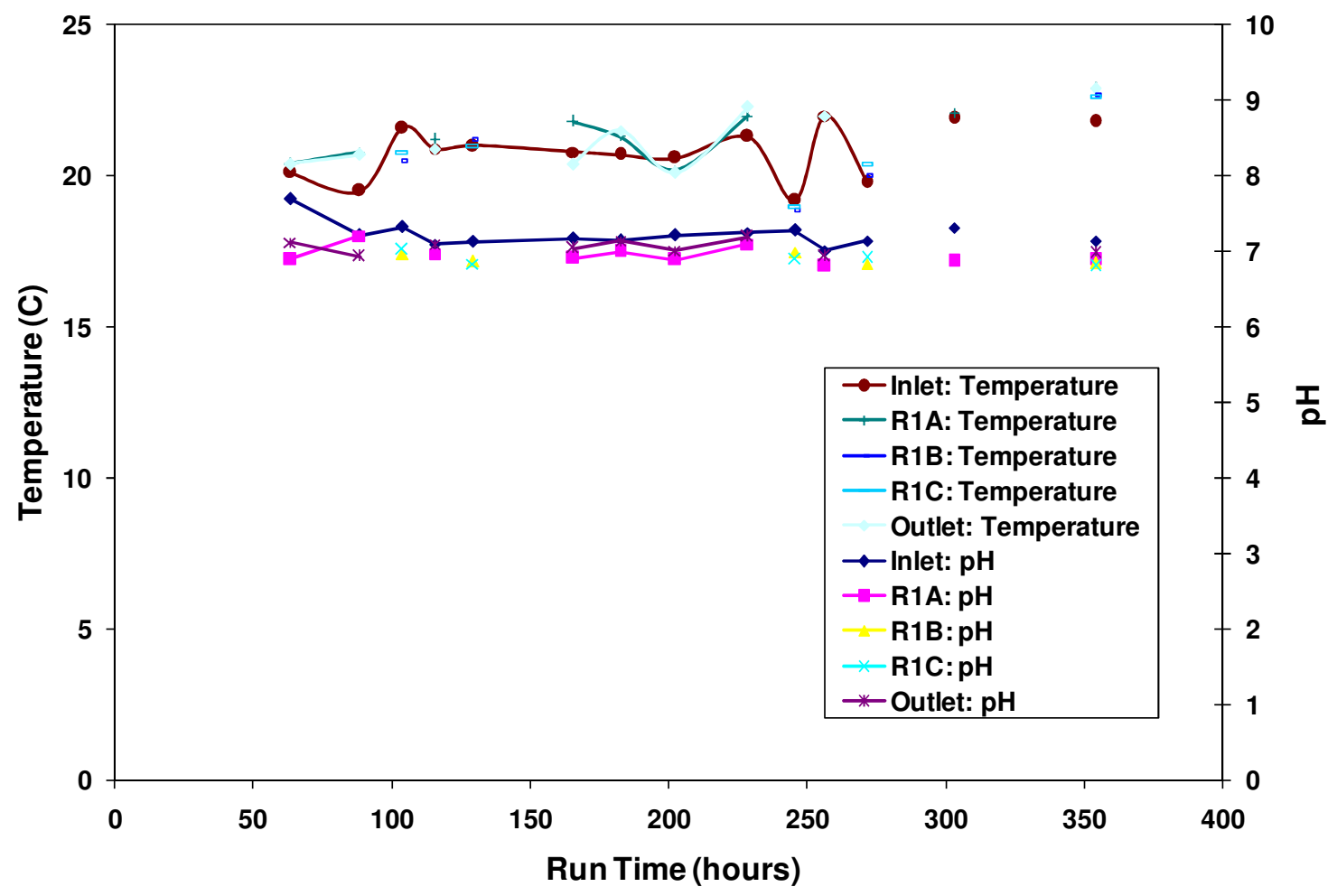

Figure 4.37: pH and Temperature Profile for Experiment CW5

Using this method to try and control the influent concentrations, the process worked to control the fluctuating ammonia concentrations. However, nitrate and nitrite concentrations still had large fluctuations. Nitrate changes were much more severe, and made analysis of the acquired data much more difficult to analyze the possibility of differences between the influent fluctuations and the wastewater that had traveled through the MABR and was hopefully treated (Figure 4.38). Due to the fact that the ammonia concentrations between the two graphs were very similar, the nitrate peaks were determined to be due to the influent nitrate concentrations and not due to the nitrification of the ammonia within the MABR. However, there was still possibility of denitrification to occur within the reactor. The changes between the initial concentration of $26.9 \mathrm{mg} / \mathrm{L}$ as $\mathrm{N}$ at the $37^{\text {th }}$ hour of running and the effluent concentration of $9.91 \mathrm{mg} / \mathrm{L}$ as $\mathrm{N}$ at the $64^{\text {th }}$ hour could be due to denitrification within the reactor (Figure 4.38). But 
due to a lack of consistency and continuity within the reactor, the data is difficult to make

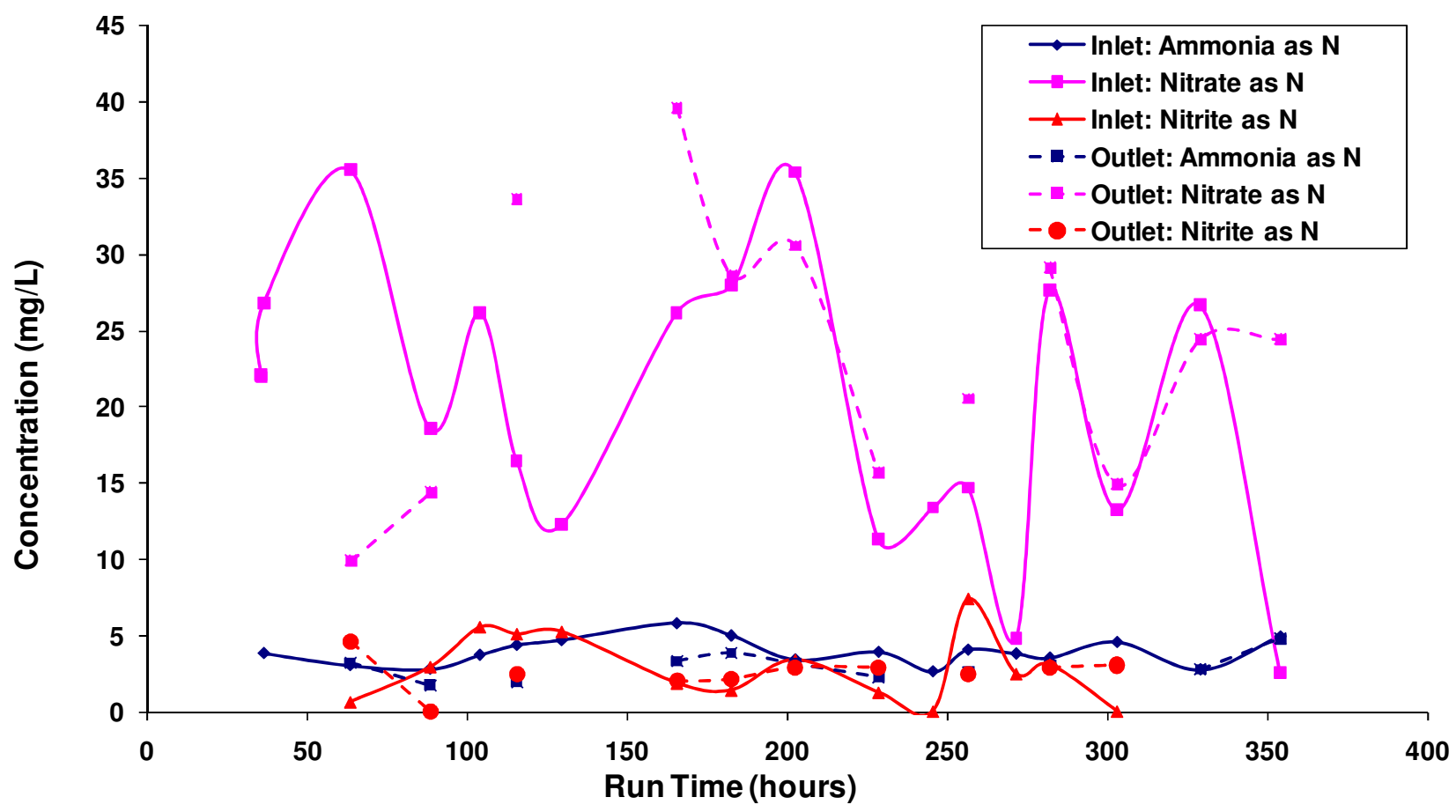

such conclusions.

Figure 4.38: Ammonia, Nitrate and Nitrite Curves for Experiment CW5

Ion Chromatograph confirmation samples were also taken and the nitrate concentrations fluctuated between 67.7 and $677 \mathrm{mg} / \mathrm{L}$ as $\mathrm{N}$. The extremely high values led us to believe a malfunction with the Ion Chromatograph, but the nitrite concentration fluctuations ranged between 1.83 and $6.09 \mathrm{mg} / \mathrm{L}$ as $\mathrm{N}$ and theses fluctuations were similar to the data found with the other analysis method. But the drastic changes led us to believe that the data shows inconclusive results for this reaction (Figure 4.39). 


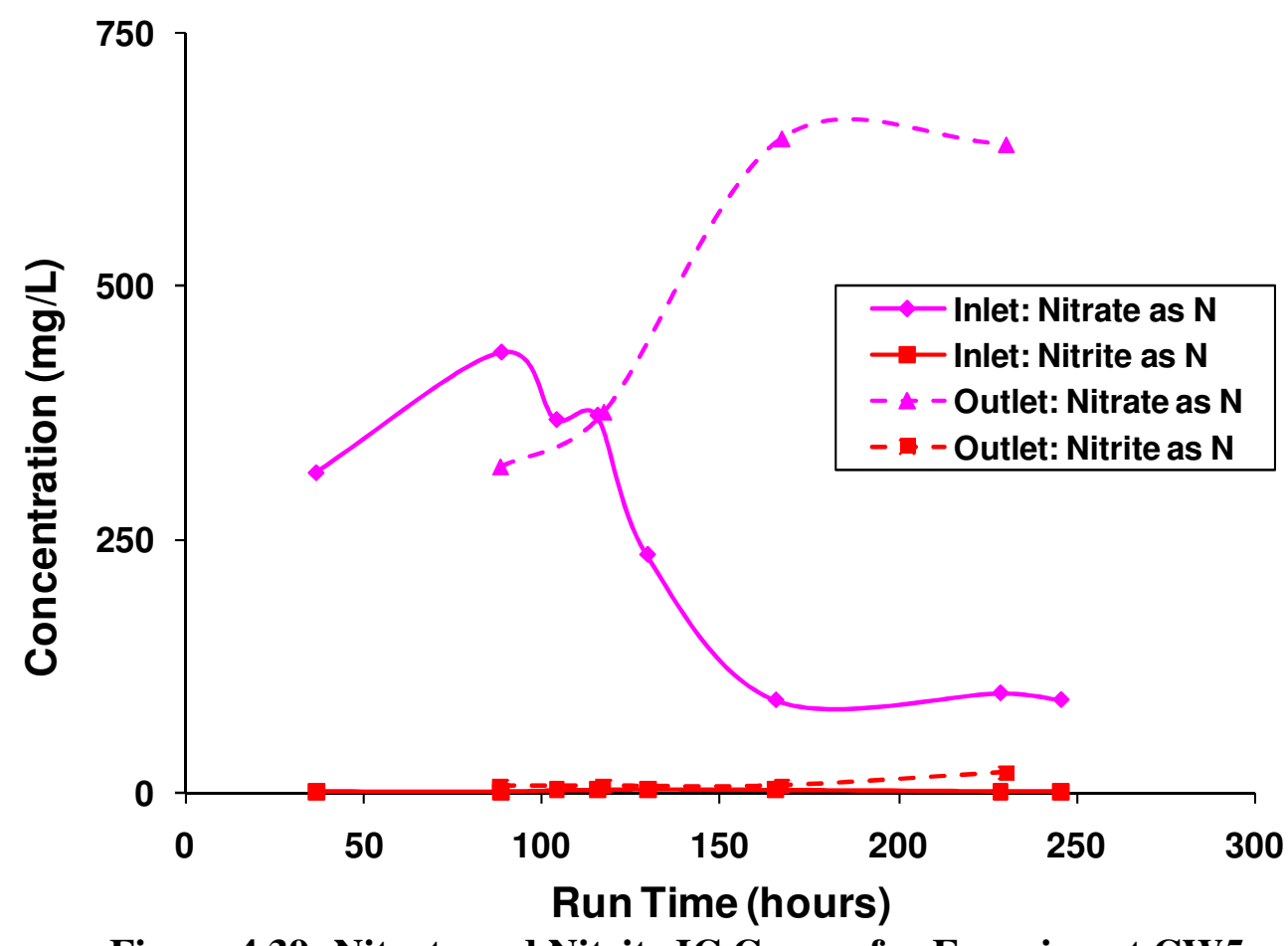

Figure 4.39: Nitrate and Nitrite IC Curves for Experiment CW5 


\section{CHAPTER 5: CONCLUSIONS}

\subsection{Experimental Conclusions}

From the data acquired and analyzed, there is potential for the MABR to successfully nitrify and denitrify ammonia in a minimal media and wastewater, but the biggest necessity to acquire better results is to simplify the investigation and try to have more control of the run experiment that are being used.

The batch experiments at the beginning of the investigation showed positive nitrification results with initial decreases in ammonia concentrations, and simultaneously increasing the nitrate concentrations within the reactor. Batch experiment B2 showed the best results, with an initial ammonia removal of $79 \%$ following first-order kinetics. However, the results were could not be replicated in further experiments.

The continuous - flow experiments also appeared to function successfully, but the biggest issues with these experiments came with the constant changes of ammonia, nitrate, and nitrite concentrations and the inability to reach steady state. Experiment C6 had an $86 \%$ ammonia degradation during the first half of the experiment, but the nitrate and nitrite concentrations never had the increases that were hoped for. The minimal media never maintained a constant concentration during this experiment, and the other experiments had the same issues. The use of many different growth media ammonia concentrations eliminated the ability to thoroughly examine a single experiment, and made analysis difficult. 
The continuous - flow experiments using municipal wastewater did not show any analyzable data. The variability of ammonium, nitrate, and nitrite concentrations during the entire wastewater experiments made analysis almost impossible. The constant fluctuations could not be controlled, and more research needs to be done to be able to utilize the MABR for the municipal wastewater studies.

The MABR apparatus also had un-foreseeable problems that added analytical problems to the investigation. The malfunctioning air-line and the inability to increase the air pressure due to the designs inability to hold very high pressures limited the investigation of the effects of changes in air pressure. Reactor optimization needs to be investigated more thoroughly to better understand the needs for these experiments to take place in controllable ways.

\subsection{Future Research}

For future research, the biggest goal is to create experimental scenarios that are more controlled and understood in all aspects of the reaction. There needs to be more focus on individual experiment success instead of trying multiple experiments that repeatedly do not have measureable results. This also includes the importance of reaction optimization. The MABR experiments have worked before in previous research (Copeland, 2007), but a greater understanding of individual steps needs to be investigated in greater and slower detail to find ways for the experiments to work desirably and repeatedly. 


\section{REFERENCES}

American Public Health Association. 1992. Standard Methods for the Examination of Water and Wastewater. $18^{\text {th }}$ edition. Washington D.C.: American Public Health Association.

Brindle, K., T. Stephenson, M. Semmens. 1998. Nitrification and oxygen utilization in a membrane aeration bioreactor. Journal of Membrane Science 144: 197-209.

Casey, E., B. Glennon, G. Hamer. 1999. Review of membrane aerated biofilm reactors. Resources, Conservation and Recycling 27: 203-215.

Copeland, M. 2007. Denitrification in a silicone-membrane bioreactor designed for simultaneous nitrification/denitrification. Graduate research thesis, California State University, San Luis Obispo.

Environmental Protection Agency. 2006. Consumer factsheet on: nitrates/nitrites. http://www.epa.gov/OGWDW/dwh/c-ioc/nitrates.html

Franco-Rivera, A., J. Paniagua-Michel, J. Zamora-Castro. 2007. Characterization and performance of constructed nitrifying biofilms during nitrogen bioremediation of a wastewater effluent. J Ind Microbial Biotechnology 34:279-287.

Gong, Z., F. Yang, S. Liu, H. Bao, S. Hu, K. Furukawa. 2007. Feasibility of a membraneaerated reactor to achieve single-stage autotrophic nitrogen removal based on anammox. Chemosphere 69: 776-784.

González-Brambila, M., O. Monroy, F. López-Isunza. 2006. Experimental and theoretical study of membrane-aerated biofilm reactor behavior under different modes of oxygen supply for the treatment of synthetic wastewater. Chemical Engineering Science 61: 5268-5281.

Grunditz, C., G. Dalhammar. 2001. Development of nitrification inhibition assays using pure cultures of Nitrosomonas and Nitrobacter. Water Resources 35:433-440.

Hao, X., J. Heijnen, M. Van Loosdrecht. Model-based evaluation of temperature and inflow variations on a partial nitrification-ANAMMOX biofilm process. Water Research $36: 4839-4849$

LaPara, T., S. Ghosh. 2006. Population dynamics of the ammonia-oxidizing bacteria in a full-scale municipal wastewater treatment facility. Environmental Engineering Science 23:309-319. 
Matsumoto, S., A. Terada, S. Tsuneda. 2007. Modeling of membrane-aerated biofilm: Effects of $\mathrm{C} / \mathrm{N}$ ratio, biofilm thickness and surface loading of oxygen on feasibility of simultaneous nitrification and denitrification. Biochemical Engineering Journal 37: 98107.

Matsumoto, S., A. Terada, Y. Aoi, S. Tsuneda, E. Alpkvist, C. Picioreanu. 2007. Experimental and simulation analysis of community structure of nitrifying bacteria in a membrane-aerated biofilm. Water Science \& Technology 55: 283-290.

Metcalf and Eddy, Inc. Wastewater engineering: treatment and reuse fourth edition. New York: McGraw Hill, 2003.

Pankhania, M., K. Brindle, T. Stephenson. 1999. Membrane aeration bioreactors for wastewater treatment: completely mixed and plug-flow operation. Chemical Engineering Journal 73: 131-136.

Sabumon, P. 2007. Anaerobic ammonia removal in presence of organic matter: a novel route. Journal of Hazardous Materials

Satoh, H., H. Ono, B. Rulin, J. Kamo, S. Okabe, K. Fukushi. 2004. Macroscale and microscale analyses of nitrification and denitrification in biofilms attached on membraneaerated biofilm reactors. Water Research 38: 1633-1641.

Schmidt, I., O. Sliekers, M. Schmid, E. Bock, J. Fuerst, J. Gijs Kuenen, M. Jetten, M. Strous. 2003. New concepts of microbial treatment processes for the nitrogen removal in wastewater. FEMS Microbiology Reviews 27:481-492.

Shin, J., B. Sang, Y. Chung, Y. Choung. 2005. Feasibility study on the removal of nitrous compounds with a hollow-fiber membrane biofilm reactor. Water Science \& Technology 51: 365-371.

Shrestha, N., S. Hadano, T. Kamachi, I. Okura. 2002. Dinitrogen production from ammonia by Nitrosomonas europaea. Applied Catalysis A: General 237:33-39.

Slade, C., R. Perrin. Form and Style thirteenth edition. Boston: Houghton Mifflin Company, 2008.

Sliekers, A., N. Derwort, J. Gomez, M. Strous, J. Kuenen, M. Jetten. 2002. Completely autotrophic nitrogen removal over nitrite in one single reactor. Water Research 36:24752482.

Terada, A., K. Hibiya, J. Nagai, S. Tsuneda, A. Hirata. 2003. Nitrogen removal characteristics and biofilm analysis of a membrane-aerated biofilm reactor applicable to high-strength nitrogenous wastewater treatment. Journal of Bioscience and Bioengineering 95: 170-178. 
Terada, A., T. Yamamoto, R. Igarashi, S. Tsuneda, A. Hirata. 2006. Feasibility of a membrane-aerated biofilm reactor to achieve controllable nitrification. Biochemical Engineering Journal 28: 123-130.

Tsushima, I., Y. Ogasawara, T. Kindaichi, H. Satoh, S. Okabe. 2007. Development of high-rate anaerobic ammonium-oxidizing (anammox) biofilm reactors. Water Research 41:1623-1634.

Vadivelu, V., J. Keller, Z. Yuan. 2007. Effect of free ammonia on the respiration and growth processes of an enriched Nitrobacter culture. Water Research 41:826-834. 


\section{APPENDIX A}

Ammonia, Nitrate and Nitrite Calibration Curves

Ammonia Probe Calibration Curve:

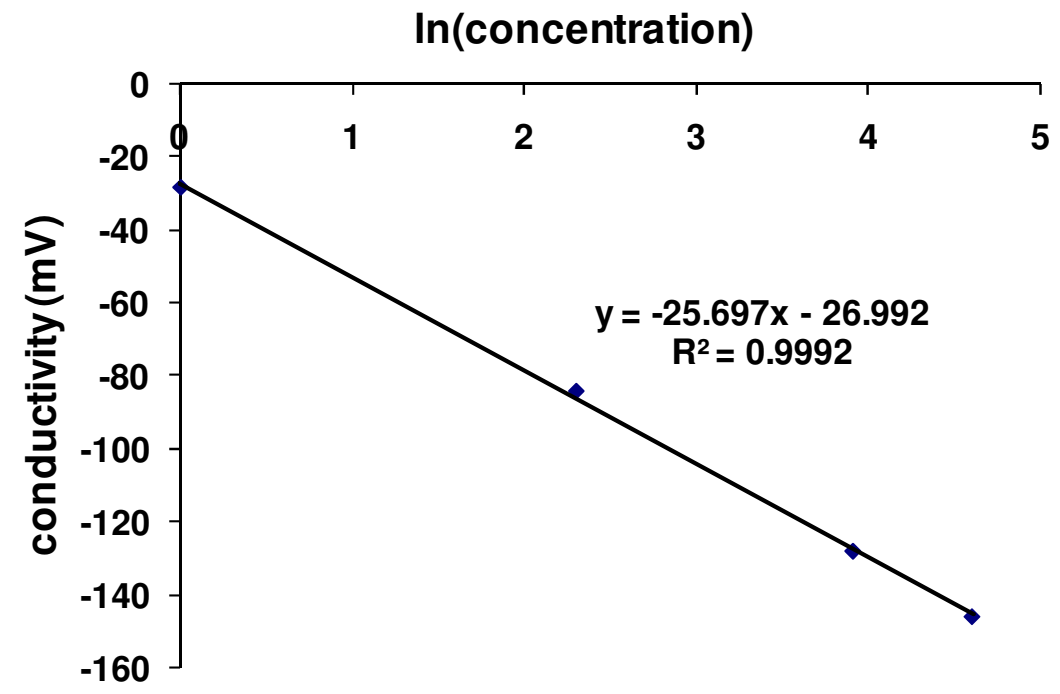

Ammonia HACH Calibration Curve:

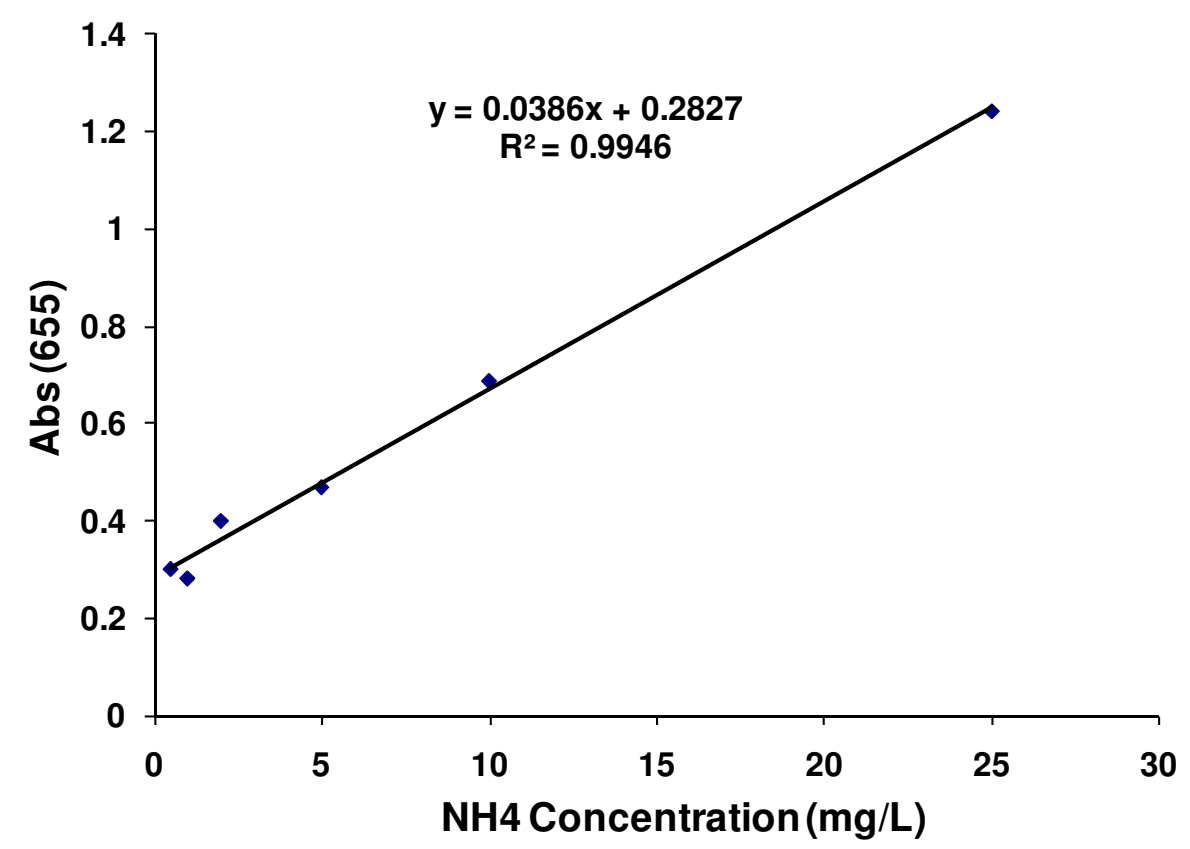


HACH Nitrate Calibration Curve:

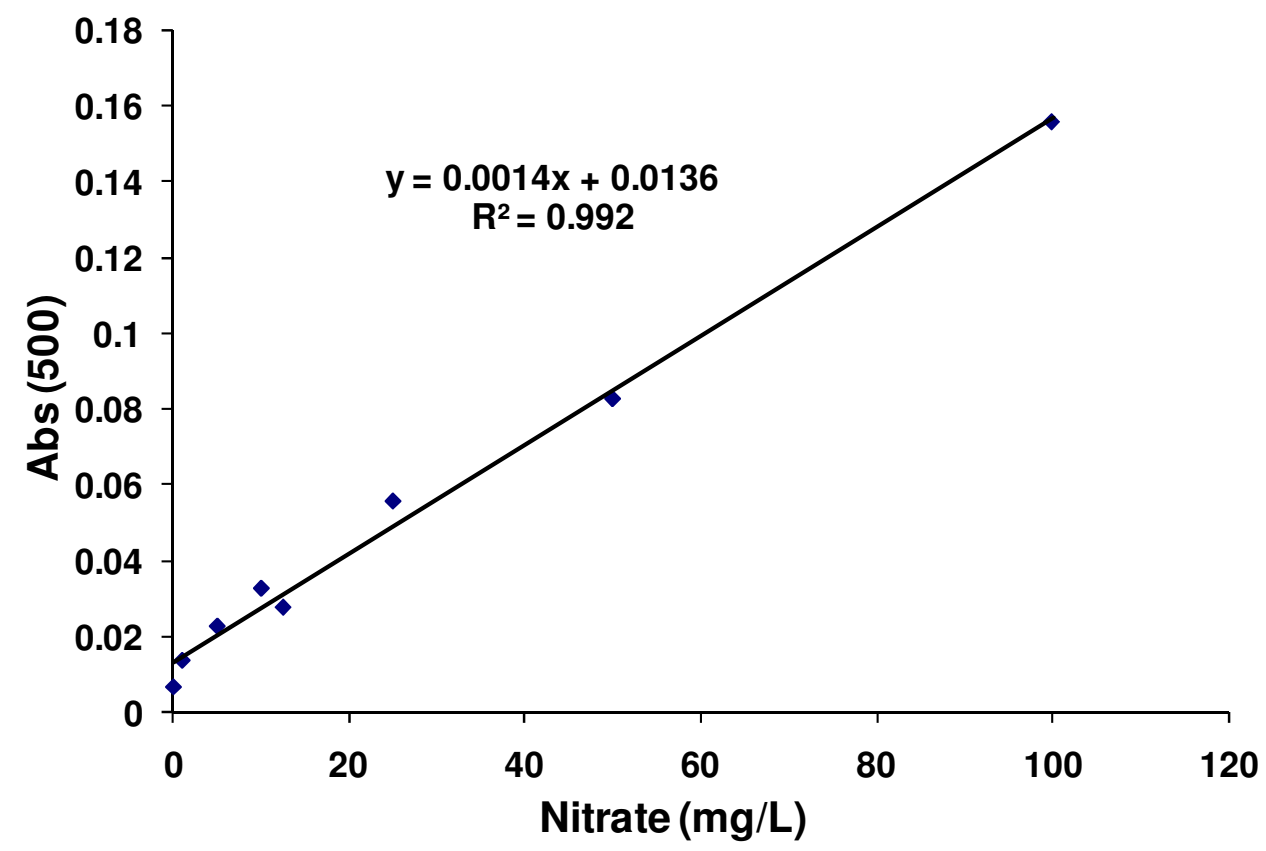

HACH Nitrite Calibration Curve:

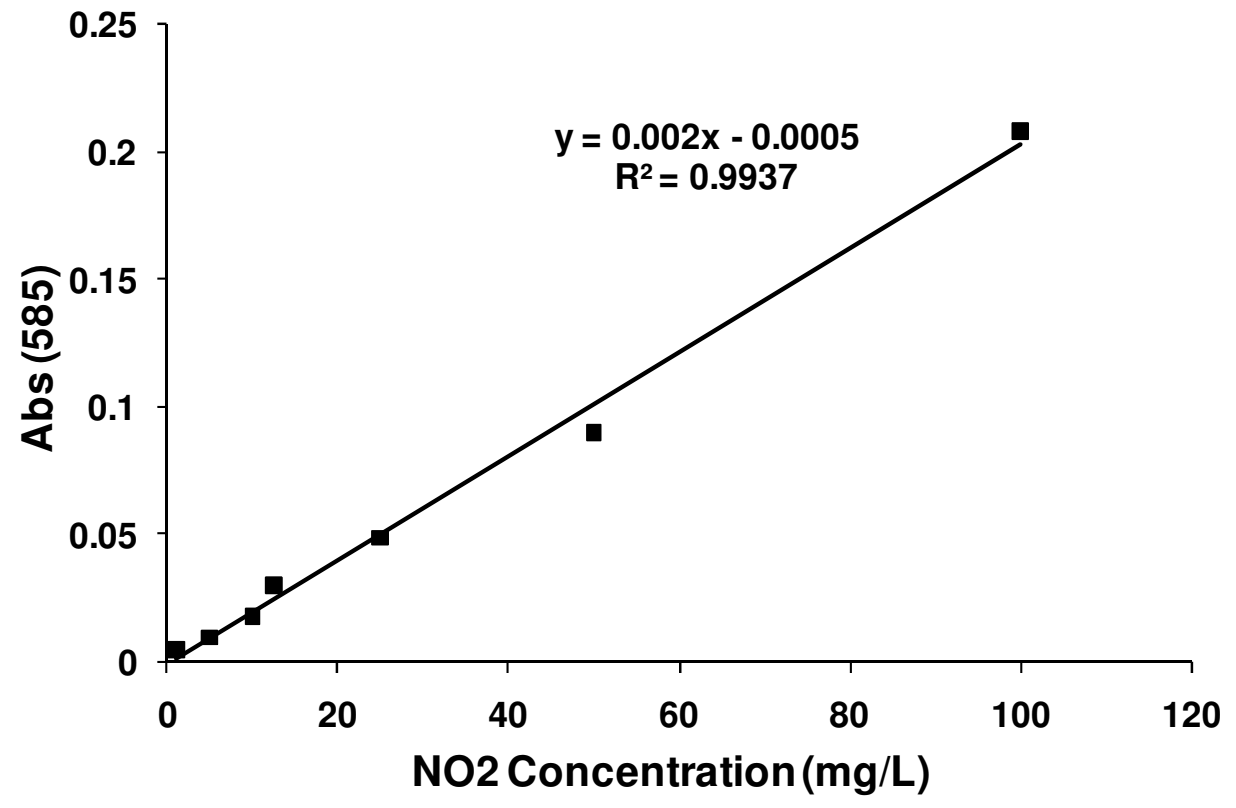


IC Nitrate and Nitrite Calibration Curves:

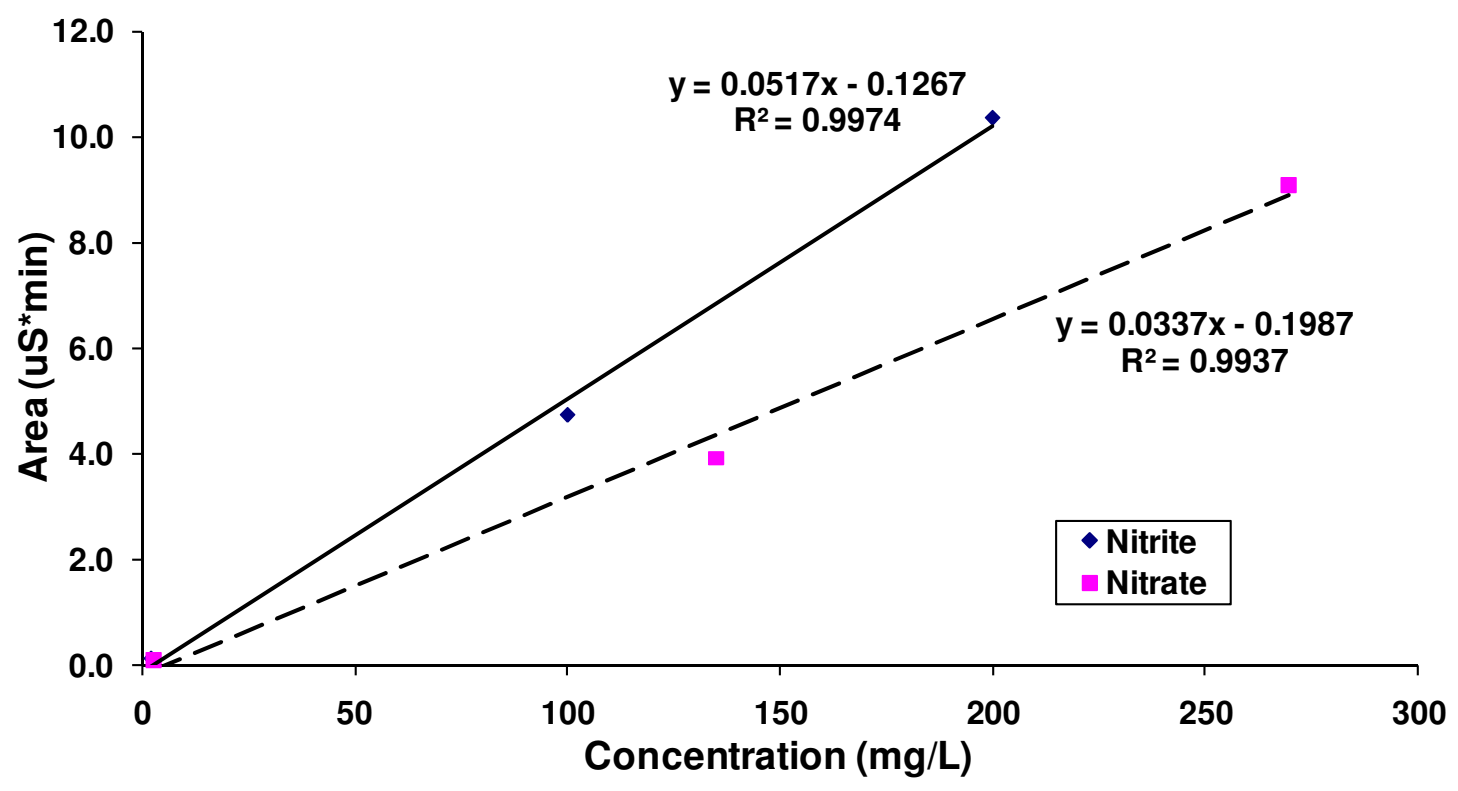

